\title{
Public health and international health educational programmes for low- and middle-income countries: questioning their outcomes and impact
}

Citation for published version (APA):

Zwanikken, P. A. C. (2015). Public health and international health educational programmes for low- and middle-income countries: questioning their outcomes and impact. [Doctoral Thesis, Maastricht University]. Datawyse / Universitaire Pers Maastricht. https://doi.org/10.26481/dis.20150123pz

Document status and date:

Published: 01/01/2015

DOI:

10.26481/dis.20150123pz

Document Version:

Publisher's PDF, also known as Version of record

Please check the document version of this publication:

- A submitted manuscript is the version of the article upon submission and before peer-review. There can be important differences between the submitted version and the official published version of record.

People interested in the research are advised to contact the author for the final version of the publication, or visit the DOI to the publisher's website.

- The final author version and the galley proof are versions of the publication after peer review.

- The final published version features the final layout of the paper including the volume, issue and page numbers.

Link to publication

\footnotetext{
General rights rights.

- You may freely distribute the URL identifying the publication in the public portal. please follow below link for the End User Agreement:

www.umlib.nl/taverne-license

Take down policy

If you believe that this document breaches copyright please contact us at:

repository@maastrichtuniversity.nl

providing details and we will investigate your claim.
}

Copyright and moral rights for the publications made accessible in the public portal are retained by the authors and/or other copyright owners and it is a condition of accessing publications that users recognise and abide by the legal requirements associated with these

- Users may download and print one copy of any publication from the public portal for the purpose of private study or research.

- You may not further distribute the material or use it for any profit-making activity or commercial gain

If the publication is distributed under the terms of Article 25fa of the Dutch Copyright Act, indicated by the "Taverne" license above, 


\title{
Public health and international
}

\author{
health educational programmes \\ for low- and middle-income countries: \\ questioning their outcomes and impact
}


The research reported here was carried out at:

Maastricht University in Lending ing!

In the School of Health Professions Education

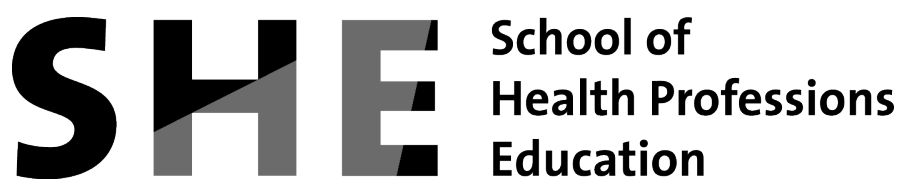

(c) Prisca Anna Cornelia Zwanikken, Maastricht 2014

Cover design: Ton Langenhuyzen

Print \& Layout: Datawyse/ Universitaire Pers Maastricht

ISBN 9789461593795 


\title{
Public health and international health educational programmes for low- and middle-income countries: questioning their outcomes and impact
}

\author{
DISSERTATION \\ to obtain the degree of Doctor at Maastricht University, \\ on the authority of the Rector Magnificus, Prof. dr. L.L.G. Soete, \\ in accordance with the decision of the Board of Deans, \\ to be defended in public, \\ on Friday 23 January 2015 at 14.00
}

by

Prisca Anna Cornelia Zwanikken

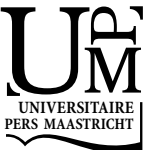




\section{Promotor}

Prof. dr. A.J.J.A. Scherpbier

\section{Copromotor}

Dr. Nguyen Thanh Huong, Hanoi School of Public Health, Vietnam

\section{Assessment Committee}

Prof. dr. Job F.M. Metsemakers (chair)

Prof. dr. J. Cohen-Schotanus, Rijksuniversiteit Groningen

Dr. J.S.M. Krumeich

Prof. dr. E.J. Ruitenberg, VU Universiteit Amsterdam

Prof. dr. G.J.Wesseling 


\section{Content}

$\begin{array}{lll}\text { Chapter } 1 & \text { General introduction } & 7\end{array}$

Chapter 2 A systematic review of outcome and impact of Master's in 19

health and health care

Chapter 3 Fifteen years of the tropEd Masters in International Health programme: what has it delivered? Results of an alumni survey of masters students in international health

Chapter 4 Quality assurance in transnational higher education: a case study of the tropEd network

Chapter 5 Validation of public health competencies and impact variables for low- and middle-income countries

Chapter 6 Outcome and impact of MPH programs across six countries: education for change

Chapter 7 Discussion

Chapter 8 Valorization

Appendices Summary

Samenvatting (Dutch summary)

Acknowledgements

Curriculum vitae

SHE dissertation series 

CHAPTER 1

General Introduction 



\section{Introduction}

In this chapter the background of the thesis and the relevant terms are explained; the problem definition is elaborated; the research question is defined; and an overview of the thesis is provided.

\section{Background}

Many publications have highlighted the need to train more human resources for health to address the shortage of health care workers (1-3); in 2006 WHO showed that 57 countries had a shortage of human resources in health, i.e. less than 2.5 health workers per 1,000 population (3). Recently the call to increase the numbers of human resources for health, including scaling up of training, was again emphasised (4-7), leading to increased interest in health professional education. The emphasis on scaling up training included increasing training of health workers with higher degrees in public health, as a shortage in skilled managers, researchers and policy-makers was also noted (4, 8-10).

Recently, it was questioned whether training in public health provided graduates with the competencies that are relevant in low- and middle-income countries (LMIC) (4, 8, 11-12). Sadana, Petrakova and Plugge asked whether public health graduates are able to build more equitable health systems, able to serve the marginalised and those in need, to advocate for better health outcomes and to collaborate across sectors for pro-health policies. They also noted that most Schools of Public Health (SPH) are located in high-income countries and wondered whether the curricula were appropriate for those working or wanting to work in LMIC. A number of authors asked similar questions regarding the competencies as well as the quality and relevance of the master's programmes in high- and middle-income countries. These questions regarding competences and relevance surfaced due to the rapid expansion of SPH and Master of Public Health (MPH) programmes, for example, in Canada after the SARS epidemic, Australia, USA, Europe, India and China (10,13-19). WHO identified the evaluation of the education of health professionals as a knowledge gap, especially the evaluation of its impact on practice, effectiveness of education and recommended more research on professions other than medicine and nursing and on LMIC (20).

The question regarding the relevance of higher education in public health and other health related master's programmes is influenced by a general debate on the quality, outcome and impact of higher education (21-24). Higher education institutions are under pressure from different stakeholders - governments, employers, taxpayers, fellowship-granting institutions as well as the prospective fee-paying students - to provide comparable information on the outcomes and impact of their education programmes.

This demand originates in part from the discussion whether higher education is a private or a public good. In the mid-1990s higher education came under the framework 
of the World Trade Organisation (WTO) and the General Agreement on Trade and Services (GATS). Some authors have questioned the approach to view higher education as an export good, stating that it undermines the public nature of education, and challenges the existing quality assurance, accreditation and qualification recognition mechanism (25-26). The scrutiny of the impact of higher education in part originates from funders, like governments and international funding actors (27).

When the World Bank decided to expand its funding strategy to include not only primary education but all education levels starting at the end of the 1990s, the relevance and effectiveness of tertiary education was put under question (28). A recent review of higher education interventions, including scholarship programmes, by the London International Development Centre showed that impact should be more thoroughly assessed (29). The question of impact evaluation was also spurred by policymakers and tax payers from high-income countries as well as educational researchers asking the more generic question on what works, why and under which circumstances (30-31).

\section{Short history of Master of Public Health and Master in International Health programmes}

Master of Public Health programmes aim to improve competencies of students, thus enabling them to contribute to the improvement of the health of the population, especially the marginalized and excluded, by educating professionals to analyse the situation, plan, manage and steer public health programmes as well as to influence public health policy (32-33). The definition of "public health" has changed over time, as public health has evolved. A commonly used definition is that of Acheson (34): "Public Health is the science and art of preventing disease, prolonging life and promoting health through the organized efforts of society". A more recent definition of public health is as follows: "Collective action for sustained population-wide health improvement" (35). Common to most definitions is the concern with public interest, as explained by Beaglehole in his article in The Lancet: " . . a sense of general public interest, a focus on the broader determinants of health and a desire to improve the health of the entire population."

MPH programmes are mostly multidisciplinary, enrolling bachelor's graduates from a variety of backgrounds (such as medicine, nursing and social sciences), but some focus only on medical doctors (36). Most MPH programmes are postgraduate, although graduate or even intercalated programmes exist (37-38). MPH programmes can be part- or fulltime, and mostly last one year fulltime. MPH programmes classically contain core subjects such as epidemiology and biostatistics, with most programmes covering topics such as management, planning, research, disease control and health systems ( 32 , 39). After WHO reaffirmed the importance of social determinants of health, in a num- 
ber of programmes more emphasis has been put to determinants of health (40-41). MPH programmes are traditionally provided either by medical universities, departments of Public Health or SPH $(4,10)$. Careers after an MPH include areas such as management, policy and research (42).

The development of SPH graduate degrees in public health started in the USA by the Welch-Rose report in 1915. Rose could not find at that time competent full-time public health professionals for the hookworm eradication programme and stated that the country needed leaders, specialists and fieldworkers (43). In Mexico the first SPH was established in 1922, the second in the Americas (44). In the UK the first SPH, London School of Hygiene and Tropical Medicine, was established in 1924. In 1960 public health training became more academically oriented, and in 1970s university MPH degrees were established; before that only MDs required diplomas. Only in 1990 was professional public health training made accessible also to non-MDs (45).

MPH programmes gradually expanded to other parts of the world. In China the first formalized public health education started at the beginning of the 20th century at the Peking Union Medical College and re-emerged in 1978 with undergraduate and graduate level training (46). In Vietnam the Hanoi School of Public Health started to develop an MPH programme in 1995 (47). In Africa starting in the 1970s some departments of schools of medicine developed into specialized institutions or schools of public health (32). In South Africa, the University of the Western Cape (UWC) established its Public Health Programme in 1993, transforming into a School of Public Health in 2000 (48). In Sudan the MPH programme at the University of Medical Sciences and Technology was established in 2002 as part of the Graduate College ( $\mathrm{H}$. Tahir, personal communication).

MPH programmes sometimes started in response to lack of adequate public health cadre in LMIC. At the Royal Tropical Institute (KIT) Amsterdam, the International Course on Health Development (ICHD) started in 1964, at the same time and in collaboration with the Institute of Tropical Medicine in Antwerp. From 1970 onwards ICHD graduates were rewarded a Master of Public Health degree (49). While MPH competencies have been developed and validated in different high-income countries such as in the USA, Europe and Australia (50-52), public health competencies for LMIC have not been developed nor validated transnationally.

The Masters in International Health $(\mathrm{MIH})$ programme is geared towards students with a bachelor's degree in health with limited work experience who seek to work at the interface of international organizations and national health systems. "International Health is a discipline that systematically compares factors that affect the health of all human populations with a special focus on poverty-related health problems in low- and middle-income countries. International Health includes the promotion of health, prevention and treatment of diseases and rehabilitation. Knowledge, skills and the ability to critically analyse and draw implications for practice related to the major endemic diseases, health systems research, health economics, health policy and management of health services are essential" (53).The programme is a flexible, modular programme 
which can be taken fulltime, but very often participants take the programme part-time, lasting up to five years. The MIH is a relatively young discipline, in Europe it started with a network of institutions, tropEd, coming together to develop a framework for a postgraduate MIH in 1996 (53). Since then the network has expanded to more than 30 institutions, covering 5 continents (53). Students start learning at one institution, called a "home" institution, with a core course of 3 months, and can then follow advanced modules accredited by the network, at different institutions, concluding the master's with a thesis. To gain tropEd recognition master's students are expected to gain some European credits outside the country of their home institution. Common MIH competencies as well as a common professional profile were developed in 2004 by the general assembly of tropEd, representing all participating institutions of tropEd (54). The common competencies are in line with the bachelor/master descriptors, and concentrate on the analysis and identification of solutions for the health and well-being of populations in LMIC, as well as planning, implementation, research and communication (5455).

\section{Outcome, impact and quality assurance of master's programmes}

Blömeke et al. (2013) pointed at the dearth of literature regarding measuring outcomes of students and graduates in higher education, especially international comparable measurements. The "Teacher Education and Development Study: Learning to Teach Mathematics" (TEDS-M) in 2008 was one of the first attempts to measure higher education outcomes on a large, international scale with representative samples (56). Van der Velden reported that there are only a few international comparative studies in higher education: the CHEERS survey "Careers after higher education" and the REFLEX project "Research into employment and professional flexibility" (57). The OECD had identified this measurements gap and has recently completed a feasibility study on the assessment of higher education learning outcomes (AHELO), developing tools to be used internationally to assess generic and specific skills of bachelor's degree graduates (58).

Very few published studies exist on the education of public health professionals, their career and ensuing competencies, as stated by Evashwick in her review of public health education literature (59). Outcome and impact evaluations of a Master's of Public Health and a Master's of International Health are scarce; since 1999 only 10 have been published, of which only 3 concentrate on LMIC $(47,60-68)$. There are no transnational evaluations of outcome and impact of master's degrees in health, possibly because of the numerous issues involved, such as different educational policies, curriculum content, and even teaching philosophies (69). Educational impact evaluations are not easy to develop and conduct, since the influencing factors before and after a programme cannot be controlled. Kirckpatrick's evaluation framework (70) has been cited over three decades as the basis of many educational and training evaluations. Kirckpat- 
rick uses four levels of evaluation: reaction, a measure of satisfaction; learning, increased knowledge and skills; behaviour, a measure of behaviour change; and results, a measure of results. During a systematic review of inter-professional education Hammick (2007) elaborated on the model and developed four inter-professional outcomes (71). In 2010, while developing a framework for evaluating the impact of UN fellowships, Rothem identified the following impacts: improved individuals capacity, improved services and improved outcomes for clients (27). In this thesis outcome is defined as the application of competencies at the workplace as well as changes in individual career development, such as promotion and new responsibilities. Impact is defined as the effected changes at the workplace, i.e. workplace performance as well as in the sector/society.

Since the 1990s, in schooling and higher education globally, detailed descriptions of expected performance or "effective application of available knowledge, skills, attitudes and values in complex situations" have been defined as competencies $(72,73)$. These competencies have been commonly used as drivers of curriculum development, programme evaluation, delineation of job functions and assessments of continuous professional development $(10,59,72,74-76)$.

Questions have been raised regarding the quality of higher education, especially given the current changes such as increasing transnational education, i.e. in terms of number of students and importance, as well as changing modes in teaching and learning e.g. e-learning (77-78). In quality assurance of postgraduate public health education on the one hand, general quality and accreditation standards are being followed, such as the Bologna process in Europe, while on the other hand specific accreditation mechanisms are either being developed or have been developed (79-80). Even though the Council on Education for Public Health (CEPH) increasingly accredits MPH programmes outside the US, the issue of how to ensure quality in transnational education does not seem to have been addressed. In Europe the Agency for Public Health Education Accreditation (APHEA) was established in 2011; to date MPH programmes of 3 institutions have been accredited, of which 2 institutions outside of Europe. APHEA accredits MPH programmes in order to enhance transferability of public health degrees in Europe (79); however the transferability of components or modules and quality assurance is not the focus. Therefore we decided to study the quality assurance of the Master's in International Health as a transnational master's degree, with students studying different components at different institutions within a transnational network.

\section{Research question}

Given the fact that outcome and impact evaluations have not been done for either $\mathrm{MPH}$ or MIH geared towards LMIC, and given the questions surrounding impact of master's programmes in general, the following overall research question was formulated: 
Are the MPH and the MIH relevant, and what is the influence of the MIH and MPH programmes on the graduates and their work?

The overall question was subdivided into a number of sub-questions:

- When evaluating master's in health and health care: which outcome and impact are examined and how?

- Do the graduates of the MIH programme find the programme appropriate? Do they feel confident in applying their newly gained competencies, and what kind of influence did the programme have in their career?

- What are the key issues in quality assurance in a transnational network master's in health?

- What are relevant public health competencies for LMIC and what are relevant impact variables on the work and on society?

- Do the graduates of MPH programmes apply their newly gained competencies? Do they attribute it to their MPH programme? What influence did the MPH programme have on their career? Do alumni attribute to the master's any influence on their work or society at large?

\section{Overview of the thesis}

Chapter 2 explains the conceptual framework of the impact evaluation of the master's in health and health care programmes. Outcome and impact are defined; the method how outcome and impact of master's programmes in health and health care are studied are identified; and influencing factors on outcome and impact are reviewed. Chapter 3 presents the results of the alumni survey of a network $\mathrm{MIH}$, in particular the outcome, i.e. appropriateness and confidence of the competencies gained as well as the effect on career development, responsibilities and financial rewards. Chapter 4 takes a closer look at the quality assurance of the network MIH. Chapter 5 explains the process and the results of the construction and validation of competencies as well as the impact variables on work and society of the MPH. Chapter 6 analyses the results of an alumni survey amongst graduates of six MPH programmes geared towards LMIC countries, asking whether alumni applied the learned competencies and attributed this improvement to the master's as well as whether it influenced their work and society at large. Chapter 7 provides the main conclusions of the different studies and discusses the implications of the findings. Chapter 8 provides recommendations for practice and for further research.

As most chapters have been written as individual articles some overlap between chapters may occur. 


\section{References}

1. Hongara C, McPake B: How to bridge the gap in human resources for health. Lancet 2004, 364:14511458

2. Chen L, Evans T, Anand S, Boufford JI, Brown H, Chowdhury M, Cueto M, Dare L, Dussault G, Elzinga G, Fee E, Habte D, Hanvoravongchai P, Jacobs M, Kurowski C, Michael S, Pablos-Mendez A, Sewankambo N, Solimano G, Stilwell B, de Waal A, Wibulpolprasert S: Human Resources for Health: overcoming the crisis. Lancet 2004, 364:1984-1990

3. World Health Organisation: The World Health Report 2006: Working together for health. Geneva: WHO press, World Health Organisation; 2006

4. Frenk J, Chen L, Bhutta ZA, Cohen J, Crisp N, Evans T, Fineberg H, Garcia P, Ke Y, Kelley P, Kistnasamy B, Meleis A, Naylor D, Pablos-Mendez A, Reddy S, Scrimshaw S, Sepulveda J, Serwadda D, Zurayk H: Health professionals for a new century: transforming education to strengthen health systems in an interdependent world. Lancet 2010, 376:1923-1958.

5. Global Health Workforce Alliance: Human resources for health: critical for effective universal health coverage http://www.who.int/workforcealliance/knowledge/resources/hrhforuhcpost2015/en/index.html

6. UN General Assembly 2012: Resolution on Global Health and Foreign Policy. http://www.un.org/ga/search/view_doc.asp?symbol=A/67/L.36

7. Campbell J, Buchan J, Cometto G, David B, Dussault G, Fogsta H et al: Human resources for health and universal health coverage: fostering equity and effective coverage. Bull World Health Organ 2013; 91:853-863.

8. Sadana R, Chowdhury AMR, Petrakova A: Strengthening public health education and training to improve global health. Bulletin of the World Health Organization 2007, 85:163.

9. Sanders D, Guwatudde D, Alexander L: Accessible public health education: A potential growth area? Bull World Health Organ 2008; 86:577-656

10. Evashwick, CJ: Educating the public health workforce. Frontiers in public health 2013, 1.

11. Petrakova A, Sadana R: Problems and progress in public health education. Bulletin of the World Health Organization 2007, 85(12):963-965.

12. Plugge $E$, Cole D: Oxford graduates' perceptions of a global health master's degree: a case study. Human Resources for Health 2011, 9(1):26.

13. Bennett CM, Lilley K, Yeatman H, Parker E, Geelhoed E, Hanne EG, Robinson P: Paving pathways: Shaping the public health workforce through tertiary education. Australia and New Zealand Health Policy 2010, 7:2

14. Griffith SM, Li ML, Tang JL, Ma X, Hu YH, Meng QY, Fu H. The challenges of public health education with a particular reference to China. Public health, 2010 124:218-224

15. Massé R, Moloughney B: New era for schools of public health in Canada. Public Health Reviews 2011, 33:277-88

16. Tulchinsky T, McKee M: Education for a Public Health Workforce in Europe and Globally. Public Health Reviews 2011, 33:7-15

17. Rosenstock L, Helsing K, Rimer BK: Public health education in the United States: then and now. Public Health Reviews 2011, 33:39-65

18. Adany R, Villerusa A, Bislimovska J, Kulzhanov M: Public health education in Central and Eastern Europe, and Central Asia. Public Health Reviews 2011, 33:105-33.

19. Bangdiwala S, Tucker J, Zodpey S, Griffiths S, Li LM, Reddy KS, Cohen M, Gross M, Sharma K, Tang JL: Public health education in India and China: history, opportunities, and challenges. Public Health Reviews 2011, 33:204-24

20. WHO: Transforming and scaling up health professionals' education and training. WHO Education Guidelines 2013 at http://www.who.int/hrh/resources/transf_scaling_hpet/en/ 
21. Nusche D: Assessment of learning outcomes in higher education: a comparative review of selected practices OECD Education Working Paper No. 15D 2008. http://econpapers.repec.org/paper/oeceduaab/15-en.htm

22. Kristensen B: Has external quality assurance actually improved quality in higher education over the course of 20 years of the 'quality revolution'? Quality in Higher Education 2010, 16(2):153-157.

23. Jacobs GJ: Quality's Higher Education Dividends: Broadened Custodianship and Global Public Scholarship. Quality in Higher Education 2010, 16(2):163-167.

24. Blömeke S, Zlatkin-Troitschanskaia O, Kuhn C, Fege J. Modeling and Measuring Competencies in Higher Education: tasks and challenges. SensePublishers 2013 ISBN: 978-94-6091-867-4 (e-book)

25. Gu J: Transnational education: current developments and policy implications. Frontiers of Education in China 2009, 4(4):624-649.

26. Walker M, McLean M, Dison A, Vaughan R: Higher education and poverty reduction: the formation of public good professionals in universities. Nottingham: School of Education, University of Nottingham; 2010. http://www.dfid.gov.uk/r4d/PDF/Outputs/ESRC_DFID/60622_Case_Studies_Final.pdf

27. Rothem A, Zinovieff MA, Goubarev A: A framework for evaluating the impact of the United Nations fellowship programmes. Hum Resour Health 2010, 8:7.

28. World Bank, Constructing Knowledge Societies: New Challenges for Tertiary Education 2002, Washington DC, World Bank

29. Creed C, Perraton $\mathrm{H}$, Weege J: Examining development evaluation in higher education interventions: a preliminary study London International Development Centre 2012 http://www.lidc.org.uk/_assets/LIDC\%20Higher\%20Education\%20study\%20final.pdf

30. White H: A Contribution to Current Debates in Impact Evaluation Evaluation 2010, 16, 153 DOI: $10.1177 / 1356389010361562$

31. Wong G, Greenhalgh T, Westhorp G, Pawson R: Realist methods in medical education research: what are they and what can they contribute? Med Educ 2012, 46:89-96

32. IJsselmuiden CB, Nchinda TC, Duale S, Tumwesigye NM, Serwadda D: Mapping Africa's advanced public health education capacity: the AfriHealth project. Bulletin of the World Health Organization 2007, 85(12):914-922.

33. Genat B, Robinson P, Parker E: Foundation competencies for Master of Public Health graduates in Australia. Brisbane QUT Publications: Australian Network of Academic Public Health Institutions; 2009

34. Acheson D: Independent inquiry into inequalities in health. London 1988, HM Stationary Office UK

35. Beaglehole R, Bonita R, Horton R, Adams O, McKee M: Public health in the new era: improving health through collective action. Lancet 2004, 363(9426):2084-2086.

36. Birt CA, Foldspang A: Public health capacity building-not only the property of the medical profession. The European Journal of Public Health, 2009 19(3):232-235

37. Harris R, Kinsinger L, Tolleson Rhinehart S: The MD-MPH program at the University of North Carolina at Chapel Hill. Academic Medicine 2008, 83(4):371-377

38. Kuiper T, Meijer A, Moust J: Innovation in Public Health Teaching: The Maastricht Experience. Public Health Reviews 2011, 33(3):2107-6952

39. Bjegovic-Mikanovic V, Vukovic D, Otok R, Czabanowska K, Laaser U: Education and training of public health professionals in the European Region: variation and convergence. International journal of public health 2013, 58(6):801-810.

40. Marmot M, Friel S, Bell R, Houweling TA, Taylor S: Closing the gap in a generation: health equity through action on the social determinants of health. Lancet 2008, 372(9650):1661-1669.

41. Commission on Social Determinants of Health. Closing the gap in a generation: health equity through action on the social determinants of health. Final Report of the Commission on Social Determinants of Health. World Health Organization 2008 Geneva

42. Ackerly DC, Parekh A, Stein D: Perspective: A Framework for Career Paths in Health Systems Improvement. Academic Medicine 2013, 88(1):56-60.

43. Fineberg HV, Green GM, Ware JH, Anderson BL: Changing public health training needs: Professional Education and the Paradigm of Public Health. Annu. Rev. Public Health 1994, 15:237-57 
44. Magaña-Valladares L. Cooper K The National Institute of Public Health: Shaping Public Policy to Advance Population Health in Mexico Public Health Reviews 2011, 33(1):331-338

45. Cole K, Sim F, Hogan H. The Evolution of Public Health Education and Training in the United Kingdom Public Health Reviews 2011, 33(3):2107-6952

46. Bangdiwala S, Tucker J, Zodpey S, Griffiths S, Li LM, Reddy KS, Cohen M, Gross M, Sharma K, Tang JL: Public health education in India and China: history, opportunities, and challenges. Public Health Reviews 2011, 33:204-24.

47. Le LC, Bui Q, Nguyen HT, Rotem A: Alumni survey of masters of public health (MPH) training at the Hanoi School of Public Health. Human Resources for Health 2007, 5.

48. Alexander L, Igumbor, EU, Sanders, D: Building capacity without disrupting health services: public health education for Africa through distance learning. Hum Resour Health 2009, 7, 28.

49. Bouter L, Donner D: Self-evaluation report Master of Public Health/ International Course on Health Development, 2010, Vrije Universiteit Amsterdam/ Royal Tropical Institute

50. The Council on Linkages Between Academia and Public Health Practice: Core Competencies for Public Health Professionals Tier 1, Tier 2 and Tier 3 (adopted 3 May 2010)

51. Birt CA, Foldspang A: The Developing Role of Systems of Competences in Public Health Education and Practice. Public Health Reviews 2011, 33(1):134-147

52. Genat B, Robinson P, Parker E: Foundation competencies for Master of Public Health graduates in Australia. Australian Network of Academic Public Health Institutions, 2009

53. tropEd secretariat, tropEd Network for Education in International Health: Profile of tropEd. http://www.troped.org/sites/default/files/tropEd0201-tropEd\%20Profile-May\%202013.pdf

54. tropEd General Assembly, Meeting minutes Madrid, May 2004

55. The Bologna declaration (1999) The European Higher Education Area: Joint declaration of the European Ministers of Education convened in Bologna on the 10th of June 1999. http://www.ehea.info/Uploads/Declarations/BOLOGNA_DECLARATION1.pdf

56. Blömeke S: The challenges of measurement in higher education, IEA's Teacher Education and Development Study in Mathematics (TEDS-M). in: Blömeke ea (2013) Modeling and Measuring Competencies in Higher Education: tasks and challenges SensePublishers ISBN: 978-94-6091-867-4 (e-book)

57. van der Velden R: Measuring competencies in higher education: what next? in: Blömeke S, ZlatkinTroitschanskaia O, Kuhn C, Fege J. Modeling and Measuring Competencies in Higher Education: tasks and challenges. 2013 SensePublishers ISBN: 978-94-6091-867-4 (e-book)

58. OECD 2013 Assessment of higher education learning outcomes. Feasibility study report Vol. 2 Data analysis and national experiences http://www.oecd.org/edu/skills-beyond-school/AHELOFSReportVolume2.pdf

59. Evashwick CJ, Tao D, Bax K: Analysis of the literature pertaining to the education of public health professionals. Frontiers in Public Health 2013, 1

60. Finocchio LJ, Love MB, Sanchez EV: Illuminating the MPH health educator workforce: results and implications of an employer survey. Health Educ Behav 2003, 30(6):683-694.

61. Davis MV, Sollecito WA, Shay S, Williamson W: Examining the impact of a distance education MPH program: a one-year follow-up survey of graduates. J Public Health Manag Pract 2004, 10(6):556-563

62. Ruth BJ, Wyatt J, Chlasson E, Geron SM, Bachman S: Social work and public health: comparing graduates from a dual-degree program. J Soc Work Educ 2006, 42(2):429-439.

63. Petersen $D$, Hovington $M$, Pass $M$ : Assuring public health professionals are prepared for the future: the UAB Public Health Integrated Core Curriculum. Public Health Rep 2005, 20:496-503

64. Harris R, Kinsinger LS, Tolleson-Rinehart S, Viera AJ, Dent G: The MD-MPH program at the University of North Carolina at Chapel Hill. Acad Med 2008, 83(4):371-377

65. Stellman JM, Cohen S, Rosenfield A: Evaluation of a one-year masters of public health program for medical students between their third and fourth years. Acad Med 2008, 83(4):365-370

66. Bradley EH, White W, Anderson E, Mattocks K, Pistell A: The role of gender in MPH graduates' salaries. $J$ Health Adm Educ 2000, 18(4):375-389 
67. Kellerman R, Klipstein-Grobusch K, Weiner R, Wayling S, Fonn S: Investing in African research training institutions creates sustainable capacity for Africa: the case of the University of the Witwatersrand School of Public Health masters programme in epidemiology and biostatistics. Health Res Policy Syst, 2012 10(11).

68. Jeannot E, Stoll B, Chastonay P: Alumni Evaluation of a Community-Oriented Master of Public Health Program. Journal of community health 2013, 38(2):357-359

69. Blömeke S, Paine L: Getting the fish out of the water: Considering benefits and problems of doing research on teacher education at an international level. Teaching and Teacher Education, 2008, 24(4), 2027-2037

70. Kirkpatrick DL, Kirkpatrick JD: Evaluating Training Programs: The four levels. 3rd edition. San Francisco CA: Berrett-Koehler Publishers; 2006

71. Hammick M, Freeth D, Koppel I, Reeve S, Barr H: A best evidence systematic review of interprofessional education: BEME Guide no. 9. Med Teach 2007, 29:735-75

72. Calhoun JG, Davidson PL, Sinioris ME, Vincent ET, Griffith JR: Toward an understanding of competency identification and assessment in health care management. Qual Manag Health Care 2002, 11(1):14-38.

73. Albanese MA, Mejicano G, Mullan P, Kokotailo P, Gruppen L: Defining characteristics of educational competencies. Medical Education 2007, 42: 248-255

74. Calhoun J, Ramiah K, McGean Weist E, Shortell SM: Development of a core competency model for the Master of Public Health degree. Am J Public Health 2008, 98:1598-1607

75. Frank JR, Mongroo R, Ahmad Y, Wang M, De Rossi S, Horsley T: Toward a definition of competencybased education in medicine: a systematic review of published definitions. Medical Teacher 2010, 32:631-637

76. Birt CA, Foldspang $A$. The developing role of systems of competences in public health education and practice. Public Health Reviews 2011, 33:134-47.

77. Knight J: Cross-border higher education: quality assurance and accreditation issues and implications. In: Globalisation and tertiary education in the Asia-pacific: The changing nature of a dynamic market. Edited by Tierney W, Findlay C. Singapore, Hackensack N.J: World Scientific 2010, 73-92

78. Ewell $P$. Twenty years of quality assurance in higher education: what's happened and what's different? Quality in Higher Education 2010, 16(2):173-175

79. Otok R, Levin I, Sitko S, Flahault A. European Accreditation of Public Health Education. Public Health Reviews 2011, 33(3):2107-6952

80. Council on Education for Public Health (CEPH), http://ceph.org/, dated 2013 


\section{CHAPTER 2}

\section{A systematic review of outcome and impact of Master's in health and health care}

Published as:

Zwanikken PAC, Dieleman M, Samaranayake D, Akwataghibe N, Scherpbier A: A systematic review of outcome and impact of Master's in health and health care. $B M C$ Medical Education 2013, 13:18 doi:10.1186/1472-6920-13-18 


\begin{abstract}
Background: The 'human resources for health' crisis has highlighted the need for more health (care) professionals and led to an increased interest in health professional education, including master's degree programmes. The number of these programmes in low- and middle-income countries (LMIC) is increasing, but questions have been raised regarding their relevance, outcome and impact. We conducted a systematic review to evaluate the outcomes and impact of health-related master's degree programmes.
\end{abstract}

Methods: We searched the databases Scopus, Pubmed, Embase, CINAHL, ERIC, Psychinfo and Cochrane (1999 - November 2011) and selected websites. All papers describing outcomes and impact of health-related Master programmes were included. Three reviewers, two for each article, extracted data independently. The articles were categorised by type of programme, country, defined outcomes and impact, study methods used and level of evidence, and classified according to outcomes: competencies used in practice, graduates' career progression and impact on graduates' workplaces and sector/society.

Results: Of the 33 articles included in the review, most originated from the US and the UK, and only one from a low-income country. The programmes studied were in public health (8), nursing (8), physiotherapy (5), family practice (4) and other topics (8). Outcomes were defined in less than one third of the articles, and impact was not defined at all. Outcomes and impact were measured by self-reported alumni surveys and qualitative methods. Most articles reported that competencies learned during the programme were applied in the workplace and alumni reported career progression or specific job changes. Some articles reported difficulties in using newly gained competencies in the workplace. There was limited evidence of impact on the workplace. Only two articles reported impact on the sector. Most studies described learning approaches, but very few described a mechanism to ensure outcome and impact of the programme.

Conclusions: Evidence suggests that graduates apply newly learned competencies in the field and that they progress in their career. There is a paucity of well-designed studies assessing the outcomes and impact of health-related master's degree programmes in low- and middle-income countries. Studies of such programmes should consider the context and define outcomes and impact. 


\section{Background}

Many publications have addressed the need to train more health workers to meet the human resources for health crisis $[1,2,3]$ including the shortage of higher cadre staff in public health [3]. Recently, it was questioned whether training of higher level cadres in public health prepared graduates with competencies that are relevant to low- and middle-income countries (LMIC) [4-6], and similarly in high-income countries [7,8]. The question about the relevance of (public) health-related higher education is probably influenced by the trend towards outcome-based education for the health professions $[9,10]$ and by the general debate on the assessment of learning outcomes [11] and the impact of higher education [12-14]. Studies of the impact of master's degree programmes have mainly focused on the effectiveness of programmes to meet the economic needs of a country and on their contribution to economic productivity in Africa [15-17].

Since the outcomes and impact of master's degree programmes are also affected by factors occurring after completion of the programme, it is not easy to separate effects directly related to programmes and other influences. Outcomes and impact are thus not easy to measure, and researchers have to decide what variables to measure, what evaluation methods to use, and how to take into consideration the context in which graduates apply their newly learned competencies to achieve the desired outcome and impact.

Kirkpatrick's evaluation framework is used in many studies evaluating educational results [18]. It distinguishes four levels of evaluation: reaction (a measure of satisfaction); learning (increased knowledge and skills); behaviour (a measure of behaviour change); and results (a measure of results). Hammick et al. [19] elaborated on Kirkpatrick's framework by developing four interprofessional outcomes: reaction; modification of perceptions and attitudes, including acquisition of knowledge and skills; behavioural change; and change in organisational practice as well as benefits to clients/patients. In 2010, Rothem et al. [14] developed a logical pathway and benefit chain that identifies improved capacity, improved services and improved outcomes for clients.

In this study we used a conceptual framework (Figure 1) based on a revised version of Kirkpatrick's original framework by Hutchinson [20]. We developed the framework using an iterative process based on the literature review and discussions in the research team. Curriculum output is influenced by the components of the curriculum, the learning objectives, curriculum content and factors such as the selection of students. The learning of students is influenced by individual student and school factors. The curriculum and the learning of students are influenced by higher education policies and budgets. 


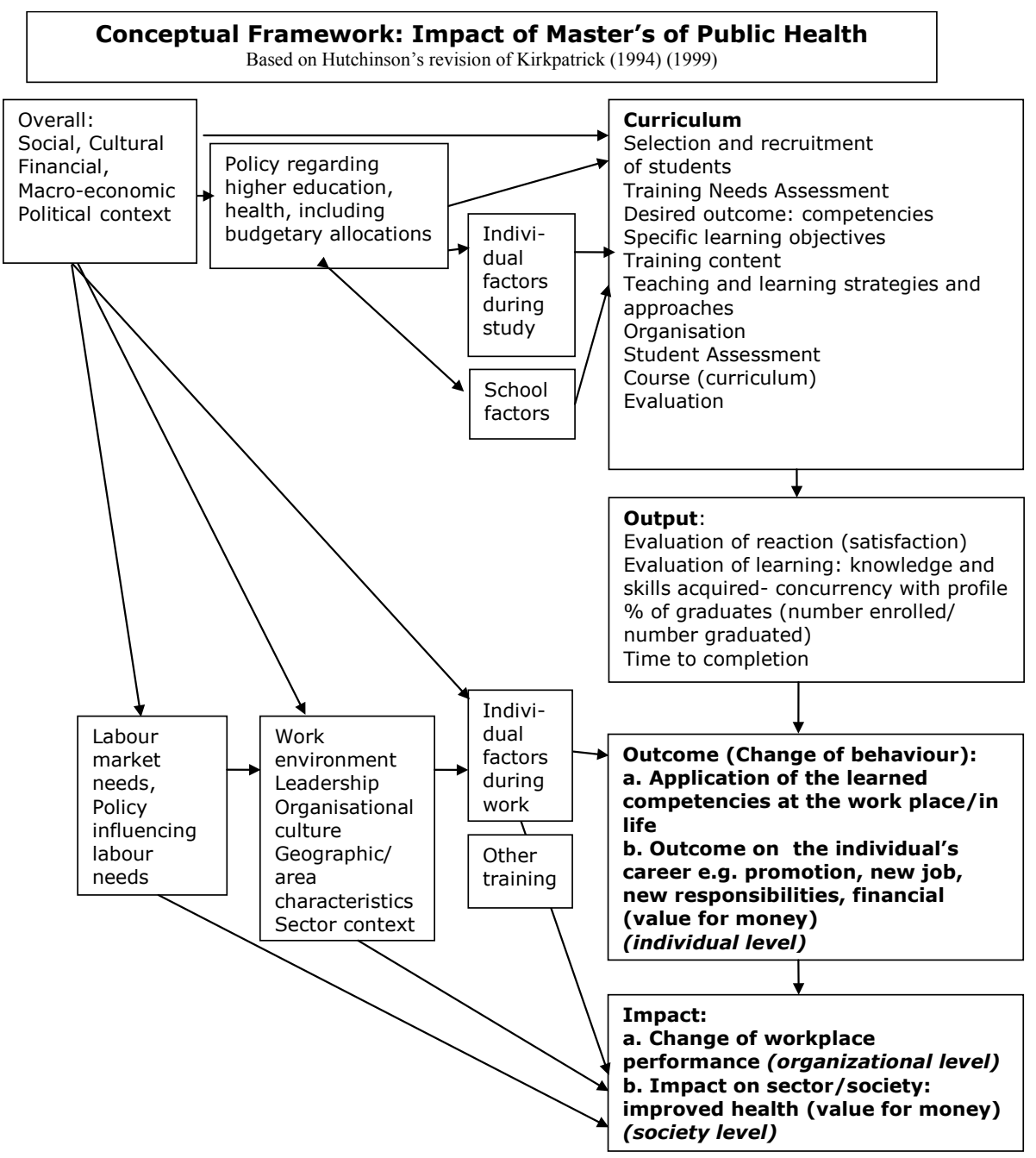

Figure 1: Conceptual Framework: Impact of Master's Degree Programmes in Public Health.

In the framework, output is defined as the level of satisfaction with the programme expressed by the students and the number of students passing tests, thereby showing they have acquired specific knowledge and skills. The output is not the focus of this study.

In this paper, outcome is defined as the application in practice of competencies learned, such as developing and managing programmes and performing research, and as the effects on careers, i.e. job promotion. Impact is defined as the impact on the workplace, such as changes made by graduates, and the impact on the sector and society, such as improved quality of care. 
We identified other factors with a negative or positive effect on programme outcomes or impact, such as individual factors like additional training, personal issues and motivation; work-related factors, such as organisational culture, gender barriers, and income as well as influences from the labour market and overall policies. This paper aims to critically review the methods used to evaluate outcome and impact of master's degree programmes in the field of health and health care as well as the outcome and impact on the performance of both graduates' and their workplace.

\section{Methods}

We conducted a systematic review of the literature.

\section{Search strategy}

For the literature search we used the key words: (TITLE-ABS-KEY(\{master degree\} OR \{masters degree\} OR \{masters education\} OR \{master's\} OR \{masters degree in public health\}) OR TITLE-ABS-KEY(\{master degree in public health\} OR \{masters of public health\} OR \{masters in public health\} OR \{master of public health\} OR \{master in public health\}) AND (\{impact*\} OR \{effect*\} OR \{result*\} OR \{outcome*\} OR \{evaluation*\} OR \{organizational performance*\} OR \{career mobility\})). We searched literature published between 1999 and 30 November 2011, because 1999 was the year in which the Bologna declaration on Master's educational programmes in Europe was signed [21]. The document types searched for were: (systematic) reviews, primary research studies, evaluation reports and all types of review articles. At the start of the search no limits were set as regards language of publication.

Title/abstract/keywords were searched in the following databases: Scopus, Pubmed, Embase, CINAHL, ERIC, Psychinfo and Cochrane, as well as Google and Google Scholar by two authors and an information specialist. Figure 2 presents a flow chart of the search. Scanning Google scholar using the same key words yielded about 5000 hits. After excluding duplicates 1894 unique references the titles were screened by two independent reviewers, which resulted in 168 abstracts. At this stage, we decided to exclude studies of programmes that were not directly related to health or health care. This reduced the number of abstracts to 99 which were read independently by two of the three reviewers (PZ, DS and NA). After exclusion of abstracts that did not report a primary study or a review of primary studies and had no relevance to the study question, a total of 59 abstracts remained. Of these, two were excluded because of the language (Portuguese). After the reviewers had read the full text of the remaining articles, 29 articles were excluded. Of the thirty articles left, the full text of one could not be retrieved. A further search of the references of the articles with revealed additional four relevant articles. 


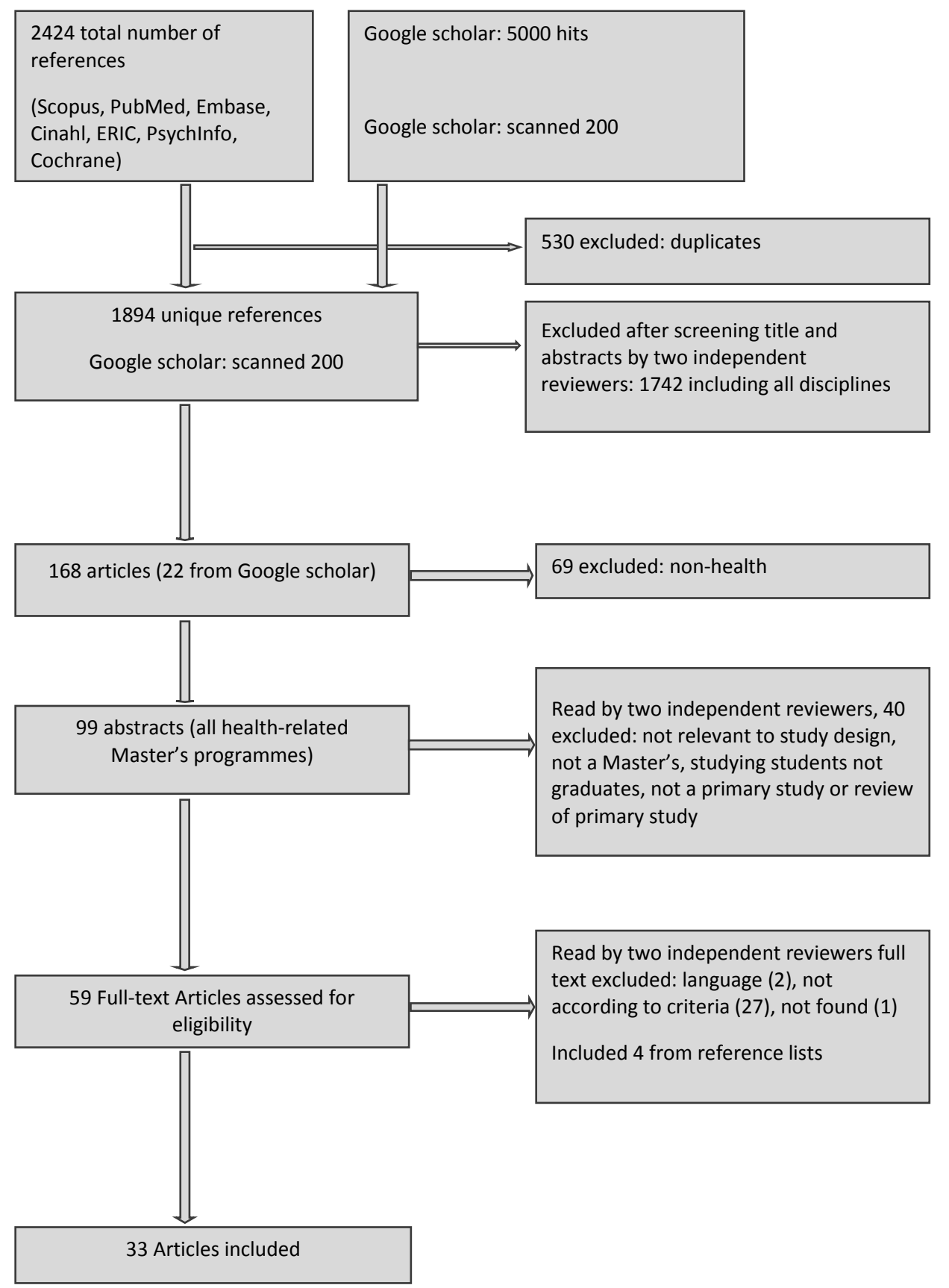

Figure 2: Flow chart of included studies on outcome and impact of health and healthcare-related Master's. 


\section{Data processing and analysis}

The 33 articles were read independently by two researchers in pairs (PZ and NA or PZ and DS). Using the framework developed by the research team, the researchers extracted the following data: name of the programme, target group, programme content/ educational methods/ assessment methods, time at which graduates were approached ( $x$ years after obtaining the degree of interest), level of evidence, study design, methods used to measure outcome and impact, definition of outcome and impact, outcomes studied (application of competences in the workplace, effect on individual careers), working environment of graduates, impact on the workplace, impact on the sector, mechanisms to ensure outcome and impact, the context in which the programme was successful (Additional file 1). The first five articles were analysed by the three researchers together to reach consensus on the data extraction. Whenever there was doubt about data extraction, a third researcher was consulted and consensus was reached through discussion.

The results were synthesised using simple calculation and qualitative analysis. No statistical analysis was performed because of the wide variety of study designs and methods.

Results

We first present an overview of the studies according to the type and provenance of the programme. Next, we describe how outcome and impact were defined, the methods used to measure these and the level of evidence provided (Table 1). The aggregated results with respect to outcomes (application of competencies in the workplace and career progression) and the impact in the workplace and in society are presented. We then describe the intervention logic and the context of the programmes, the target groups, the contents, the learning approaches and mechanisms to ensure the achievement of outcome and impact. 
Table 1: Characteristics of the 33 studies reviewed

\begin{tabular}{|c|c|}
\hline \multirow[t]{5}{*}{ Country } & USA (15) \\
\hline & UK (13) \\
\hline & Australia, Canada, Ireland (1 each) \\
\hline & Vietnam (1) \\
\hline & Systematic review (1) \\
\hline \multirow[t]{6}{*}{ Type of Master's } & MPH (8) \\
\hline & Nursing (8) \\
\hline & Physiotherapy (5) \\
\hline & General or family medicine (4) \\
\hline & Occupational therapy (2) \\
\hline & $\begin{array}{l}\text { Others (6: physician assistants, allied health professionals, health commu- } \\
\text { nication, pharmacists, global health, psychiatric rehabilitation) }\end{array}$ \\
\hline \multirow[t]{6}{*}{ Level of evidence: all level 4} & 'Triangulation' design (18) (17 alumni surveys and 1 employer survey) \\
\hline & Comparison with non-independent reference standard (3, alumni surveys) \\
\hline & Sequential design (1) \\
\hline & Mixed methods approach (3): sequential exploratory (2), triangulation (1) \\
\hline & Qualitative (7) \\
\hline & Systematic review (1) \\
\hline \multirow[t]{4}{*}{ Study design } & Quantitative (22) \\
\hline & Qualitative (7) \\
\hline & Mixed methods (3) \\
\hline & Systematic review (1) \\
\hline
\end{tabular}

\section{Country and type of programme}

The articles reviewed related to programmes in the USA (15), UK (13), Australia (1), Canada (1) and Ireland (1). There was one systematic review of studies on programmes in several high-income countries. Only one study related to a low- or middle-income country (Vietnam).

The articles related to programmes in public health (8), nursing (8), physiotherapy (5), general or family practice (4), occupational therapy (2) and six other professions (physician assistant, allied health professions, health communication, pharmacists, global health, psychiatric rehabilitation). Three articles specified that they dealt with distance-learning programmes, of which two were e-learning programmes. Two studies addressed international programmes, which were open to students from different countries. 


\section{Defined outcome and impact}

Less than one third of the articles defined programme outcomes before the study was conducted. None of the articles gave a definition of programme impact. Outcomes were defined in terms of the application of competencies, but references to career improvement were virtually absent. Generic descriptions of outcome were used in some studies, such as increased confidence and commitment to the profession and integration with academic skills [22]. Some studies defined outcomes as 'to become an expert in the profession' [23] or 'an expectation of improved leadership, management, supervision and teaching in a specific topic' [24], with specific skills added [25]. Stark examined the changes in roles [26]. Others clarified that the programme was set up to meet changed needs by training physicians with a population perspective $[27,28]$. Plugge and Cole [6] reported quite broadly defined learning outcomes, while Calvert and Britten [29] reported learning objectives only.

\section{Methods used to study outcomes and impact}

A total of 22 articles used quantitative methods, of which 21 reported the use of selfreported alumni surveys and 1 used an employer survey. In one article two quantitative methods were combined: an alumni survey with an employer survey. Three articles used a mixed methods approach: alumni survey combined with either focus group discussions, or focus group discussions and in-depth interviews or group interviews with students. Of the seven articles using qualitative methods, six reported the use of one method only: either focus group discussions (2), semi-structured interviews (3) or unstructured individual interviews (1). Only one qualitative study used two methods (semi-structured interviews and focus group discussions). One article was a systematic review (see Table 2).

Table 2: Methods used to study outcome and impact

\begin{tabular}{ll}
\hline Quantitative methods (22) & - Alumni survey (20) \\
& - Employer survey (1) \\
& - Alumni survey combined with employer survey (1) \\
Mixed methods (3) & - Alumni survey and focus group discussion \\
& - Alumni survey and in-depth interview and focus group discussion \\
& - Alumni survey and group discussion \\
& One method only (6): \\
Qualitative methods (7) & - focus group discussions (2) \\
& - semi-structured interviews (3) \\
& - unstructured interviews (1) \\
& Two methods (1): \\
& - semi-structured interviews and focus group discussions \\
\hline Systematic review (1) & \\
\hline
\end{tabular}


For the studies alumni were approached immediately after graduation $[23,24]$, one year after graduation [30], at least three years after graduation [26,31], and up to thirty years after graduation [32]. Eleven studies did not report how many years after graduation alumni were approached.

As for the application of competencies, almost all evidence was from self-report alumni surveys. Only two studies surveyed employers [33,34]. No pre- or postmeasurements were carried out, colleagues were not surveyed, and no other methods were used (such as observation or document review). The majority of studies did not report whether graduates attributed career advancement to their attendance of the master's programme. Impact in the workplace or the sector/ society relied exclusively on self-reports by alumni.

\section{Level of evidence}

All articles evaluated education at level 4 (i.e. case series) [35]. One article compared graduates of two different programmes, one article compared graduates from three different programmes and one article compared alumni from different cohorts. Since these articles did not use an independent reference standard, they were all classified as level 4.

The quality of the studies was further specified based on the Mixed Methods Appraisal Tool [36]. The design of the articles using alumni surveys only (17) was classified as triangulation, because of the concurrent use of closed and open questions. This classification is questionable, however, in the case of studies that did not use other methods or qualitative results to interpret the quantitative data. A study that used an employer survey with a time series analysis was also classified as triangulation [33]. One study used a sequential design with alumni and employer surveys [34]. Only three articles used a mixed methods approach. Cragg and Andrusyszyn [37] mention 'four focus groups with a total of nine participants', which does not meet the quality criteria for focus group discussions [38]. The study designs were generally of low quality [36], comprising case series and depending mostly on self-reporting, with little triangulation.

\section{Studied outcomes: application of new competencies in the workplace}

There is reported evidence that graduates applied at least some of their newly acquired competencies in the workplace. They reported improved leadership skills $[30,39,40]$, better job performance [30,34] or improved skills [34,41]. In the study by Murray [34], employers corroborated employees' enhanced job skills and job performance as a direct result of the master's programme. Alumni used their research skills $[23,42,43]$ or were involved in research [22]. In a number of studies, graduates reported improvement in the clinical care they provided $[22,42-46]$ and in their attitude towards patients $[43,47]$. Alumni also reported enhanced self-confidence $[22,23,29,37,43,48,49]$. 
The skills that were measured were specified in some articles: management $[25,30]$, problem solving [44], use of strategic or new approaches [30,50], academic skills [22], teaching skills [42], presentation skills [51] and a range of public health skills [52]. The application of some specific skills were reported, such as clinical practice $[49,50]$, health education and community approaches [33], pharmacy business skills [25], communicating at a higher level [44], a translation function [37], applying a changed perspective on public health [30] and being better equipped for general practice [53]. The use of generic competencies such as: critical reflection $[29,46,48]$, critical thinking and/or analysis $[23,29,46,50]$, the use of evidence $[37,46,47]$ and critical appraisal of the literature [28] was reported in some articles.

Some articles, however, reported that graduates experienced difficulties using newly gained competencies in the workplace [43]. Mental health nursing graduates reported uncertainty about their role and having to compromise their values. They also experienced a gap between theory and practice [22]. Green [42] reported an increased demand for teaching and expectations of advice.

\section{Outcomes studied: career}

Seven studies identified career improvement as an effect of the programme [27,29,34,44,49-51]. Other studies reported specific job changes, such as a higher position/ promotion in the same workplace [24,25,30,39-41,47,54], a new job $[25,30,51]$, increased job responsibilities [40], additional roles [53], a new role [42], a new role at a higher level in the system [41] or an appointment in a position where a Master's degree was required [37].

Three studies reported graduates pursuing an academic career or an increased involvement in academia $[34,42,47]$. Others reported more management responsibilities $[25,42,46,54]$, less clinical work $[39,42]$ and more involvement in education $[25,40,46,47,53,54]$. Some reported monetary rewards, such as a higher salary $[24,31,54,55]$ or a higher grade $[43,54]$. Two articles specifically reported new affiliations [30] and membership of a professional organisation [34]. In some articles alumni reported increased job satisfaction $[34,40,47,50]$ or a higher level of career satisfaction [49]. A number of alumni reported pursuing other studies $[30,40,47,54,56]$ or a PhD degree $[23,40]$.

\section{Impact studied: in the workplace}

Gijbels et al. in their systematic review [43] reported limited evidence of a direct impact on organisational changes and changes in service delivery, including Brooker's article on improvement in patients' and carers' knowledge. Self-reported retention of General Practitioners was described by Baron et al. [53]. Alumni reported the publication of books or book chapters and conference presentations in the articles by Tsimtsiou et al. 
[47], Richardson et al. [40] and Schattner et al. [39]. Richardson et al. [42] reported popular publications, such as brochures and educational videos. In addition Schattner et al. [39] reported completed research projects and research grants. Davis et al. [30], Cragg and Andrusyszyn [37] and Perry et al. [44] noted that graduates reported encountering resistance in the workplace when trying to implement changes.

\section{Impact studied: on sector and society}

Only two studies mentioned any impact on the sector or on society. In their systematic review, Gijbels et al. [43] reported limited evidence of benefit to patients and carers. They cited evidence from Brooker, for example on mental health care and improvements in patients' and carers' knowledge and shorter hospital stays. Richardson et al. [40] stated that graduates from an online master's programme in occupational therapy reported launching community programmes, developing hospital and clinic programmes and receiving funds for development grants written by graduates. They were also involved in advocacy for improved client benefits and in state regulatory legislative issues [40].

\section{Intervention logic and context of health-related master's degree programmes}

We use the framework developed for this study to describe different aspects of curricula and the wider context of programmes and graduates' work settings to identify if and how studies addressed the intervention logic of the programmes.

Regarding the target group: of the eight programmes in public health described in the articles, five did not specify a target group. One article stated that the target group comprised a mix of nurses, healthcare administrators and health educators [29], and two studies reported third-year medical doctors/students as the target group [27,28]. The target group of the Global Health programme was described as a mix of clinicians and non-clinicians [6]. In other studies, the target group was implied in the professional orientation of the programme. For example, nurses were the target group of the nursing programme. Most articles provided little information about the selection and recruitment of students, training needs assessment, specific content and organisation.

A variety of learning methods were used, such as peer group reflection on practice work combined with personal education plans [53], a portfolio combined with course work [53], course and practice work [51], topical modules such as tobacco (including discipline-specific content) [52], mentoring in clinical practice $[45,48]$, different tracks with electives [34] and one track with electives [6]. A Master's thesis was often mentioned as a final programme component. The assessment methods used were described in ten of the studies. The ten articles described at least two different methods, and some programmes used more methods and combinations of different methods. Course evaluation consisted mostly in end-of-course evaluation procedures. 
Learning approaches define how students are expected to learn. Mechanisms to ensure achievement of outcomes and impact included learning approaches as well as approaches to ensure that graduates can apply what they have learned in the workplace. Most of the studies described learning approaches, such as a learner-centred approach [53], and some studies identified a mechanism to ensure the achievement of outcomes and impact, with participants going through a learning cycle of contemplation, assimilation, conflict and resolution [22]. Most of the studies describing such a mechanism also described the learning approach during the programme. Only one study reported that students were selected and the curriculum adapted to their needs as a mechanism to ensure outcomes and impact, although the study did not describe what happened after the programme or what was done during the programme to enhance its impact for alumni.

As regards programme context, a number of articles referred to national or regional government policy (usually health ministries or departments) [22,26,34,39, $41,42,46,51,52]$ and the labour market [26-28,34,47,53]. These policies and the labour market influenced the initial development of and the reasons for starting a programme, programme content, financing or the number of graduates.

Graduates' work settings were described only rarely. Baron et al. [53] described a shortage and early retirement of general practitioners.

\section{Discussion}

Although quite a few of the studies we reviewed measured the outcomes of master's degree programmes in health-related subjects, few measured programme impact. Although it should be noted that though the studies focused largely on graduates' perspectives, and triangulation of data was rare, the review revealed some general issues in relation to the outcomes and impact of programmes.

The studies were limited to programmes in high-income countries, except for one programme in Vietnam. This highlights the dearth of literature on health-related master's degree programmes in low- and middle-income countries. Despite the large numbers of graduates in public health and nursing, programmes in these areas were the subject of only eight articles each.

Interestingly, very few studies defined the outcomes and impact before or at the start of the study. This may be explained by the difficulty of defining outcomes and impact of degree programmes like public health, which cover a broad field and are also highly context dependent. However, for master's degree programmes in physiotherapy or nursing, the impact might be easier to define, for example by measuring reduced duration of patients' hospital visits or faster recovery [43]. Insofar as outcomes and impact were defined, they were mostly quite generic. This may be inherent in the nature of higher education, with master's degrees often being pursued to achieve a 'high- 
er' level of thinking, such as critical analysis, problem solving, etc. On the other hand, however, efforts have been made in a number of countries to assess the learning outcomes of master's degree programmes at national level [11]. Davis [9], Harden [10] and Harden et al. [57] argue that defining learning outcomes and therefore overall outcome is important to steer content and approaches to learning. This suggests that welldefined learning objectives may be considered to provide sufficient assurance that graduates will be able to perform competently in the workplace and promote changes in society.

The articles we reviewed studied outcomes and impact for different reasons. Interestingly, almost all articles on programmes in physiotherapy, nursing and general practice discussed the question of the validity of a clinical course taught masters. It was often mentioned that even the universities offering the courses did not consider them valuable because they were not aimed at training researchers or did not lead to a PhD degree. Some of the studies were even designed to refute the assertion that these master's degree programmes were not worthwhile, or to show that they made explicit contributions to either retention of professionals or the development of evidencebased practice in general.

As for the application of competencies in the workplace, graduates reported being able to apply their newly gained competencies, whether they were generic, academic or specific. In terms of career-related outcomes, graduates reported being given more responsibilities, receiving promotions, changing jobs and changing careers (for example going into academia or rising within the academic system). Some studies specifically reported higher financial rewards for graduates. In some studies, graduates attributed career changes to the master's degree, but in other studies the attribution question was not asked. Graduates gain experience over time, which may offer sufficient explanation for career advancement. As for changes in the workplace, many studies referred to publishing in both academic and popular outlets and obtaining grants, but also resistance to change in the workplace. Again, these changes were mostly self-reported by graduates. As for impact on sector/ society, one article [40] very specifically mentioned advocacy, launching community programmes and getting involved in state regulatory issues. What was observed by Gijbels et al. [43] in their review, namely that very few studies identified impact, appears to be confirmed by our review, with impact being largely neglected in the majority of the studies. As for factors affecting outcome and impact, some studies reported that resistance to change in the workplace was part of the leadership or organisational culture [43]. Some studies discussed outcomes and impact in relation to the sector, stating that general practitioners or occupational therapists were more motivated to remain in their job as a result of attendance of a master's degree programme. Only one study discussed the influence of geographical area: Bradley et al. [55] discovered that those who opted to work in a certain area were more likely to receive a higher salary. 
The intervention logic and context of the programme received only limited attention in most of the studies. Often some information was provided about the target group, programme content and assessment methods. This information may have been readily available from documents. The educational approaches and methods, however, received scant attention. Information about needs assessment, recruitment and selection of students, course facilitators and the organisation and evaluation of courses was limited, if provided at all. Although most of this information could probably have been obtained through document review, many researchers may have considered it to be outside the scope of their study. Hardly any mention was made of the presence of a mechanism to ensure the achievement of outcomes and impact in the workplace and the sector. A possible explanation for this may be that it is generally felt that once students are graduated they fall outside the responsibility of the institution where they received their education. One method of ensuring the applicability of learned competencies in the workplace might be to deliver a part of the curriculum in the future workplace $[45,47,51,53]$.

Also the work setting of graduates was mentioned rarely. Some studies reported graduates encountering resistance to change in the workplace, which limited their ability to apply what they had learned. The lack of interest in the setting in which graduates apply what they have learned may be attributable to the considerable amount of time and effort required to fully understand this aspect of the outcomes and impact of master's programmes. Very often the wider context in which a programme was developed or delivered was described, such as the national or regional policy of ministries or departments of health or of the labour market. These are important factors to be considered.

The outcomes and impact of programmes was mostly studied through alumni surveys. Although such surveys may give a reasonably good insight into the careers of graduates and whether they have found their competencies to be useful in the workplace, alumni surveys are self-reported and therefore prone to bias. All study designs were retrospective, using alumni surveys, focus group discussions and semi-structured interviews. The sample sizes of the surveys ranged from 20 [23] to 478 graduates [32], but mostly did not exceed one hundred participants, with response rates varying between $37 \%$ and $90 \%$. The limited sample sizes and low response rates undermine the value of the findings. In some studies a mixed group was approached, such as students undertaking a bachelor's or master's degree programme [46], postgraduate and master's degree students [42] or a mix of medical graduates with only a medical degree, another degree or a degree in public health [28]. In the analysis of these studies, however, no distinction was made between these groups, and consequently any changes could not be attributed to the master's degree or any other level of achievement. In several studies graduates were approached directly after or in their year of graduation. It seems likely that it may have been difficult for these graduates to identify any career changes, as they might still have been in the phase of applying for new jobs or getting 
back to work. Most studies used instruments that were not validated. Overall the evidence levels were at level 4 and of relatively low quality.

It is therefore not easy to attribute outcomes and impact of master's degree programmes to specific factors. Triangulation of information from students, peers and employers or superiors or of information obtained using different methods, such as interviews, surveys or observation was rarely reported. It should be noted that interviews with peers and employers can also introduce bias, due to interviewees giving socially desirable answers but also because graduates change jobs often or are given more responsibilities. Observation seems preferable and may be easier for graduates of programmes in physiotherapy or teaching [58], but would probably be more complicated for programmes in public health.

\section{Limitations}

Although there was no language restriction in our literature search, some languages, Chinese for instance, were in fact excluded from the beginning, and this may have biased the results. Our inability to trace one article may have caused bias as well. In some articles, some results or statements of results were not clearly defined. For example, it was not specified what was meant by 'increased satisfaction'. Job satisfaction was not included in the framework we developed, and this should probably be added. As we stated earlier, the framework makes a clear distinction between outcomes and impact, but in some of the articles and in reality this distinction may be less clear cut.

The framework we developed was helpful in identifying and distinguishing the outcomes and impact of health-related master's degree programmes. In some studies, however, outcomes and impact were defined differently, and consequently great care had to be taken in the data extraction. In the framework, a clear distinction was made between outcomes and impact, but in reality this distinction may be blurred and there may be some overlap between these categories.

\section{Conclusion}

The number of studies explicitly describing the outcomes and impact of a healthrelated master's degree programmes was limited. Despite the growing attention for improving the quality and quantity of human resources for health in low- and middleincome countries, we found only one study on a programme being offered in such a country. Although it is important to define the outcomes and impact of health-related master's degree programmes in order to identify their contribution to changes in health care, apart from increasing the number of trained professionals, the studies we found revealed a general lack of interest in and provided scant information about these factors. What information was provided was mostly derived from self-reported alumni surveys, and consequently subject to bias. However, although seemingly desirable, a 
randomised controlled trial over time would be ethically questionable and very difficult to perform. The fact that both the intervention and the outcome take place in a complex environment seems to call for complexity thinking and complexity theory [59]. Another study design that could provide the insights we are after might be a cohort study with follow-up over time, although there are likely to be time constraints. Carefully designed alumni surveys with well-defined outcomes and impact, using triangulation of information from peers and employers, seem to offer a promising approach as well.

Unfortunately, the studies we reviewed rarely considered contextual factors, even though these factors can be crucial in determining whether graduates are able to apply their newly learned competencies and improve the workplace or the sector. We recommend that studies of the effects of master's programmes address these contextual factors, as we believe such studies will be able to reveal whether graduates of master's degree programmes are 'fit for purpose'. These studies might use a realist review $[60,61]$ to enhance the applicability and usability of results to other master's programmes.

\section{Additional file}

Additional file 1: Summary systematic review outcome and impact Master's in Health and health care.

To be found at: http://www.biomedcentral.com/1472-6920/13/18 


\section{References}

1. Hongara C, McPake B: 2004 How to bridge the gap in human resources for health. Lancet 2004, 364:1451-1458.

2. Chen L, Evans T, Anand S, Boufford JI, Brown H, Chowdhury M, Cueto M, Dare L, Dussault G, Elzinga G, Fee E, Habte D, Hanvoravongchai P, Jacobs M, Kurowski C, Michael S, Pablos-Mendez A, Sewankambo N, Solimano G, Stilwell B, de Waal A, Wibulpolprasert S: Human Resources for Health: overcoming the crisis. Lancet 2004, 364:1984-1990.

3. World Health Organisation: The World Health Report 2006: Working together for health. Geneva: World Health Organisation; 2006.

4. Sadana R, Petrakova A: Shaping public health education around the world to address health challenges in the coming decades. Bulletin of the World Health Organisation 2007, 85(12):902.

5. Petrakova A, Sadana R: Problems and progress in public health education. Bulletin of the World Health Organisation 2007, 85(12):963-5.

6. Plugge E, Cole D: Oxford graduates' perceptions of a global health master's degree: a case study. Human Resources for Health 2011, 9(1):26.

7 Davis MV, Dandoy S, Greaves W: Graduate programs: What is their contribution to the training of public health workforce? American Journal of Preventive Medicine 2003, 24(4):361-6.

8. Bennett CM, Lilley K, Yeatman H, Parker E, Geelhoed E, Hanne E, Robinson P: Paving pathways: Shaping the public health workforce through tertiary education: Australia and New Zealand Health Policy 2010, 7:2.

9. Davis MH: Outcome based education. Journal of Veterinary Medical Education 2003, 30(3)227-232.

10 Harden RM: Outcome-based education: the future is today. Medical Teacher 2007, 29:625-629.

11. Nusche D: Assessment of learning outcomes in higher education: a comparative review of selected practices. OECD Education Working Paper No. 15D Nusche, 2008. http://econpapers.repec.org/paper/oeceduaab/15-en.htm.

12. Gu J: Transnational education: Current developments and policy implications. Frontiers of Education in China 2009, 4(4)624-649.

13. Walker M, McLean M, Dison A, Vaughan R: Higher education and poverty reduction: the formation of public good professionals in universities. Nottingham: School of Education, University of Nottingham; 2010. http://www.dfid.gov.uk/r4d/PDF/Outputs/ESRC_DFID/60622_Case_Studies_Final.pdf.

14. Rothem A, Zinovieff MA, Goubarev A: A framework for evaluating the impact of the United Nations fellowship programmes. Human Resources for Health 2010, 8:7.

15 Bloom D, Canning D, Chan K: Higher Education and Economic Development in Africa. World Bank 2005. http://siteresources.worldbank.org/INTAFRICA/Resources/afrhdwps_102.pdf

16. Ginevičius R, Ginevičienè V: The compliance of Master's degrees studies with the economic needs of the country. Baltic Journal on Sustainability 2009, 15(1):136-153.

17. Nasrin F: Investment in graduate and professional degree education: Evidence of state workforce productivity growth. Florida Journal of Educational Administration \& Policy 2009, 3(1):9-35

18. Kirkpatrick DL, Kirkpatrick JD: Evaluating Training Programs: The four levels. $3^{\text {rd }}$ Edition, San Francisco CA: Berrett-Koehler Publishers; 2006.

19. Hammick M, Freeth D, Koppel I, Reeve S, Barr H: A best evidence systematic review of interprofessional education: BEME Guide no. 9. Medical Teacher 2007, 29:735-75.

20. Hutchinson L: ABC of learning and teaching: educational environment. BMJ 2003, 326:810-812.

21. The Bologna declaration (1999) The European Higher Education Area. Joint declaration of the European Ministers of Education convened in Bologna on the $10^{\text {th }}$ of June 1999. http://www.ehea.info/Uploads/Declarations/BOLOGNA_DECLARATION1.pdf.

22 Stacey G, Felton A, Joynson K: Masters at work: A narrative inquiry into the experiences of mental health nurses qualifying with an undergraduate Masters degree. Nurse Education Today 2010, 30:333337. 
23. LeCount J: Education, Empowerment, and Elderly Adults - Enhancing nursing expertise in the long-term care setting. Journal of Gerontological Care 2004, 6-13.

24. Gill, KJ: Turjanick M, Bagherian P, Ali D: Evaluation of a Master's Degree Program in Psychiatric Rehabilitation. American Journal of Psychiatric Rehabilitation 2005, 8(2):165-174. Special issue: Psychiatric Rehabilitation Education and Credentials.

25. Wilson JP, Wen LK: Influence of a nontraditional master's degree on graduates' career paths. American Journal of Health-System Pharmacy 2000, 57(23) 2196-2201.

26. Stark S: The effects of master's degree education on the role choices, role flexibility, and practice settings of clinical nurse specialists and nurse practitioners. Journal of Nursing Education 2006, 45(1)715.

27. Stellman JM, Cohen S, Rosenfield A: Evaluation of a one-year masters of public health program for medical students between their third and fourth years. Academic Medicine 2008, 83(4):365-370.

28. Harris R, Kinsinger LS, Tolleson-Rinehart S, Viera AJ, Dent G: The MD-MPH program at the University of North Carolina at Chapel Hill. Academic Medicine 2008, 83(4)371-377.

29. Calvert G, Britten N: The United Medical and Dental School of Guy's and St Thomas's hospitals' MSc in general practice: graduates perspectives. Medical Education 1999, 33:130-135.

30. Davis MV, Sollecito WA, Shay S, Williamson W: Examining the impact of a distance education MPH program: a one-year follow-up survey of graduates. Journal of Public Health Management and Practice 2004, 10(6): 556-563

31. Ruth BJ, Wyatt J, Chlasson E, Geron SM, Bachman S: Social work and public health: comparing graduates from a dual-degree program. Journal of Social Work Education 2006, 42(2)429-439.

32. Evans TC, Wick KH, Brock DM, Schaad DC, Ballweg R: Academic degrees and clinical practice characteristics: The University of Washington physician assistant program: 1969-2000. Journal of Rural Health 2006, 22(3) 212-219.

33. Finocchio LJ, Love MB, Sanchez EV: Illuminating the MPH health educator workforce: Results and implications of an employer survey. Health Education and Behavior 2003, 30(6)683-694

34. Murray C: Evaluation of a post-professional master's program in allied health. Journal of Allied Health 2001, 30(4)223-228

35. Oxford Center for Evidence Based Medicine. Levels of evidence. Dated: March 2009 http://www.cebm.net/index.aspx?o=1025

36. Pluye P, Robert E, Cargo M, Bartlett G, O'Cathain A, Griffiths F, Boardman F, Gagnon MP, Rousseau MC: Proposal: A mixed methods appraisal tool for systematic mixed studies reviews. http://mixedmethodsappraisaltoolpublic.pbworks.com.

37. Cragg CE, Andrusyszyn M: Outcomes of Master's education in nursing. International Journal of Nursing Education Scholarship, 2004, 1,1.

38. Kitzinger J: The methodology of focus groups: the importance of interaction between research participants. Sociol Health IIIn 1994, 16(1):103-121

39. Schattner P, Klein B, Piterman L, Sturmberg J, McCall L: Impact of master of family medicine degree by distance learning on general practitioners' career options. Medical Teacher 2007, 29(4)e85-e92.

40. Richardson PK, MacRae A, Schwartz K, Bankston L, Kosten C: Student outcomes in a postprofessional online master's-degree program. American Journal of Occupational Therapy 2008, 62(5)600-610.

41. Le LC, Bui Q, Nguyen HT, Rotem A: Alumni survey of masters of public health (MPH) training at the Hanoi School of Public Health. Human Resources for Health 2007, 5.

42. Green A, Perry J, Harrison K: The influence of a postgraduate clinical master's qualification in manual therapy on the careers of physiotherapists in the United Kingdom. Manual therapy 2008, 13(2)139-147.

43. Gijbels $\mathrm{H}$, O'Connell $\mathrm{R}$, Dalton-O'Connell $\mathrm{C}$, O’Donovan $\mathrm{M}$ : A systematic review evaluating the impact of post-registration nursing and midwifery education on practice. Nurse Education in Practice 2010, 10:6469

44. Perry J, Green A, Harrison K: The impact of Masters education in manual and manipulative therapy and the 'knowledge acquisition model'. Manual Therapy 2010, 16(3)285-290. 
45. Petty N, Scholes J, Ellis L: The impact of a musculoskeletal masters course: Developing clinical expertise. Manual Therapy 2011, 16:590-595.

46. Hardwick S, Jordan S: The impact of part-time post-registration degrees on practice. Journal of Advanced Nursing 2002, 38(5):524-535.

47. Tsimtsiou Z, Sidhu K, Jones R: The benefits and costs of a master's programme in primary health care: a cross-sectional postal survey. The British Journal of General Practice 2010, 60(580):e434.

48. Petty NJ, Scholes J, Ellis L: Master's level study: learning transitions towards clinical expertise in physiotherapy. Physiotherapy 2011, 97(3)218-225.

49. Stathopoulos I, Harrison K: Study at Master's Level by Practising Physiotherapists. Physiotherapy 2003, 89(3), 158-169. .

50. Whyte DA, Lugton J, Fawcett TN: Fit for purpose: Relevance of Master's preparation for the professional practice of nursing. Journal of Advanced Nursing 2000, 31(5):1072-1080.

51. Edgar T, Hyde, JN: An alumni-based evaluation of graduate training in health communication: Results of a survey on careers, salaries, competencies, and emerging trends. Journal of Health Communication 2005, 10(1):5-25.

52. Petersen $D$, Hovington $M$, Pass $M$ : Assuring public health professionals are prepared for the future: The UAB Public Health Integrated Core Curriculum. Public Health Reports 2005, 120:496-503.

53. Baron R, McKinlay D, Martin J, Ward B: Master's degree-accredited professional education and development courses for general practitioners in the North Western Deanery 1997-2002: Impact on effectiveness, retention and recruitment to additional roles. Education for Primary Care 2006, 17(2):147-154.

54 Drennan J: Professional and academic destination of masters in nursing graduates: A national survey. Nurse Education Today 2008, 28:751-759.

55. Bradley EH, White W, Anderson E, Mattocks K, Pistell A: The role of gender in MPH graduates' salaries. The Journal of Health Administration Education 2000, 18(4):375-389.

56. Conneely AL: Study at Master's level: A qualitative study exploring the experience of students. British Journal of Occupational Therapy 2005, 68(3):104-109.

57. Harden RM, Crosby JR, Davis MH: Outcome based education part 1: An introduction to outcome-based education. Medical Teacher 1999, 21(1):7-14.

58. Lewis NS, Jeanpierre B: An Evaluation of a Master's Degree in K-8 Mathematics and Science. Classroom Practice School Science and Mathematics 2006, 106(6):231-240.

59 Gilson L (Ed) 2012 Health Policy and Systems Research: A methodology reader. Geneva: Alliance for Health Policy and Systems Research/ WHO; 2012.

60 Pawson R, Tilley N: Realistic Evaluation. London: Sage Publications; 1997.

61 Wong G, Greenhalgh T, Westhorp G, Pawson R: Realist methods in medical education research: what are they and what can they contribute? Medical Education 2012, 46:89-96. 


\section{CHAPTER 3}

\section{Fifteen years of the tropEd Masters in}

International Health programme: what has it delivered? Results of an alumni survey of masters students in international health

\section{Published as:}

Gerstel L, Zwanikken PAC, Hoffman A, Diederichs C, Borchert M, Peterhans B: Fifteen years of the tropEd Masters in International Health programme: what has it delivered? Results of an alumni survey of masters students in international health. Tropical Medicine \& International Health 2013, 18(3), 377-384 


\begin{abstract}
Objectives: In 2010-2011 recent graduates (2008 or earlier) of the Masters in International Health (MIH) (as offered by over 30 universities and institutions collaborating in the tropEd network) were surveyed. We aimed to examine whether the competencies gained proved appropriate for alumni's current positions, and to develop the programme according to alumni's needs.
\end{abstract}

Methods: An online questionnaire was sent to 327 alumni. One hundred seventyseven responded, and 99 met the inclusion criteria. We calculated frequency distributions of the answers and performed a bivariate analysis of certain variables.

Results: Alumni feel confident in all areas covered by the MIH. Most competencies acquired are perceived as essential or very relevant to their current position. Many respondents (77\%) changed jobs after graduation, mostly from curative care to public health. More African and Asian alumni work in their country of origin (66\% and 63\%, respectively) than alumni from other continents (42\%). The respondents had mostly worked at a national or provincial level, but after graduating mostly worked at an international or national level. Alumni said that the network's mobility and flexibility had important advantages and disadvantages.

Conclusions: This is the first alumni survey of the MIH programme offered through the international network tropEd. The results suggest that competencies gained by graduates are relevant for their current careers. We recommend offering better guidance to students planning modules and to improve administration. 


\section{Introduction}

TropEd is an international network of 31 international health higher education institutions. It began in 1996 with 13 European partners and has since extended to institutions in Africa, Asia and Latin America and more recently to Australia. The network has developed a framework for a postgraduate Masters in International Health (MIH) that aims to make use of the experience and expertise of the participating institutions. The programme is open to students with a bachelors or equivalent degree in a healthrelated field (i.e. medical doctors, nurses, social scientists) from around the world. Teaching is predominantly but not exclusively in English. A limited number of student grants are available each year through European (Erasmus Mundus) and national funding schemes (e.g. by the German Academic Exchange Service DAAD, the Swiss government and the Canton of Basel City). The programme is based on the mobility of staff and students, the sharing of experiences across health disciplines, and the development of common standards in education. The MIH should prepare students to work effectively in an international, multicultural and multidisciplinary environment (tropEd 2012, www.troped.org). The MIH is a modular programme consisting of a core course, advanced modules, and a research project submitted as a thesis (monograph or peerreviewed publication) (Figure 1). Tuition fees vary considerably, from $€ 6000$ to $€ 22000$, depending on the institution. The MIH is designed to be completed within 1-year fulltime or 4-5 years part-time. 


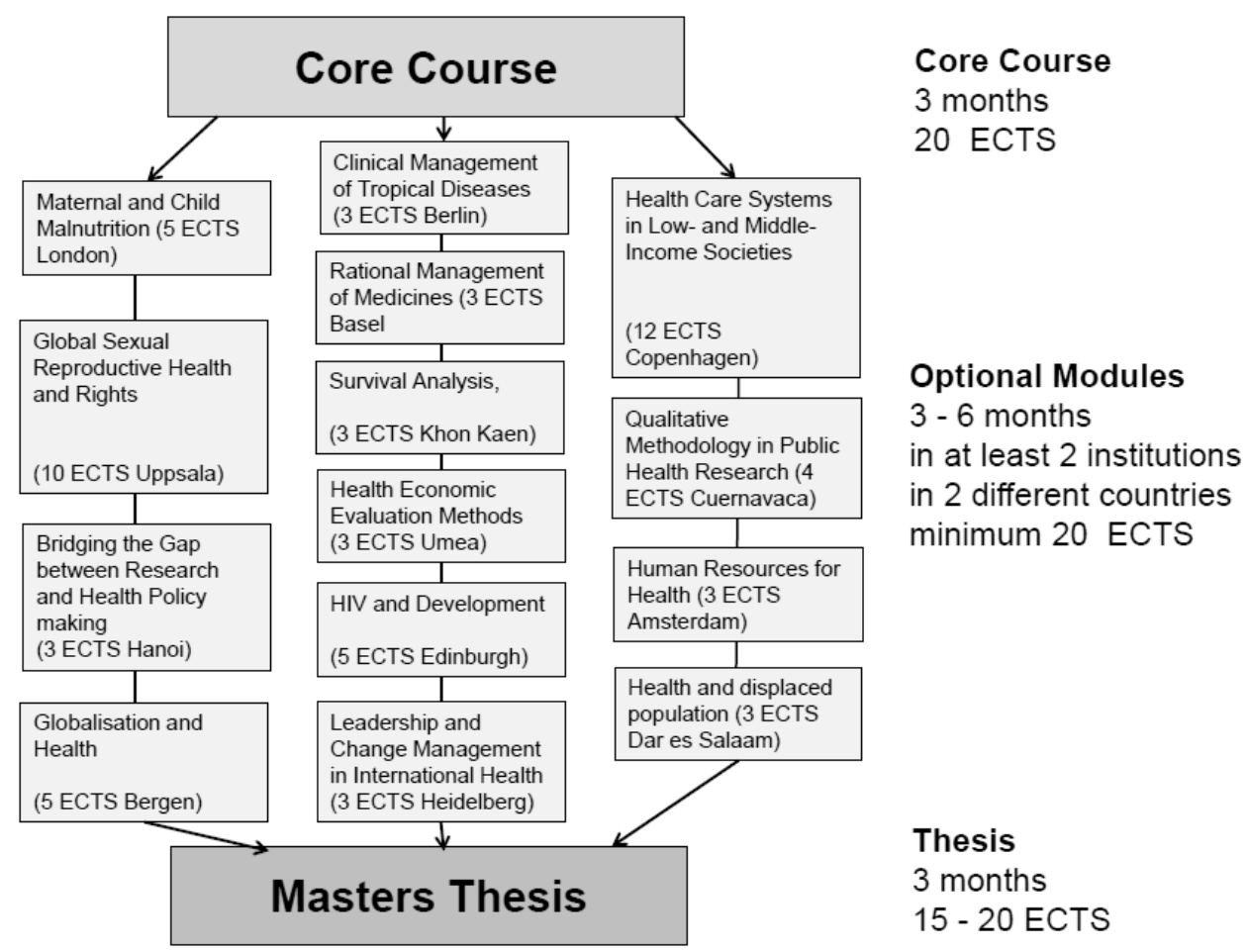

Figure 1: Schematic view of the tropEd Master in International Health programme with three examples of possible study programmes. These programmes need to be agreed with the Course Coordinator of the home institution and must be aligned with the intended learning objectives.

The students enroll for the MIH at one of the institutions offering a core course, referred to as the students' 'home institution'. TropEd students are expected to acquire some European Credit Transfer and Accumulation System (ECTS) credits through advanced modules at a tropEd institution outside the country of their home institution. The thesis component can be completed at their home institution or at another tropEd institution. The MIH degree is always awarded by the home institution. In addition to their MIH degree, students receive the tropEd recognition if they comply with the following criteria:

- A minimum of 2 years of professional work experience before graduation from the MIH programme, of which at least 1 year was spent in a low- and/or middle-income country/society;

- At least 10 ECTS credits earned through advanced modules accredited by tropEd, outside the country of their home institution; and

- Completion of studies within 5 years.

Although individual tropEd home institutions have evaluated the Masters in International Health programme for their own students, no network-wide alumni survey has 
been performed since the start of the programme 15 years ago. A literature search found several studies reporting how well United States (Davis et al. 2003; Petersen et al. 2005) and Vietnamese (Le et al. 2007) Masters programmes in Public Health and a UK Masters Programme in Global Health (Plugge \& Cole 2011) meet the needs of their alumni, but no study reported on a Masters in International Health, or on a Masters programme offered by a network of institutions of higher education. We therefore surveyed alumni of different home institutions to examine whether the competencies gained from the programme have proved to be appropriate for the alumni's current work situation; to further develop the tropEd MIH programme according to the needs expressed by the alumni; and to offer comparable programs a format to evaluate their Masters.

\section{Methods}

An anonymous online questionnaire was designed with 29 items asking about demographics, educational background, current and previous work situation, confidence in and relevance of the competencies gained by the $\mathrm{MIH}$, and perceived strengths and weaknesses of the programme. The questionnaire was based on alumni surveys from the network's member institutions and was discussed during the quality assurance committee meeting and finally approved by a tropEd General Assembly meeting. The survey targeted alumni who had finished the MIH programme at least 2 years earlier, to allow time for students to use their newly acquired competencies and to find a new position after completing the programme. Initially, we intended to complement the alumni survey by an employer survey, but we did not reach an acceptable response rate in employers.

Each home institution made the survey available via free online tools (www.surveymonkey.com and www.quicksurveys.com) and advertised it to their MIH alumni between April 2010 and February 2011. The answers from all the institutions were combined and analysed using Microsoft Excel 2010 and Epi-info 7 (CDC, Atlanta). Only respondents who reportedly had obtained tropEd recognition were included. Other respondents were excluded as they did not sufficiently use the mobility of the network, took longer than 5 year or had less work experience than students with tropEd recognition. Answers to open questions were coded and transformed into categorical variables. We performed a descriptive analysis with frequency distributions of categorical answers to multiple-choice questions. We also performed a bivariate analysis for the variables gender, part-time/full-time student, professional background MD yes/no, year start MIH programme, and age, cross-tabulated against: working outside the region of origin, promotion, increased responsibilities, mobility scheme of the $\mathrm{MIH}$, and costs as a weakness of the programme. 


\section{Results}

\section{Response rate}

Three out of seven home institutions participated in the survey: The Royal Tropical Institute (KIT) in Amsterdam, The Institute of Tropical Medicine and International Health (ITMIH) in Berlin, and the Swiss Tropical \& Public Health Institute (SwissTPH) in Basel. The main reasons that other home institutions did not participate were a lack of staff and time. Also some institutions had joined the network only recently, so very few of their graduates had finished more than 2 years ago. 327 alumni were invited to participate, of whom 177 (54\%) responded. Of these 99 indicated that they had obtained tropEd recognition. All data presented below refer to these 99 alumni.

\section{Demographics of respondents}

Respondents started their MIH between 1996 and 2008 and had Berlin ( $N=63)$, Basel (26) and Amsterdam (10) as their home institution. Most (72) students started between 2003 and 2007 and had a professional background in medicine (61\%), nursing /midwifery $(9 \%)$, social science $(5 \%)$, dentistry $(3 \%)$, pharmacy $(3 \%)$, or other professions (19\%). Alumni originated from 40 different countries in five continents (see Table 1).

Table 1: Characteristics of respondents to tropEd alumni questionnaire 2010-2011, N=99

\begin{tabular}{ll}
\hline Characteristics & Respondents \\
\hline Part-time study & $50 \%$ \\
Average duration study & 3.7 years \\
Fully self-funded & $40 \%$ \\
Women & $50 \%$ \\
Age group at start of study 26-35 years & $67 \%$ \\
Region of origin & \\
$\quad$ Europe & $43 \%$ \\
$\quad$ Asia & $32 \%$ \\
Africa & $17 \%$ \\
$\quad$ Latin America & $5 \%$ \\
$\quad$ North America & $3 \%$ \\
\hline
\end{tabular}

Data are comparable to the characteristics of current tropEd MIH students, who may or may not gain tropEd recognition, except for continent of origin: today $60 \%$ of current tropEd students are from Europe, 16\% from Africa and 17\% from Asia. 


\section{Relevance of tropEd Masters in International Health}

Alumni were asked to indicate the three main reasons they pursued a tropEd MIH. The most frequent answers were to improve their professional competency, develop a career in international health, or validate their own experience (Figure 2). Other answers were desire to earn a higher salary, a superior recommended the $\mathrm{MIH}$, won a scholarship, and the option to study part-time.

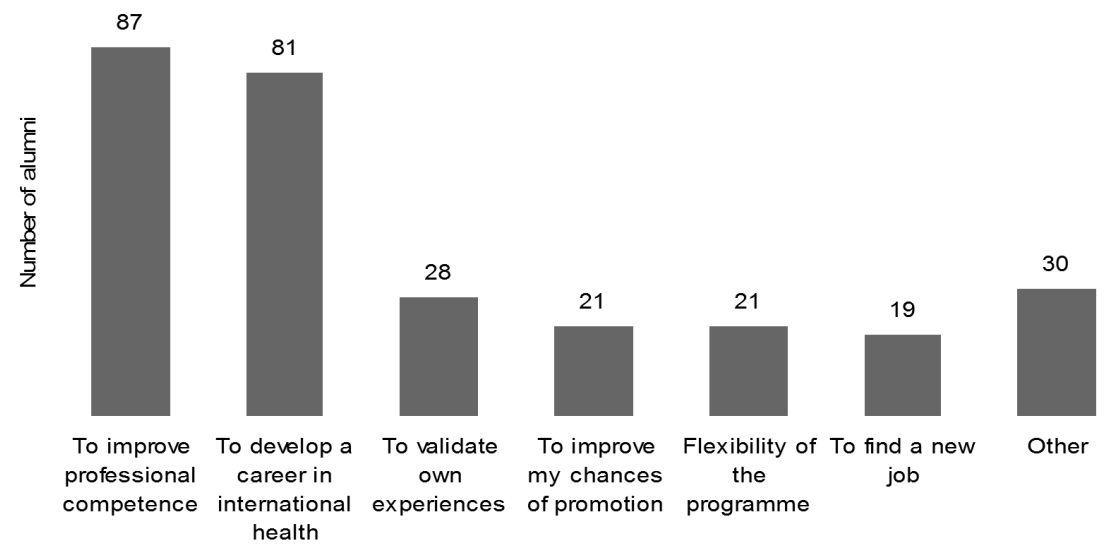

Figure 2: Three main reasons for pursuing a tropEd $\mathrm{MIH}$ ( $n=99$; non-exclusive)

Most respondents (77\%) changed jobs after graduation, and $46 \%$ are currently working outside their country of origin. More alumni from Africa (66\%) and Asia (63\%) work in their country of origin, than alumni from other continents (43\%). Before taking the tropEd Masters respondents mostly worked at the national or provincial level (27 each), whereas after graduation 49 were working at the international level (Figure 3).

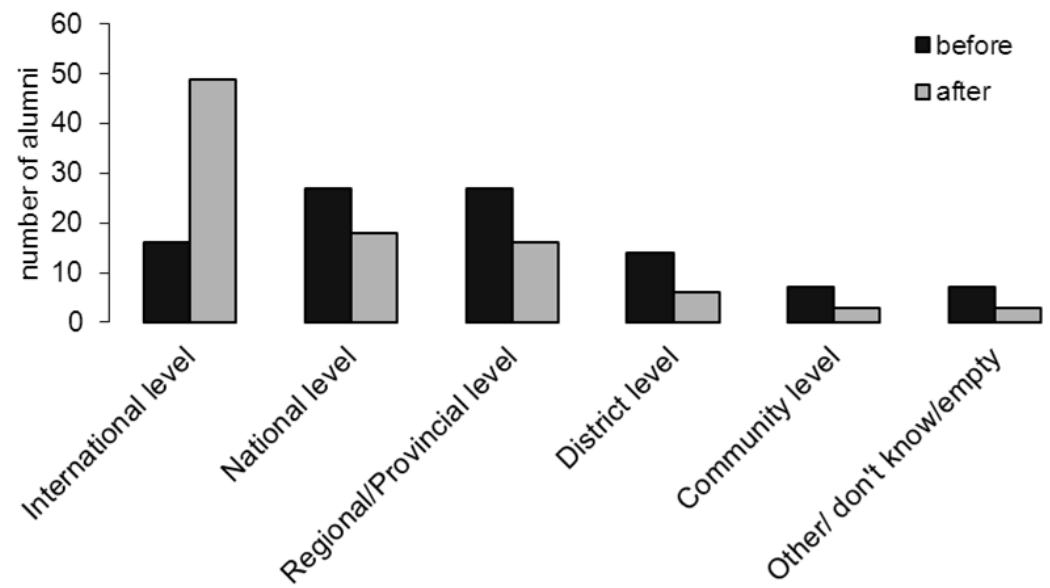

Figure 3: Level of employment of alumni before and after the tropEd MIH ( $n=99)$ 
Most MIH alumni indicated that they worked in clinical care and general public healthcare before graduating, while after graduation they mostly worked in programme management, monitoring and evaluation, and education and research (Figure 4).

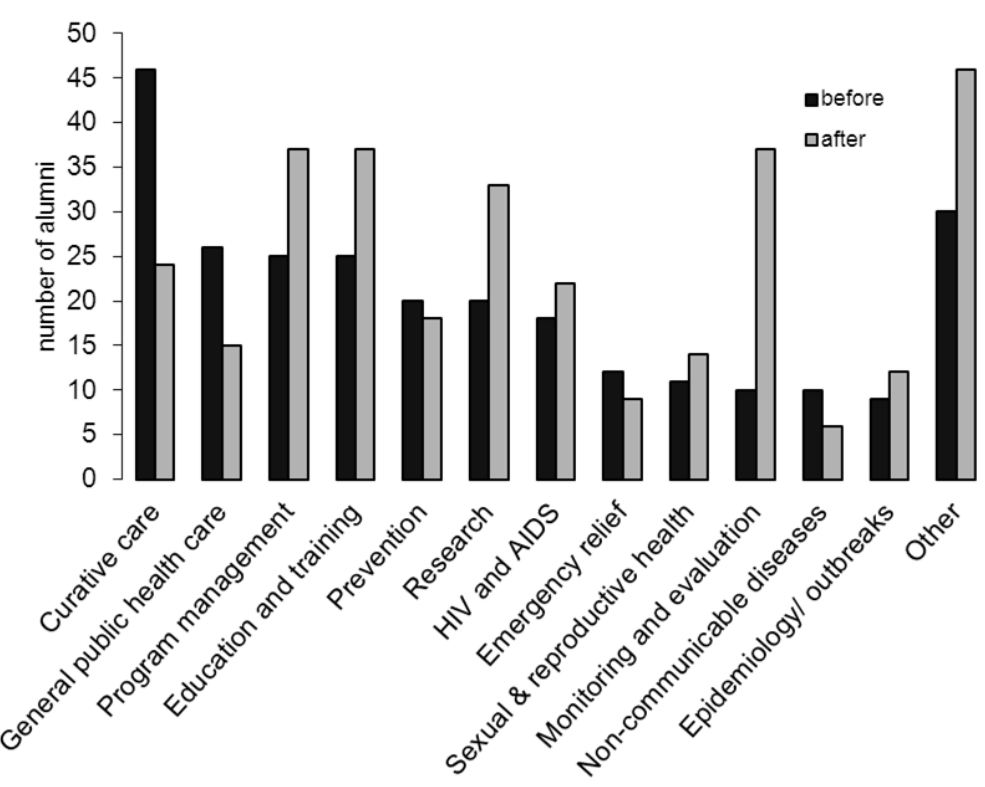

Figure 4: Alumni's reported three main areas of work before and after the tropEd MIH ( $n=99$; non-exclusive)

Most alumni reported that their functions and tasks after graduation represented an increase in responsibilities, management, co-ordination, and research and training, and a decline in clinical work (Figure 5). Salaries increased for $57 \%$, and decreased for $9 \%$.

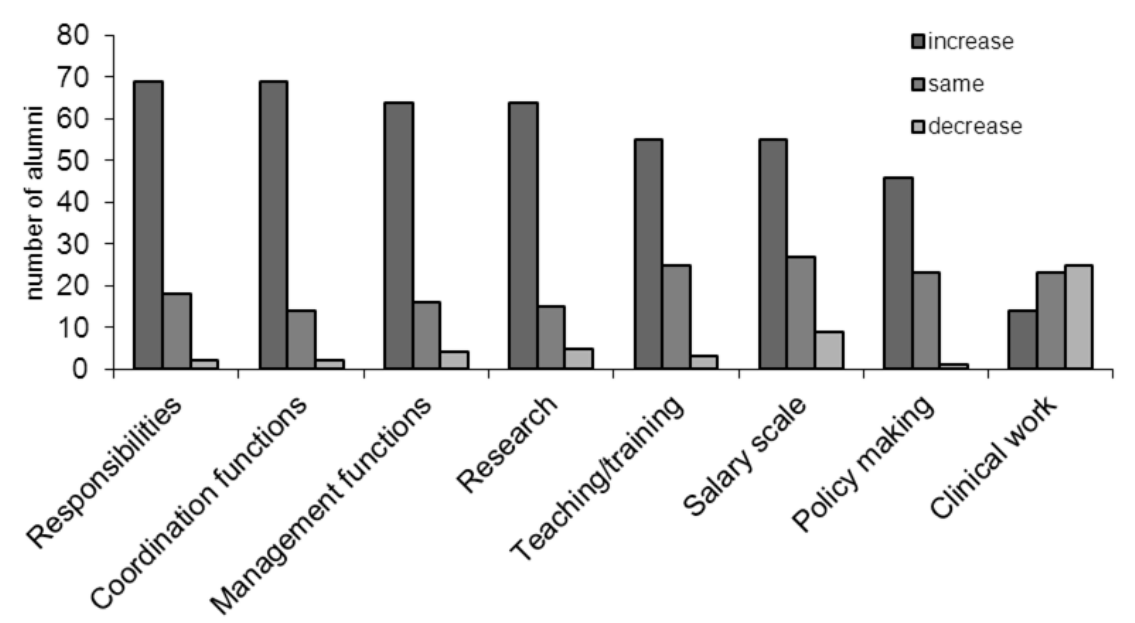

Figure 5: Alumni's reported change in functions/roles after completing the tropEd MIH ( $n=99)$ 
Alumni still felt confident in all areas covered by the $\mathrm{MIH}$. Alumni are least confident in identifying the influence of globalization on population health and in formulating responses to complex international issues (Figure 6), and indicate that these competencies are the least relevant for their current work situation. Most competencies are perceived as essential or very relevant for their current position (Figure 7).

Nearly half of the alumni have published or are in the process of publishing. After completing their $\mathrm{MIH} 30 \%$ of alumni pursued further studies, with $25 \%$ of alumni either preparing for, currently studying, or having completed a PhD.

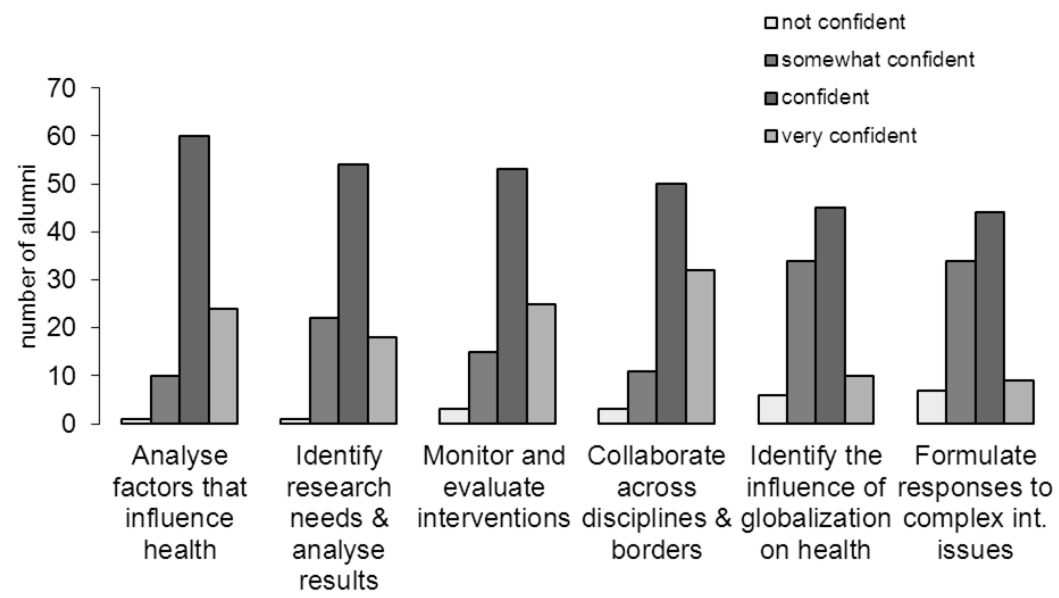

Figure 6: Alumni's reported confidence in MIH competencies $(n=99)$

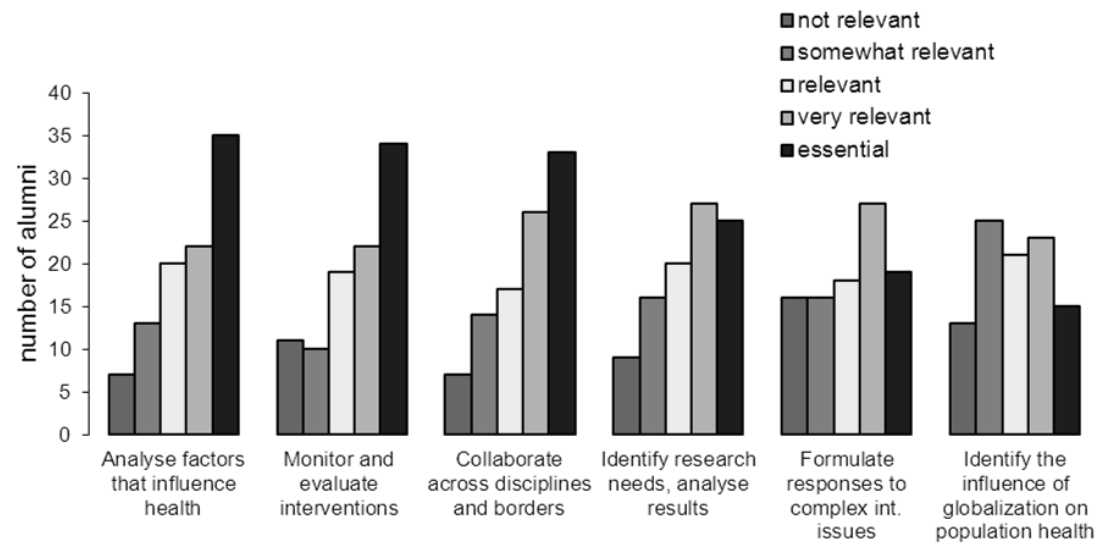

Figure 7: Alumni's reported relevance of competencies for current work ( $n=99)$

The bivariate analyses showed no significant associations except for gender and mobility. Mobility-related issues were mentioned as one of the top three strengths of the programme by 34 alumni (17 male and 17 female). One male and eight female alumni 
mentioned mobility as one of the top three weaknesses of the programme (risk ratio 8.1; 95\% confidence Interval (1.1-62.8).

\section{Strengths and weaknesses of the tropEd Masters in International Health}

The flexibility in timing and the offer of a broad range of optional modules were revealed to be major strengths, followed by the diversity of participants, the opportunities for networking and sharing of experiences. The mobility options allowed alumni to experience different approaches to international health and to benefit from the expertise of different institutions. The chance to live and study in different cultures and the general international nature of the course were both valued. Alumni appreciated the mix of theory and practice. Lectures were mostly perceived as being of high quality, and lecturers were considered to have relevant field experience. Interactive teaching, group assignments, and interdisciplinary approaches were seen as the greatest strengths of the teaching methods.

The costs of the MIH programme including the course fees, subsistence, and travel costs were perceived as high. Fees differ considerably between modules, so some students chose not the most suitable modules, but the most affordable ones. Travel may involve culture shock and the hassle of finding accommodation, arranging a visa, etc. The mobility aspect, compulsory for tropEd recognition but not required in all home institutions for the $\mathrm{MIH}$, makes it harder to build sustainable professional and social relationships.

Administrative procedures differ between institutions, which can be confusing. Registration and the issuing of grade reports, transcripts and diplomas can take a long time. The MIH programme is flexible, and students are required to propose a study plan for their advanced modules and a thesis subject to the MIH coordinator in their home institution. Alumni felt that it was not easy to create such a study programme because of the large number of modules to choose from, currently over 150, and felt more guidance is needed. The lack of one consistent grading system in all institutions was reported as another weakness. ECTS grades are used officially everywhere, but not always as relative grades, as they are intended, and students still feel there are major differences between the ways assignments are marked in different institutions. The tropEd website was criticized for making it difficult to search for advanced modules, for example, of a certain topic. Alumni suggested that the tropEd network increases its public relation efforts, since they feel the MIH is still not as well recognized as a Masters in Public Health (MPH). 


\section{Discussion}

\section{Limitations}

Respondents cannot be regarded as representative of all past MIH students who finished their degree at one of the TropEd institutions, as only those who gained tropEd recognition are included. Respondents therefore have used more mobility than the average MIH student. Students from Basel, Berlin and Amsterdam may have different experiences in the network than students from other home institutions, as the core course, thesis process and type and level of guidance may differ. Many part-time students who started after 2005 were not included in the survey as they might not have finished their Masters more than two years before the survey. The tropEd MIH Programme has evolved during the past 15 years, but the survey results will reflect the situation as it was several years ago, and recent changes will not be reflected in the results.

Respondents were only asked about their current confidence in competencies, so this study does not allow comparing this to their level of competencies prior to their study. Current confidence depends not only on confidence at graduation but also on the use of competencies since graduation.

Although students were not asked about specific personal identifiers, and results were analysed anonymously, in some instances the country of origin would have made it possible to identify the student. Therefore students may have given socially desirable answers, especially to questions about the programme's strengths and weaknesses, to keep good relationships with the network. As most questions did not ask for sensitive information, we feel that most results will not be affected by this potential bias. As for the gender difference regarding mobility, this result has to be interpreted with caution. The answer was coded 'no' if mobility was not mentioned as a top three weakness, but mobility may have been considered a weakness by others as well, even if not ranked within the top three positions. Confounding may explain the association between gender and mobility to some extent.

\section{Discussion and conclusions}

Alumni of the tropEd MIH changed jobs, have increased responsibilities, moved into more international settings, and work more often in programme management, monitoring and evaluation, education and training, and research than before embarking on their Masters training. Although this suggests that the MIH programme is highly beneficial to its alumni, this study does not allow us to attribute with certainty these changes to the MIH programme alone. Changes in careers might have happened regardless of the MIH just by gaining seniority. The observed career changes may not be specific to the tropEd MIH, as any MPH programme might have had the same effect. However, the 
reported relevance of the competencies gained through the MIH for the alumni's current work suggests that the tropEd MIH has contributed to the career changes. Moving away from curative care to public health is not considered a natural development in the career of health workers and might be the result of the Masters Programme. This is in line with a study of graduates of the MIH core course at the Swiss Tropical and Public Health Institute in Basel and the MPH for Developing Countries at the London School of Hygiene and Tropical Medicine (both carried out in 1998/1999) which show that more than half of the graduates advanced or changed their career after the course, often from a curative to a public health context (Peterhans 1999). Another study of MPH graduates in Vietnam showed that many students reported being promoted after completing their Masters Programme (Le et al. 2007).

Alumni indicated that mobility in the network has important advantages and disadvantages: enrichment of the learning process on the one hand, and financial and logistical challenges on the other. Visa issues remain a challenge, especially for citizens of countries outside the Schengen area. A tropEd course handbook with the administrative and logistical details of each institution is now available and is supposed to help students in organizational matters. The programme's flexibility has its pros and cons as well: it allows students to design their programme based on their background and future job aspirations, but they can easily get lost in the large number of modules on offer and the huge number of possible combinations, some of which are not allowed by the home institution. In Vietnam, lack of flexibility of the curriculum was seen as one of the weaknesses of the Masters of Public Health programme (Le et al. 2007). In order to profit from the tropEd programme's flexibility students should have sufficient opportunity to discuss their options and choices with their student advisor in their home institution. In 2012 key words were added to the modules on the website, which will facilitate searching for modules by content. Based on the exit interviews conducted with graduates, we believe that in the past five years the tutoring system at the home institutions has improved, and is now better equipped to help the students to select their advanced modules.

An important strength of the tropEd MIH according to the alumni is the interdisciplinary approach and diversity of participants. A study of an MPH programme in Alabama showed that the lack of an interdisciplinary approach was seen as a major weakness of the programme, limiting the ability of alumni to use the information and skills in professional practice (Petersen et al. 2005). We believe that the tropEd consortium is an excellent framework for receiving an interdisciplinary training, as the core course teaching draws on a range of experts from various disciplines and institutions, and the students themselves can select their advanced modules in a way that exposes them to the methods, contents and paradigms of a range of disciplines. Alumni did not mention problems related to the recognition of credits obtained in tropEd institutions other than their home institution, in contrast to other Master's students who take modules in different countries in Europe (Schüle 2006). In the past few years the tropEd network 
has worked hard to improve procedures regarding course registration and issuing grade reports and diplomas. The network's extensive quality-control and accreditation procedures (Zwanikken PAC, personal communication) seem to be effective in ensuring trust that ECTS credits obtained elsewhere represent relevant content and quality teaching. Even though many alumni were international students, they did not report problems regarding language, unlike international alumni in other English taught MPH programmes in the UK (Plugge \& Cole 2011).

Although credits and grades are transferred using the ECTS system, alumni criticized the lack of a common grading system in the member institutions. In Europe, the different educational systems have developed different approaches to grading, often deeply rooted in their pedagogical and cultural traditions (European Commission 2009). Often misinterpreted, the ECTS system does not harmonize the way students' performance is evaluated, but makes their performance transferable between different institutions. ECTS grades, correctly used, are not absolute but relative grades, which express the performance of students in comparison to the performance of other students for the same topic or module over a period of time. In many European countries such relative 'grading' has no history and is therefore often in contrast to the performance measures in use. This is a shortcoming not only of the tropEd MIH programme, but of all programmes following the principles of the Bologna process.

\section{Recommendations}

As the competencies acquired through the tropEd $\mathrm{MIH}$ seem relevant to current careers, they need not be changed based on this survey. The fact that many students are employed in programme management, monitoring and evaluation, education and training, and research should encourage the network to trust that the study programme addresses these fields sufficiently. It is recommended that employers and other major stakeholders be surveyed to discover whether their views concur with the alumni.

The future challenge for the network will be to address the disadvantages of mobility and flexibility. TropEd home institutions should enhance guidance for students to develop and follow their individual study programme. Establishing and strengthening alumni networks may be a new way to offer support to current students. 


\section{References}

Davis MV, Dandoy S \& Greaves WW (2003) Graduate programs: What is their contribution to the training of the public health workforce? American Journal of Preventive Medicine 24, 361-366.

tropEd. http://www.troped.org, not dated, accessed on 21 February, 2012.

European Commission (2009) ECTS User's Guide. Office for Official Publications of the European Communities, Luxembourg .

Le LC, Bui Q, Nguyen HT \& Rotem A (2007) Alumni survey of masters of public health (MPH) training at the Hanoi School of Public Health. Human Resources for Health 5,24.

Peterhans B (1999) Training public health professionals for developing countries: The challenge for today, Evaluation of the postgraduate training among graduates from PHDC and HCMTC at the London School of Hygiene and Tropical Medicine and the Swiss Tropical Institute between 1992 and 1998. Masters Thesis, London School of Hygiene and Tropical Medicine

Petersen DJ, Hovinga, ME, Pass MA, Kohler C, Oestenstad RK \& Katholi C (2005) Assuring public health professionals are prepared for the future: The UAB public health integrated core curriculum, Public Health Reports 120, 496-503.

Plugge E \& Cole D (2011) Oxford graduates' perceptions of a global health master's degree: a case study. Human Resources for Health 9,26.

Schüle U (2006) Joint and Double Degrees within the European Higher Education Area: Towards Further Internationalisation of Business Degrees. CIDD Papers on International Business Education No.1, Consortium of International Double Degrees, Paris. Available from: www.cidd.org/pdf/pub_papers_01.pdf 


\section{CHAPTER 4}

\section{Quality assurance in transnational higher education: a case study of the tropEd network}

Published as:

Zwanikken PAC, Peterhans B, Dardis L, Scherpbier A: Quality Assurance in Transnational Higher Education: a case study of the tropEd network. Medical Education 2013, 13:43 doi:10.1186/1472-6920-13-43 


\section{Abstract}

Introduction: Transnational or cross-border higher education has rapidly expanded since the 1980s. Together with that expansion issues on quality assurance came to the forefront. This article aims to identify key issues regarding quality assurance of transnational higher education and discusses the quality assurance of the tropEd Network for International Health in Higher Education in relation to these key issues.

Methods: Literature review and review of documents

Results: From the literature the following key issues regarding transnational quality assurance were identified and explored: comparability of quality assurance frameworks, true collaboration versus erosion of national education sovereignty, accreditation agencies and transparency. The tropEd network developed a transnational quality assurance framework for the network. The network accredits modules through a rigorous process which has been accepted by major stakeholders. This process was a participatory learning process and at the same time the process worked positive for the relations between the institutions.

Discussion: The development of the quality assurance framework and the process provides a potential example for others. 


\section{Introduction}

Transnational or cross-border higher education has rapidly expanded since the eighties (1). Since the mid nineties higher education (HE) has fallen under the framework of the World Trade Organisation (WTO) and General Agreement on Trade in Services (GATS) (2). In this context, transnational education has become a commodity, increasing the international trade of educational services (3). This expansion was mainly economically inspired, aiming to boost revenue, but was also driven by aims relating to capacity building, developing human resources, identifying talented students to work in the host country, and increasing international understanding (2-6). Due to the rapid rise in transnational education by profit and non-profit providers, as well as the commodification of $\mathrm{HE}(7,8)$ issues regarding quality assurance came to the forefront $(1,2)$. In Europe the Bologna process spurred interest in quality assurance as well as the transfer of credits $(9,10)$. With the development of double and joint degrees, reluctance in recognizing education followed at other universities had to be overcome (11), while other quality assurance issues remained $(12,13)$. UNESCO (United Nations Educational and Scientific Organisation) developed guidelines regarding the quality of cross-border education. However, these guidelines are voluntary (14). The World Federation for Medical Education (WFME) formulated guidelines for accreditation of postgraduate medical education as well as global standards for quality improvement of medical education (15). However, many issues regarding transnational HE remain unresolved, particularly regarding quality assurance.

\section{Definitions}

According to UNESCO 2005 the definition of cross-border HE is: "includes higher education where teacher, student, program, institutions/ provider or course materials cross national jurisdictional borders". Cross-border higher education and transnational higher education are often used interchangeably (2). Therefore both terms will be used interchangeably in the article.

The definition of quality assurance in HE has evolved in the last ten years. Woodhouse (16) referred to quality assurance as relating "to the policies, attitudes, actions and procedures necessary to ensure that quality is being maintained and enhanced". According to Harvey (17) after much discussion and input: "Assurance of quality in higher education is a process of establishing stakeholder confidence that provision (input, process and outcomes) fulfils expectations or measures up to threshold minimum requirements". According to UNESCO (2005) the following stakeholders in higher education can be distinguished: governments; higher education institutions/providers including academic staff; student bodies; quality assurance and accreditation bodies; academic recognition and professional bodies (14). 
Schüle (2006) defines a double and joint degree as follows, using as a basis the definition provided by the European Commission (latest update 2009): a "double degree: two nationally-recognised diplomas issued separately by the universities involved in the integrated study programme", and a "Joint degree: a single diploma issued by two or more institutions offering an integrated study programme. The single diploma (Bachelor, Master, Doctor) is signed by the rectors of all participating universities and recognised as substitute of the national diplomas" $(11,18)$.

\section{Background of the tropEd Network}

The initiative to create a higher education network in international health came from the directors of public/tropical health institutions who collaborated in Tropmedeurop, an association centred on tropical medicine education in Europe, in 1994. A new formalized network focused on education was established in 1996, initially with 13 institutions in Europe, named TropEdEurop. Now renamed, tropEd, the network includes more than 30 institutions of higher education in international and global health in Europe, Africa, Asia, Australia and Latin America. The tropEd network includes almost all institutions in Western Europe offering a $\mathrm{MIH}$ and a range of institutions outside Europe offering modules, the word largest network for a Master in International Health (www.troped.org). The tropEd General Assembly (GA) of the network meets three times a year. Full members in the network are institutions of higher education recognized by a national authority. The voting members are 1 representative of each institution who is a full member; voting results are by majority.

The network has developed a robust common framework for a Masters in International Health (MIH), see Figure 1. However, the network does not deliver the degree directly; rather, the member institutions do. The framework defines common minimum academic and quality assurance structures, content and criteria to which the nationally accredited degree must adhere in order to be recognized as a 'tropEd $\mathrm{MIH}^{\prime}$. This recognition is framed around a Masters level program of 60 European Credits (EC) of the European Credit Transfer system (ECTS). An institution is categorized as the "home institution', if a student can enter the Masters program there and complete a 'core course' of 3 months, equivalent to 20 EC. In 2011, 8 institutions classified as home institutions. The home institution also provides tutorial support to the student throughout the program and awards the final Masters degree. TropEd students are expected to acquire up to 10 ECTS through advanced modules at a tropEd institution outside the country of their home institution depending on institutional regulations. 


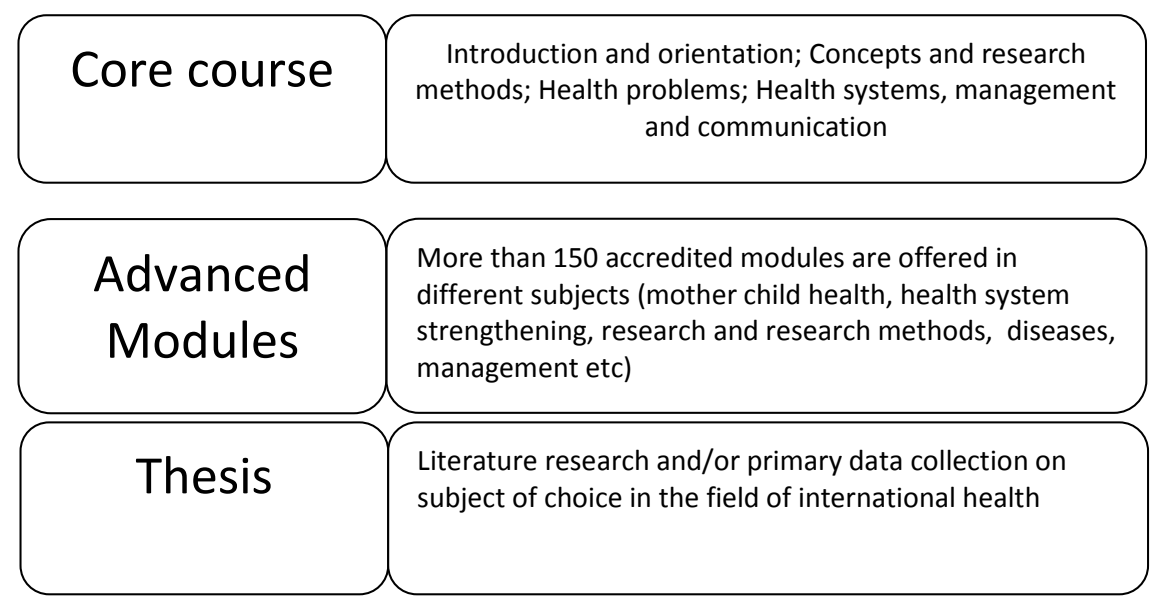

Figure 1: Schematic view of a tropEd master in international health program

In addition to the degree from their home institution, graduated Masters students receive tropEd recognition if they complied with the following criteria in addition to the mobility requirement: at least two years of relevant professional experience of which at least one year in low- and middle-income countries/societies, Master degree obtained from home institution and completion of the masters program within 5 years. In 2010, there were 479 students from different home institutions registered in the tropEd network.

Given the number of partners involved in the development and functioning of the educational network, the diversity of national structures, traditions and educational practices, there has been an consistent need for quality assurance to generate and maintain high quality standards of education.

This article aims to identify key issues regarding quality assurance of transnational higher education and discusses the quality assurance of the tropEd Network for International Health in Higher Education in relation to these key issues.

\section{Methods}

The methods used were literature review and review of documents of tropEd.

For the literature review the search terms were: higher education AND (international or transnational or cross-border) AND quality assurance or quality improvement or quality control or accreditation or quality standards or joint degrees or double degrees or "international accreditation". The databases searched were Pubmed, Google Scholar and Scopus. The Search period was 1990 - 2011, the search date: 13 July 2011, Keywords were searched in title/abstract/keywords; the language was limited to English. This led to 94 unique titles, of which 41 were considered relevant by the first three 
authors. Articles discussing distance higher education, quality assurance of professions, quality improvement, total quality management or focusing on one country only were excluded. The first author reviewed all 41 articles; the second and third author read each half of the articles (i.e. 20 and 21 articles). The articles were discussed until four major themes emerged as mentioned below.

The research team reviewed the following documents of tropEd: all GA meeting minutes, from 2005-2011, all minutes of the Quality Assurance Committee (from 20052011), all minutes of the troped Erasmus Mundus consortium (2005-2011), statutes, profile, strategic plan, work plan, annual plans, procedures and guidelines, for example: guidelines for core course and optional/ advanced modules, ethical guidelines, handbook for core course/ advanced module accreditation, professional profile, institutional self-evaluation form, and forms for tropEd recognition as well as thesis guidelines using a checklist and a topic list. The checklist centered on the accreditation of the advanced module and core courses ie numbers and year. The topic list included topics such as development process of criteria, institutional agenda, transparency, decision making.

\section{Findings}

\section{Issues regarding quality assurance in cross-border or transnational higher education}

Almost all relevant articles found in the literature search dealt with issues of quality assurance internationally relating to when a higher education institution ventured towards other countries either through branch campuses, franchising courses or working with partners to jointly deliver educational programs. In reported cases, most featured the USA, Great Britain or Australia (4,19-22). However, no description of the quality assurance process and results of a higher postgraduate education network was found.

Key themes regarding quality assurance of cross-border education which emerged from the literature review and the tropEd experience are explored below: true collaboration versus erosion of national education sovereignty, equivalence and comparability of quality assurance frameworks, accreditation agencies and transparency.

\section{True collaboration versus erosion of national education sovereignty}

\subsection{Literature}

In the literature Hodson argues that the then existing collaborative audit approaches in 'overseas' higher education lacked cultural sensitivity (4). Both Gift and Smith concur and argue from an exporting- importing model that a true collaboration between universities is often blurred by the quality demands of the exporting country or institution $(21,23)$. Smith, analysing the codes of practice of three major HE exporters (UK, USA and Australia), reveals that some codes leave little room for adaptation to 'cultural 
mores' (21). Some authors view these developments with caution, arguing that countries which are at the receiving end may have difficulties safeguarding the relevance of the education, their culture and their educational sovereignty $(3,23)$, with HE even becoming elitist (8). Stella discusses how cross-border HE often disadvantages developing countries as they are unable to participate effectively in the global trading system (2). Gu, however, also argued that continental European countries tend to act on regional integration and complement each other with their strengths (3).

\section{2. tropEd}

In the tropEd network the developed quality system was created through participatory learning for all members: from the beginning, the network decided not to have a separate curriculum committee, but rather to have every institution involved. The GA decided to aim for an open process, where the GA acted as the curriculum committee, so each member could read and comment on each core course and advanced module.

During the process of developing the quality assurance often a small group of interested representatives from different institutions worked together on different topics. This process was quite informal: during a discussion in the GA an issue needing elaboration would be identified, no terms of reference were made, and every interested GA member could join the discussion. The group would come together, sometimes during the GA meeting or sometimes in small-group meetings in between the GA meetings. Results of the discussions would be brought back and re-discussed in the GA. When necessary the small group would take the comments and suggestions from the GA and further revise before returning it to the GA for consensus. Through this process the network developed a number of documents and guidelines i.e. guidelines for core course and advanced modules, ethical guidelines, a strategic plan for the network, handbook and forms for tropEd recognition as well as thesis guidelines.

As in any multicultural and multi-country network with different interests, resistance to change or to proposed procedures sometimes emerged. Within the network this resistance was often addressed through informal discussions. Sometimes resistance emerged due to institutional agendas i.e. difference in course fee or difference in institutional procedures. These agendas were clarified, often during the GA and informal discussion, and then issues were reviewed, and possible accommodation or help/ support was offered to the members on how to deal with the resistance within the institution. To foster student mobility and with initial members being only European institutions, the network adopted the European Credit Transfer System (ECTS), given its explicit design to foster mobility within Europe. The institutions outside Europe who joined the network later kept their own credit system, while using the ECTS for tropEd students. 


\section{Equivalence and comparability of quality assurance frameworks}

\subsection{Literature}

According to literature from the nineties onwards, increasing international mobility, and therefore international comparability, became an important issue, especially in Europe and the USA $(21,24)$. Quality assurance was very often discussed from the viewpoint of 'provider' and 'receiver' institutions and countries: the degree of autonomy of either branches or local institutions granted by the 'home' institution to adhere to procedures of the 'home' institution or develop their own quality assurance processes (19$21,25)$. Stella states that national frameworks for quality assurance of cross-border education are not well developed (2), though Murray argues that for Australia a sophisticated framework for monitoring of cross-border higher education exists (26). Bolton argues that existing quality assurance frameworks often do not allow accommodation of manageable risks associated with innovation, flexibility and experimentation in new market places, discussing a partnership between Australia and China (27). Billing sees especially in Europe a 'general' model of quality assurance developing (28).

\section{2 tropEd}

In the tropEd network to admit a new institution the GA developed a standardized procedure, thereby checking its quality: the new institution has to subscribe to the definition of International Health by tropEd, complete a self evaluation and undergo an institutional site visit. The GA which meets three times a year, decides on official admission to the network through deliberation and voting. The GA developed a guideline for the self evaluation which includes details regarding i.e. academic background, faculty, services, research and resources and the site visit, which details i.e. discussion with students, staff, management and an ocular survey of the teaching and learning facilities. During the last five years (2007-2011) 18 institutions applied to become a member, 13 institutions were visited during a site visit, 10 of those institutions became a member of the network (tropEd GA meeting minutes 2007-2011). One became a member in 2012 , other institutions' membership is still pending or they declined.

To develop the Masters program at the start of the network in 1996 the GA defined standards for the core course, advanced modules and thesis. In 2004 the GA developed a professional profile of the graduate $\mathrm{MIH}$, including professional competencies and overall learning objectives. For the core course and the advanced modules the GA developed quality criteria. Later the criteria for the assessment of the core course and advanced modules became more refined, including title, learning objectives, content and alignment of assessment with learning objectives. Subsequently, further criteria were developed to support more in-depth learning, i.e. aligning learning methods with learning objectives and assessment. The curriculum content was checked for appropriateness to Masters level. 
The guidelines for the core course and the advanced modules were binding: if an institute submitted a core course or module which the GA did not accept, the core course or module would be rejected and the representative needed to go back to the institution to re-discuss the core course or module for resubmission. In the minutes of the GA the written explanation was provided as to why the core course or advanced module was rejected. The GA needs to review and accredit the core course and advanced modules every five years. According to tropEd regulations the Executive Committee approves the core course or advanced modules with minor changes upon resubmission. The GA needs to approve major changes.

From 2007-2011 the GA reviewed 8 core courses of the 8 home institutions; 2 were accepted at once, 4 had to be resubmitted with minor changes and 2 to be resubmitted with major changes, see Table 1.

From 2007-2011 the GA reviewed 269 advanced modules, of which 71 were accepted at once. Out of the 195 rejected advanced modules, 84 modules had to be resubmitted with minor changes. The other 111 modules required major changes. Three were rejected, meaning that they were not suitable for the $\mathrm{MIH}$, see Table 1 . The accreditation process was quite rigorous, as the GA accepted only $25 \%$ of the core courses and only $27 \%$ of the advanced modules at once, see Table 1.

Table 1: Nr of courses reviewed and outcome in the tropEd network from 2007-2011

\begin{tabular}{llllll}
\hline $\begin{array}{l}\text { Nr of advanced modules } \\
\text { per year/ outcome }\end{array}$ & Total reviewed & $\begin{array}{l}\text { Accepted at } \\
\text { once }\end{array}$ & $\begin{array}{l}\text { Resubmission with } \\
\text { minor changes }\end{array}$ & $\begin{array}{l}\text { Resubmission with Rejected } \\
\text { major changes }\end{array}$ \\
\hline 2007 & 46 & 11 & 10 & 25 & - \\
2008 & 67 & 24 & 19 & 24 & - \\
2009 & 48 & 17 & 15 & 15 & 1 \\
2010 & 59 & 11 & 19 & 27 & 2 \\
2011 & 49 & 8 & 21 & 20 & - \\
Total advanced modules & 269 & $71(27 \%)$ & $84(31 \%)$ & $111(41 \%)$ & $3(1 \%)$ \\
\hline
\end{tabular}

Source: minutes of the tropEd General Assembly meeting from: 2007-2011.

For the thesis, as guidelines per institution differed, the GA developed generic thesis requirements, including ethical guidelines, which could be adapted by each institution.

In 20048 tropEd member institutions established a consortium to offer 5 fulltime MIH study tracks MIH financially supported through the Erasmus Mundus program by the European Commission. Initially 1 track, and later 3 tracks offered joint degree awards while institutions of the other tracks offered double degree awards. The institutions worked closely together to align the study programs, to secure proper hand-over of students from one institution to the next institution and to fulfill all the administrative requirements to offer the double or joint degrees. Discussions and decisions regarding the Erasmus Mundus program were always reported in the GA. Because of the double and joint degree programs the participating institutions developed joint selec- 
tion criteria for the scholarships. Except for the administrative issues the double and joint degree programs did not have implications for the quality assurance of the network as a whole. Because the network had an elaborate quality assurance system the tropEd Erasmus Mundus consortium was easily formed with the 8 institutions that choose to join.

\section{Accreditation agencies}

\subsection{Literature}

The literature poses a range of challenges regarding recognition of higher education institutions and courses across borders. The rapid increase of $\mathrm{HE}$ institutions which are not accredited in their home country, nor in the country in which they offer their crossborder education, leads to questions regarding the capability and credibility of national and international accreditation agencies (1).

Concerns about the quality, consistency and relevance of accreditation are reflected internationally. Gu argues that in China there is insufficient knowledge and experience in quality assurance of transnational education, as most existing systems of quality assurance and accreditation focus on the local higher education system (3). The case of Malaysia, an export hub of $\mathrm{HE}$, demonstrates the challenge of getting national accreditation accepted internationally (29). A case study of Kenya revealed that one foreign provider was locally accredited, yet other cross-border providers or education offered were not accredited through their home country nor geared towards the needs of the country (30). Knight (31) warns of accreditation mills in the context of cross-border education. In Taiwan the discussion centers on the quality and national accreditation of international accreditation agencies, plus the additional administrative burden (22). With the emerging trend of institutions seeking accreditation internationally, increasing administrative burdens as well as possibly conflicts may arise due to the different requirements by the different agencies, thereby decreasing efficiency $(22,24,32)$.

A range of regional and global responses and frameworks have attempted to address such challenges. In the Caribbean, the withdrawal of the British accreditation and a rapid increase of foreign providers of $\mathrm{HE}$, led to the Caribbean Community and Common Market (CARICOM) establishing a regional mechanism for accreditation, to guide governments in developing national mechanisms (23). In Latin America, six countries joined forces in MERCOSUR to recognize each other's accreditation for certain degrees, provided auditors from other countries had collaborated in the accreditation (33). Haug (2003) suggests a meta-accreditation mechanism for Europe i.e. an accreditation of the accreditation agencies, thereby reducing costs, which nationally can be quite high (34). In Europe, with the establishment of the European Network of Quality Assurance Agencies (ENQA) as part of the Bologna process and the increasing tendency of national accreditation agencies to recognize each others accreditation, there seems to be some progress on a number of issues. Stella urges increasing cooperation among quality as- 
surance agencies in furthering the UNESCO guidelines on quality assurance of crossborder education (2). Van Damme advocates a global regulatory framework (35). The WFME developed accreditation standards for postgraduate medical education to stimulate local development of standards and to facilitate the acceptance of doctors in countries other than where they were trained (36).

\section{2. tropEd}

tropEd has developed an internal framework to act as its own 'accrediting' agent due to the lack of accreditation bodies for transnational higher education at international or global level. Universities, in countries where they hold degree-awarding powers, as well as national accreditation bodies, have accepted the tropEd accreditation of programmes as well as advanced modules followed by students in member institutions in other countries. The acceptance of tropEd accreditation by these national accreditation bodies can be seen as a benchmark for tropEd.

\section{Transparency}

\subsection{Literature}

In the literature Machado argues that the rapid increase of new providers demands greater clarification and transparency regarding the normative basis of transnational education (1). National governments should regulate i.e. protect educational titles, and the public should be informed. Machado sees a critical role for the ENQA in Europe, Knight discusses the role of UNESCO and the regional conventions $(1,31)$. Shanley argues for the use of a website in increasing transparency in a network of undergraduate education across Europe (37). Additionally, Bolton in her article on a Chinese-Australian collaborative educational alliance argues that transparency towards stakeholders is important to create value of the degree (27).

\section{2. tropEd}

Within the tropEd network transparency was enhanced by involving and learning from the students. By keeping in close contact with the students through involving an elected tropEd student representative in the GA meetings, the network has been able to respond to feedback on issues of importance to students. This openness meant that issues were voiced and could be taken up at a very early stage, so that the network or member institution would be able to implement improvements. Quality criteria have been revised and refined in an open process involving the full GA in decision making.

When the core course or advanced modules are submitted for reaccreditation, institutions have to give a summary of the evaluations by students over recent years, this is also published on the internet. On the internet students can find when a course or module was accredited and until when the accreditation is valid. 
In the tropEd network the degree is issued in a specific country, meaning that each institution needs to ensure that the course followed outside the country and within the network is recognized. Up to now that has never been an issue, possibly due to the fact that individual institutions can show the rigorous quality assurance process applied by tropEd in accrediting the core course and advanced modules. Furthermore, currently there are no specific professional bodies accrediting degrees for $\mathrm{MIH}$, perhaps owing to the multi-professional and multidisciplinary nature of International Health as well as the globalised context in which these graduates work.

\section{Discussion}

Linking the specific experience of the tropEd network with the broader issues in the literature, a deeper understanding emerges on the key themes:

- True collaboration versus national education sovereignty Member institutions have been able to collaborate in improving their quality through peer review as well as learning from each other in International Health. The network functions well although not always the same institutional representatives can attend meetings and despite the fact that members are to some extent competitors for the same potential students. Some members are only able to offer the Masters degree by including advanced modules from other institutions so there is a utilitarian aspect to some extent for these institutions. Other members can offer the entire degree on their own but want to be part of a bigger network due to the benefits for students, the organizational learning, as well as raising the profile of international health as an academic and professional field. Some members have been able to develop new advanced modules based on the learning within the network or developed modules together. Individual institutions felt that they benefitted being a member of the network; benefits cited are: the harmonization of contents, information for tutoring of students, validation of own standards and procedures, sharing global developments in international health for the content of courses, the development of new learning approaches, of quality improvement of own modules, of common understanding of quality standards in teaching and learning. Challenges mentioned are the frequency of the meetings, the timing of the meetings, complying with all the requirements for module accreditation and reaccreditation as well as agreeing within institutions to allow students to take modules at other institutions. As Gu argues that European countries complement each other (3), tropEd started as a European network of institutions complementing each other to offer a MIH. Institutions outside Europe who joined later, have been able to adhere to the quality assurance standards and contributing actively to the improvement. 
- Equivalence and comparability of quality assurance frameworks

The tropEd network started with European institutions first, and was aided by the Bologna process, which provided a structure for harmonizing practice across Europe. In more recent years membership from outside of Europe has extended and deepened the reach of its shared quality assurance. As Billing saw a 'general' model of quality assurance developing in Europe, tropEd becoming increasingly global, is developing towards a global quality assurance model (28).

- Accreditation agencies

Because no accreditation agency for a worldwide transnational higher education network exists, tropEd 'accredits' its own core course and advanced modules. The acceptance by national accreditation agencies of the accreditation of tropEd of modules taken outside the country by students implies that they find the quality assurance framework of tropEd credible. However the additional burden of further quality assurance measures alongside national and institutional quality assurance requirements has been mentioned (22) and the costs of running the network remain a challenge. The recognition of the network outside the network itself, for example by the EU through the Erasmus Mundus scholarships $(2004,2009)$ indicates EC approval of the tropEd framework and quality assurance standards. The tropEd network was also mentioned as an example of best practice by Ecotec Research and Consulting Ltd, commissioned by the European Commission, Directorate General for Education and Culture when studying quality assurance across Erasmus Mundus consortia (38). The question is whether tropEd would like to remain its own accreditation agency or that the ENQA or UNESCO could play a role.

- Transparency

The tropEd network has worked hard on improving its transparency towards potential students. Stakeholder engagement with regards to i.e. employers is under development. Professional bodies for MIH graduates do not exist yet. Whether achieving tropEd recognition by graduates improved the outcome has been subject of another study (39). Because of the quality assurance procedures, institutions have recognized each others' core course and advanced modules followed by the students, unlike experiences within the Erasmus program in Europe, where universities had difficulties recognizing each other's credits (11).

\section{Limitations}

For the study review of literature and review of documents were used. Observation and key informant interviews could have been conducted, however this was compensated by the fact that three of the authors were longstanding representatives of their respective institutions in the network with an in-depth knowledge of the development of the quality assurance and have participated either one, often two or three in all the GA meetings of the network. Though being a representative of their respective institution 
might constitute a bias, in-depth discussions amongst the research team during the writing of this paper deepened the understanding of the process of development.

Areas for further research could include the role of the student representative, the governance of the network, to define and study outcome and impact indicators, the impact of the tropEd quality assurance process on the actual improvement of quality of the education provided as well as student/ graduate performance or workplace/ employment success.

\section{Conclusion}

The quality assurance process in the tropEd network was and still is a participatory learning process and requires time. Quality assurance within the network has been formalized but in such a way that it is fully integrated in the functioning and learning of the network. Members of the network feel ownership of the QA standards, documents and processes and have the ability to change them and develop them. However, this process requires respect, trust and sharing tasks among the different partners. Given that in transnational HE no quality assurance frameworks or accreditation exist, tropEd has constructed an evolved and shared quality assurance structure, the validity of which has been accepted by national and international agencies and could be an example for others. 


\section{References}

1. Machado Dos Santos S: Regulation and quality assurance in transnational education. Tertiary Education and Management 2002, 8(2):97-112.

2. Stella A: Quality assurance of cross-border higher education. Quality in Higher Education 2006, 12(3):257-276.

3. Gu J: Transnational education: Current developments and policy implications. Frontiers of Ed China 2009, 4(4):624-649.

4. Hodson PJ, Thomas HG: Higher education as an international commodity: Ensuring quality in partnerships. Assessment and Evaluation in Higher Education 2001, 26(2):101-112.

5. OECD Secretariat: Cross-border education: an overview. 2003 OECD/Norway Forum on trade in educational services, OECD; 2003.

6. Santiago AL: Cross-Border Transactions in Higher Education: Philippine Competitiveness 2005 DISCUSSION PAPER SERIES NO. 2005-27 Makati City, Philippine Institute for Development Studies; 2005.

7. Baker RL: Evaluating quality and effectiveness: Regional accreditation principles and practices. Journal of Academic Librarianship 2002, 28(1-2):3-7.

8. Meek VL, Teichler U, Kearney ML: Higher Education, Research and Innovation: Changing Dynamics 2009. Report on the UNESCO Forum on Higher Education, Research and Knowledge 2001-2009. http://graduateinstitute.ch/webdav/site/developpement/shared/developpement/cours/E759/Research \%20and\%20Edu\%20changing\%20dynamics,\%202009.pdf.

9. Christensen L: The bologna process and medical education. Medical Teacher 2004, 26(7):625-629.

10. Saarinen T: Whose quality? Social actors in the interface of transnational and national higher education policy. Discourse 2008, 29(2):179-193.

11. Schüle U: Joint and Double Degrees within the European Higher Education Area Towards Further Internationalisation of Business Degrees 2006. Paris: Consortium of international double degrees; 2006.

12. Manig W: Conditions and development of joint degree programs in international educational cooperation. Journal of Agriculture and Rural Development in the Tropics and Subtropics, Supplement 2005, 82:49-53.

13. Knight J: Doubts and dilemma's with double degree programs. In: Globalisation and internationalisation of higher education Online monograph Revista de Universidad y Sociedad del Conocimiento (RUSC) 2011, 8(2):297-312. http://rusc.uoc.edu/ojs/index.php/rusc/article/view/v8n2-knight/v8n2-knight-eng

14. UNESCO-SCO: Guidelines for quality provision of cross-border education. Paris: United national Educational, Cultural and Scientific Organisation; 2005

15. Karle $\mathrm{H}$ : Global standards and accreditation in medical education: a view from the WFME. Academic Medicine 2006, 81(12 Suppl):S43-8.

16. Woodhouse D: Quality and quality assurance. In J. Knight \& Organisation for Economic Co-operation and Development. Secretary-General. Programme on Institutional Management in Higher Education (Eds.), quality and internationalisation in higher education. Edited by De Wit H. Paris: Organisation for Economic Co-operation and Development; 1999: 29-43.

17. Harvey L: Analytic Quality Glossary. Quality Research International. 2004. http://www.qualityresearchinternational.com/glossary/ Page updated 20 January, 2012 17:10.

18. European Commission, Education, Culture and Audiovisual Executive Agency: FAQ: Questions about the Erasmus Mundus Joint Programmes at master and doctoral level. http://eacea.ec.europa.eu/erasmus_mundus/programme/documents/2012/em_programmeguide_dec2012_en.pdf.

19. Chapman A: Teaching and learning in Australian university transnational education. Inter J Learning 2009, 16(1):315-321.

20. Edwards J, Crosling G, Edwards R: Outsourcing university degrees: Implications for quality control. $J$ Higher Ed Policy Manag 2010, 32(3):303-315.

21. Smith K: Assuring quality in transnational higher education: A matter of collaboration or control? Stud in High Educ 2010, 35(7):793-806. 
22. Hou Yung-Chi A: Quality assurance at a distance: international accreditation in Taiwan higher education. High Educ 2011, 61:179-191.

23. Gift S, Leo-Rhynie E, Moniquette J: Quality assurance of transnational education in the English-speaking Caribbean. Qual High Educ 2006, 12(2):125-133.

24. Woodhouse D: Quality assurance: International trends, preoccupations and features. Asses Eval in Higher Ed 1996, 21(4):347-356.

25. O'Rourke S, Al Bulushi HA: Managing quality from a distance: A case study of collaboration between Oman and New Zealand. Qual High Educ 2010, 16(3):197-210.

26. Murray D, Hall R, Leask B, Marginson S, Ziguras C: State of current research in international education. 2011. Background paper. http://www.Ihmartininstitute.edu.au/documents/publications/murraystatepaper.pdf.

27. Bolton $D$, Nie R: Creating value in transnational higher education: The role of stakeholder management. Acad Manag Learn Educ 2010, 9(4):701-714.

28. Billing $D$ : International comparisons and trends in external quality assurance of higher education: Commonality or diversity? High Educ 2004, 47(1):113-137.

29. Tham SY: Trade in Higher Education Services in Malaysia: Key Policy Challenges. Higher Educ Policy 2010, 23:99-122.

30. Kaberia F, Mutinda JM, Kobia MK: Regulation and quality assurance mechanisms for transnational (commercial) providers of higher education in Kenya. In New trends in higher education: Cross-border education: regulation, quality assurance and impact. Edited by Martin M. Argentina, Kenya, Russia 2007: International Institute for Educational Planning; 2007. http://unesdoc.unesco.org/images/0015/001578/157899e.pdf

31. Knight J: Cross-border higher education: quality assurance and accreditation issues and implications. In Globalisation and tertiary education in the Asia-pacific: The changing nature of a dynamic market. Edited by Tierney W, Findlay C Singapore, Hackensack NJ: World Scientific; 2010:73-92

32. Lim FCB: Do too many rights make a wrong? a qualitative study of the experiences of a sample of Malaysian and Singapore private higher education providers in transnational quality assurance. Qual High Educ 2010, 16(3):211-222.

33. Lemaitre MJ: Regional networks of quality assurance agencies: towards a common framework of standards and procedures for quality assurance. In Accreditation and the global higher education market. Edited by Hernes G, Martin M 2008. http://www.international.ac.uk/resources/Accreditation\%20and\%20the\%20global\%20higher\%20education\%20market.pdf\#page=267.

34. Haug G: Quality Assurance/Accreditation in the emerging European higher education: a possible scenario for the future. Eur J Educ 2003, 38(3):292-240.

35. van Damme D: Higher education in the age of globalization: the need for a new regulatory framework for recognition, quality assurance and accreditation. Paris: Introductory Paper for the UNESCO Expert Meeting, 2001:10-11

36. World Federation of Medical Education: Postgraduate Medical Education. WFME Global standards for Quality Improvement. Copenhagen WFME Office, University of Copenhagen, Denmark: World Federation of Medical Education; 2003.

37. Shanley DB, Dawling PA, Claffey N, Nattestad A: European convergence towards higher standards in dental education: the DentEd Thematic Network Project. Med Educ 2002, 36:186-192.

38. Ecotec: Handbook of quality: Support services related to the Quality of ERASMUS MUNDUS Master Courses and the preparation of quality guidelines. United Kingdom: Ecotec Research and Consulting Ltd, 2008. Unpublished.

39. Gerstel L, Zwanikken PAC, Hoffman A, Diederichs C, Borchert M, Peterhans B: $\mathbf{1 5}$ years of the tropEd Masters in International Health programme: What has it delivered? Results of an alumni survey of Masters students in International Health. Tropical Medicine and International Health 2013, doi:10.1111/tmi.12050 


\section{CHAPTER 5}

\section{Validation of public health competencies and impact variables for low- and middle-income countries}

Published as:

Zwanikken PA, Alexander L, Huong NT, Qian X, Valladares LM, Mohamed NA, Ying XH, Gonzalez-Robledo MC, Linh LC, Abuzaid Wadidi MSE, Tahir H, Neupane S, Scherpbier A: Validation of public health competencies and impact variables for low- and middleincome countries BMC Public Health 2014, 14:55 doi:10.1186/1471-2458-14-55 


\section{Abstract}

Background: The number of Master of Public Health (MPH) programmes in lowand middle-income countries (LMICs) is increasing, but questions have been raised regarding the relevance of their outcomes and impacts on context. Although processes for validating public health competencies have taken place in recent years in many high-income countries, validation in LMICs is needed. Furthermore, impact variables of $\mathrm{MPH}$ programmes in the workplace and in society have not been developed.

Method: A set of public health competencies and impact variables in the workplace and in society was designed using the competencies and learning objectives of six participating institutions offering MPH programmes in or for LMICs, and the set of competencies of the Council on Linkages Between Academia and Public Health Practice as a reference. The resulting competencies and impact variables differ from those of the Council on Linkages in scope and emphasis on social determinants of health, context specificity and intersectoral competencies. A modified Delphi method was used in this study to validate the public health competencies and impact variables; experts and MPH alumni from China, Vietnam, South Africa, Sudan, Mexico and the Netherlands reviewed them and made recommendations.

Results: The competencies and variables were validated across two Delphi rounds, first with public health experts $(\mathrm{N}=31)$ from the six countries, then with MPH alumni $(\mathrm{N}=30)$. After the first expert round, competencies and impact variables were refined based on the quantitative results and qualitative comments. Both rounds showed high consensus, more so for the competencies than the impact variables. The response rate was $100 \%$.

Conclusion: This is the first time that public health competencies have been validated in LMICs across continents. It is also the first time that impact variables of MPH programmes have been proposed and validated in LMICs across continents. The high degree of consensus between experts and alumni suggests that these public health competencies and impact variables can be used to design and evaluate MPH programmes, as well as for individual and team assessment and continuous professional development in LMICs. 


\section{Background}

Responding to the crisis in human resources for health and the need for a wellestablished public health workforce, the number of Master of Public Health (MPH) training programmes has increased, especially in low- and middle-income countries (LMICs) (1-4). As the LMIC context differs deeply from High Income Countries, the question has been posed whether existing LMIC programmes equip public health alumni to be effective, and whether the taught competencies from these programmes are relevant to their contexts (4-6). Since the 1990s, in schooling and higher education globally, detailed descriptions of expected performance or competencies have been commonly used as drivers of curriculum development, programme evaluation, job function delineation and continuous professional development assessments (7-9). For some of these purposes, competencies are defined as the "effective application of available knowledge, skills, attitudes and values in complex situations" (7).

Over the past decade, public health competencies have received considerable attention, and have been developed and refined in a range of countries: in the United States of America (USA) they were formulated by the Council on Linkages Between Academia and Public Health Practice in 2001 and revisions adopted in 2010 (10); the Public Health Agency of Canada published a list in 2007 (11), while in Europe, the Association of Schools of Public Health in the European Region (ASPHER) drafted a list in 2008, which were redefined in 2011 (12). In the same year (2008), the United Kingdom (UK) Public Health Skills and Career Framework was endorsed (13), while in Australia, the Foundation Competencies for Master of Public Health alumni (14) were published in 2009. These public health competencies were, in many instances, developed through group discussions and a modified Delphi method, with varying degrees of input from academia and public health practitioners at different levels (8,12-14).

In LMICs, the Public Health Foundation of India held a multi-country conference in 2008 , attended by a wide range of local and international delegates and experts. Some delegates were commissioned to develop reports on the state of public health training in their own countries, with a view to informing the development of the public health curriculum in India (15). Since then, public health competencies have also been developed in Latin America (16). However public health competencies have not been accepted nor validated across LMICs.

Furthermore, although restructuring curricula in terms of competencies constitutes a statement of intent on behalf of the provider, it does not demonstrate whether these competencies have been acquired, nor whether the selected competencies had impact in the workplace or in society. A review by Zwanikken et al. (17) revealed that very few Masters programmes in health and health care have defined their intended impact on the workplace and in society in general, by specifying outcome or impact indicators.

When six institutions offering MPH programmes came together in December 2011 to design a comparative impact evaluation across programmes, each brought to the 
discussion the set of key competencies which have guided their programmes over the past decade. These were to serve as the basis for formulating the competencies and impact variables against which to evaluate the impact of the MPH programmes across all six institutions involved in this study. As part of the design, these competencies and impact variables were to be validated using a Delphi process. All the institutions were engaged in training health and allied health professionals working in LMICs and included: School of Public Health, University of the Western Cape, South Africa; Hanoi School of Public Health, Vietnam; School of Public Health Fudan, China; National Institute of Public Health, Mexico; University of Medical Science and Technology (UMST), Sudan (through the Ministry of Health), and the Royal Tropical Institute, the Netherlands.

\section{Methods}

The team used a multistep process, starting with the December 2011 meeting of MPH programme convenors from six countries, to reach consensus on a set of public health competencies, develop a list of draft impact variables and design the validation process. The process of developing the competencies and variables aimed to represent the diversity amongst institutional competencies and learning objectives as well to harmonize and streamline the competency statements sufficiently to establish a shared basis for the evaluation. Specific competencies articulated by particular schools were discussed until consensus was reached on whether and how to include them. The resulting set of competencies includes the common competencies of all schools and seeks to articulate key areas of public health performance. The process of modification was discussion, careful deliberation and consensus building during the face to face meeting, email communications and two Skype meetings.

After the competencies were defined and agreed upon, impact variables were developed. The impact variables were divided into impact on the workplace, such as developing improved working procedures within a work unit, and impact on the sector or society, such as improved quality of care for patients. The team formulated the impact variables through inductive logic while taking into consideration the public health competencies that had already been defined. Although these two levels of intended impact are linked, they were not constructed to be directly equivalent.

Prior to embarking on the study, the ethics committees of the six participating institutions, ie the University of Western Cape Senate Research and Ethics Committee, Hanoi School of Public Health Ethic Committee, Fudan University School of Public Health Institutional Review Board, Sudan Medical and Scientific Research Institute (SUMASRI) Ethical Clearance Committee, National Institute of Public Health Ethic Committee, Royal Tropical Institute Research Ethics Committee, granted ethical approval for the study. 
The initial meeting was followed by a period of refinement and discussion of the validation design within the team, by email and Skype conferencing. Validation was undertaken using a modified Delphi process. A number of researchers have used the Delphi method to generate consensus on the public health competencies of different health professionals (18-21). Though the original conceptualisation of the Delphi method includes at least two and sometimes three rounds of feedback by the same experts (21), a modified Delphi process was chosen: this involved consulting a group of experienced public health experts ( $1^{\text {st }}$ round) invited by each convenor on the basis of maximum diversity, and if need be, a second round by the experts, followed by consultation of a similarly selected group of programme alumni $\left(2^{\text {nd }}\right.$ or $3^{\text {rd }}$ round), and possibly another round with the alumni. The rationale for including alumni was that their experience would enable them to critique the competencies and impact variables from the perspective of what they regard as relevant in their field of work. Maximum professional, gender and cohort diversity criteria were used in their selection.

The five public health experts from each country $(\mathrm{N}=31)$ were asked to review and validate the public health competencies and impact variables using a Likert scale graded from 1 (signifying that the competence was of 'poor' relevance) to 5 (indicating 'excellent' relevance to the field of public health practice). The intention was that the decision to undertake further rounds of consultation with the same groups should be based on the degree of consensus found. Qualitative comments and suggestions were also invited.

Responses were entered and stored in Microsoft Office Excel ${ }^{\circledR} 2003$ (Microsoft Corporation, USA), and calculations were made using Excel. Since the results from the first round showed considerable consensus, a further round was not deemed to be required. The experts' feedback, however, guided further refinement of the competencies and impact variables, which was then circulated to alumni $(\mathrm{N}=30)$ across the six MPH programmes for further validation. Once again, based on the level of consensus in the results of the graduate round, a further round with them was not deemed necessary.

No agreement exists in the literature on how to measure consensus; measures of central tendency and measures of dispersion are often used (22). According to Argyrous (23), the median can be used with ranked data (ordinal and interval/ratio), but this is not considered useful for scales with few values; in addition the mean can be used for data that are not skewed. Initially we determined the cut-off points as a mean $<=3.9$ or a variation coefficient $>=0.26$. However, the data appeared to be skewed, so the median was chosen: a median of 4 or 5 was considered a good degree of consensus.

\section{Developing the public health competencies and impact variables}

The competencies and impact variables which were validated in the Delphi process had been developed through the deliberations of the six LMIC schools of public health. At 
an early stage, the competencies were compared with those of the Council on Linkages Between Academia and Public Health Practice (10), as these competencies have been widely used elsewhere as a basis for curriculum design (24-26). Having considered this framework, the team decided to structure the list of competencies into seven competency clusters. Taking into account the argument against 'atomization' or fragmentation into component parts of competencies/outcomes, and the recognition that the overarching competence is often considered the best expression thereof $(27,28)$, the team used the clusters to condense and clarify the competencies. In the course of this clustering process, we, decided to group 'analytical/assessment skills' with 'public health sciences skills', as we consider 'analytical/assessment' skills to be embedded in, and the active component of 'public health skills'.

In making this comparison, additions to our competencies are notable because we view them as important in the LMICs context. Gender issues were absent from the Council on Linkages framework. The 'pro-poor and equity-based approach' was specifically added in response to population needs of LMICs. Furthermore, the team added competencies related to the social determinants of health, as they are considered to be an important foundation for public health practice, as acknowledged in the work of the WHO Commission on the Social Determinants of Health, and others (29). The conceptualization of cultural competencies was also expanded to encompass 'contextsensitive competencies', in recognition that health status is determined by far more than cultural or background factors, including social, economic, political and gender factors. 'Policy advocacy' was added to the domain of policy, as well as the need for 'context sensitivity' of policies. 'Intersectoral competencies' were added to community competencies, because intersectoral engagement is regarded as a critical principle in furthering the impact of public health. A further contrast with the Council on Linkages framework is that where they assign an important role to financial planning and management, this group's competencies emphasize planning and management as a whole, including finances (Figure 1). 


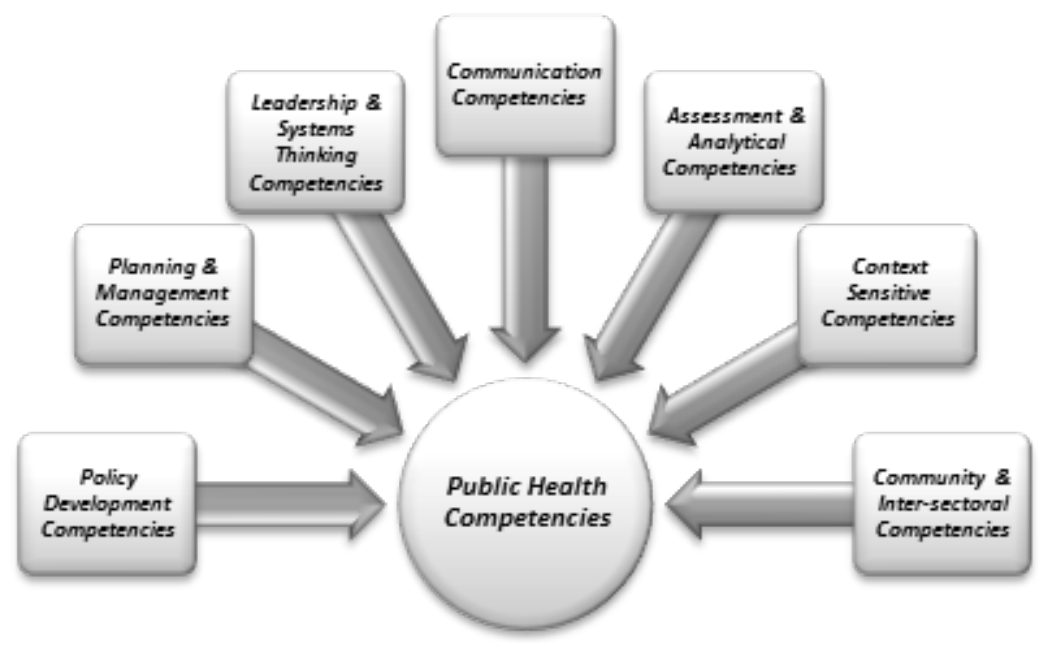

Figure 1: Public health competencies

\section{Results}

As described in the Methodology, the competencies and impact variables were validated using two Delphi rounds, yielding quantitative and qualitative results.

\section{Validation by experts}

To ensure a maximum variation sample of experts in the public health field, the following criteria were used: reviewers should have a broad view on public health, at least 10 years' work experience in public health, and work at different workplace types. The expert group was required to include both men and women, at least one person from a university (e.g. professor/programme trainer/policymaker of an educational department), one from health system management (i.e. at national/provincial level), one from a service delivery institution (e.g. Centers for Disease Control and Prevention or other public health institutions) and one from a non-governmental organization (NGO). Respondents were recruited by the MPH convener of the respective schools by email or telephone.

Respondents were provided the competencies and impact variables and asked to rate the relevance of each competency and impact variable using a Likert scale from 1 ('poor' relevance) to 5 ('excellent' relevance'). The key to the competencies and impact variables noted: 'Relevance in this study means that this particular competency is expected of a Public Health Masters graduate working in the field of Public Health'. As regards impact variables: 'excellent relevance' suggested that this effect on the graduate's workplace or sector of society was very important, e.g. they were asked to rate 
the relevance of 'Contributed to equity/pro-poor orientation towards health access at all levels'. Comments and additional suggestions were also received from the expert group.

Responses were received over two months from 31 experts ( 21 men and 10 women). Eighteen of the experts were from universities, seven from health system management, three from service delivery institutions and three from NGOs, including international agencies such as the United Nations Family Planning Association. All public health experts had more than 10 years of experience in public health. In the analysis of data, medians were calculated for all scores as well as for each country to identify cross-country variability (see Additional file 1 ).

Quantitative analysis across all six countries revealed that 11 of the competencies had a median of 4 , while 12 competencies had a median of 5 , which shows a high degree of consensus. Qualitative comments focused mainly on the formulation of selected competencies, either pointing out vagueness of expression, a dual focus question or adding to and improving formulations.

Results for the workplace impact variables also showed a high level of consensus: 19 of them had a median of 4, two had a median of 4.5, and three had a median of 5 (Table 1). Two of the lowest variables (with a median of 3) were: the graduate had 'published book chapters', which was considered too high an expectation for an MPH graduate; and 'Projects [were] rewarded and by what amount'; this was also considered too ambitious and concern was expressed that raising funds could often not be attributed to one person alone. Some experts commented that several workplace variables required a scale, that some were difficult to measure, some too broad and some too ambitious, given certain contexts.

Table 1: Results of two Delphi validation rounds

\begin{tabular}{|c|c|c|c|c|}
\hline Round/median & Median 3 & Median 4 & Median 5 & Total \\
\hline \multicolumn{5}{|l|}{ Round 1 (experts) } \\
\hline Number of competencies & & 11 & 12 & 23 \\
\hline Number of impact variables work & 2 & 19 & 5 & 26 \\
\hline Number of impact variables society & & 9 & & 9 \\
\hline \multicolumn{5}{|l|}{ Round 2 (alumni) } \\
\hline Number of competencies & & 10 & 13 & 23 \\
\hline Number of impact variables work & & 19 & 7 & 26 \\
\hline Number of impact variables society & & 7 & 3 & 10 \\
\hline
\end{tabular}

All nine of the impact variables on society had a median of 4 (Table 1) across the six countries. General feedback by some experts was that it was difficult to score these variables, as the scoring would depend on the context in which a graduate works. The importance of each variable would depend on the level and role of the graduate, as well as the specific field in which they work, for example as a policy maker, implemen- 
tation manager, educator or researcher. One expert commented that it would be difficult to attribute an indicator to one person, as so often public health workers operate in teams. Qualitative comments suggested that some society level impact variables were too broad, and too ambitious given certain contexts; in some cases, clarifications were suggested.

Some cross-country variability was identified, with one school scoring overall lower regarding the competencies and variables. In this school's survey, four out of 23 competencies had a median of 3, while other schools had only one competency with a median of 3 , or none. For the impact variables at work, the same school scored three variables less than 3, while other schools scored one to three variables with a median of 3.

For impact variables on society, there were two schools which scored four variables with a median of 3 . The competencies and variables which were scored lower in the one school were also not rated highly in other schools, and were changed.

Based on the quantitative results and the qualitative comments from the experts, 14 of the 23 competencies were reworded to improve clarity (Tables 1 and 2). Two of the workplace impact variables were changed because the median of 3 was low: 'Achievements which can be attributed to the leadership of the graduate, e.g. individual or organisational awards' was deleted as it was seen as overlapping with another variable, and the following variable was added: 'Participated in building a successful partnership', based on comments from experts. Eleven of the 26 impact variables in the workplace were reworded, based on qualitative feedback (Tables 1 and 3). Four of the nine impact variables on society were reworded based on the qualitative feedback, and one variable was added, based on comments from experts: 'Influenced better understanding of public health measures amongst the general population' (Tables 1 and 4).

\section{Validation by alumni}

After the researchers reached agreement on the revision, each school sent the competencies and impact variables out to five alumni for a second round of validation. The selection of alumni was based on maximum variation per school using criteria of gender, geographical location, year of graduation (between 2004 and 2010) and workplace type. Respondents were again asked to rate the relevance of each competency on a five-point Likert scale - i.e. whether each competency is expected of an MPH graduate working in public health; the key for scoring was revised for greater clarity, and ranged from 1 ('Not a key competency') to 5 ('Highly relevant') on the advice of one of the experts. Respondents were also asked to rate the drafted impact variables from 1 ('Not a key variable') to 5 ('Highly relevant'). They were also asked for comments and additional suggestions. It took a further two months to gather feedback from these 14 men and 16 women. One of the alumni graduated in 2004; two in 2005; five in 2006; four in 2007; six in 2008; six in 2009; five in 2010; and one in 2011. Of them, ten alumni 
worked for higher education institutions, 12 in health system management, seven for service delivery institutions and one for an NGO.

Medians for each country were computed to identify cross country variability. Quantitative results revealed that ten competencies had a median of 4, and 13 competencies a median of 5 (Tables 1 and 2), showing a high degree of consensus (see Additional file 2).

Table 2: Results of validation of competencies

\begin{tabular}{|c|c|}
\hline Competencies\validation & Experts Alumni \\
\hline $\begin{array}{l}\text { Cluster of Detailed competencies (as sent to alumni) } \\
\text { competencies }\end{array}$ & Median Median \\
\hline
\end{tabular}

Public Health 1. Applies the basic Public Health sciences (including but not limited to

science skills biostatistics, epidemiology, environmental health services, health services

including administration and social and behavioral health sciences) to Public Health

analytical policies and programs

assessment

competencies

2. Appraises scope, function and role of Public Health in relation to local

4

4 context, health system and other social sectors

3. Assesses population health status and identifies population health problems, risk factors, related Social Determinants, and determines needs

4. Commissions and critically interprets research findings and/or develops protocol and collects, analyses and synthesizes reliable and valid data using qualitative and quantitative methods

Policy devel- 5. Analyzes and evaluates policy options and determines feasibility for

opment com- Public Health policies/ programs in diverse community contexts, using

petencies appraisal of evidence

6. Participates in developing context sensitive policies and strategic plans and translates them into action

7. Understands and contributes to developing and using mechanisms to monitor and evaluate Public Health policies and regulations

8. Contributes to advocacy of new and existing health policies to the public health and other sectors

Communication 9. Communicates concisely in writing and orally, in person and through

competencies electronic means with linguistic and cultural proficiency and appropriateness

10. Facilitates and integrates input to Public Health policy and programs from a wide range of individual and organizational stakeholders

11. Uses a variety of culturally appropriate approaches to disseminate Public Health information with consideration to ethical and confidential issues

Context sensi- 12 . Analyzes the role of gender, cultural, social, economic, political and tive behavioral factors in the accessibility, availability, acceptability and delivcompetencies ery of Public Health services and programs

13. Incorporates a Social Determinants of Health approach to Public 


\begin{tabular}{lrl}
\hline Competencies/validation & Experts Alumni \\
\hline $\begin{array}{l}\text { Cluster of } \\
\text { competencies }\end{array}$ & Detailed competencies (as sent to alumni) & Median Median \\
\hline
\end{tabular}

Health needs

Community and 14. Assesses and engages community actors and communities and their

$4 \quad 4$

inter-sectoral linkages and relationships that affect health in diverse social and cultural

competencies situations

15. Collaborates in community-based participatory efforts

5

16. Develops and maintains partnerships with key stakeholders, including

4

from different sectors

Planning and

management

17. Uses evidence and good practice to address Public Health policy, plan-

4

competencies

ning and management issues

18. Plans, implements, monitors and evaluates Public Health interventions, $\quad 5 \quad 5$

programs, resources, services including input, process, outcome and im-

pact

19. Prepares and contributes to manage and evaluate Public Health

4

4

information systems, human, financial and logistic resources

Leadership and 20. Demonstrates leadership as a manager and in team efforts, and is

systems think- able to lead in Public Health emergencies

ing competen-

cies

21. Demonstrates professional judgment and ethical standards in data handling and addressing Public Health issues and diverse opinions

22. Leads with applying the understanding of the interconnectedness and

dynamic interactions of the Public Health system

$5 \quad 5$

23. Continues life-long learning and professional development, and

5 stimulates team to do so

*Bold type indicates that the competency was changed after feedback from experts and discussion by the research group 
Table 3: Results of validation of impact variables in workplace

Impact variables at workplace (as sent to alumni)

1. Created evidence (primary or secondary) for decision-making

Median Median

2. Developed a study or a research proposal

3. Reported and made recommendations or population health status or needs

$5 \quad 5$

$4,5 \quad 5$

4. Contributed to change in policy at workplace where needed

5. Contributed to change in policy at one level higher than work institution

$5 \quad 5$

$4 \quad 4$

6. Participated and influenced working committees for program design or policy formula-

$4 \quad 4$
tion at provincial, national or international level

7. Published or posted in popular (including electronic) media

8. Made presentations at conferences

9. Published in peer reviewed publications

10. Contributed to writing a published chapter of a book

11. Tutored or taught Public Health professionals, trainees or students in the community

12. Developed, reviewed or commissioned educational or Health Promotion media and materials

13. Planned or implemented community health education courses and workshops

14. Intervened or worked with a Social Determinants of Health Framework in a way that promotes equity and/or is pro-poor

15. Collaborated/networked/developed partnerships successfully with other departments than health

16. Initiated, sustained and evaluated projects with community participation

$\begin{array}{cc}4 & 4 \\ 4 & 4,5 \\ 4 & 4 \\ 3 & 4 \\ 4 & 4 \\ 4 & 4\end{array}$

17. Planned and implemented Public Health interventions, programs or policies based on consultation with stakeholders and using evidence and best practice

18. Implemented performance improvement strategies in response to monitoring and evaluation findings

19. Contributed to improvements in human resource management

20. Contributed to improving regular working procedures

21. Instrumental in initiating a change within the workplace, or at some level beyond

$\begin{array}{cc}4 & 4,5 \\ 4 & 4\end{array}$

22. Contributed to addressing the determinants of health e.g. through planning processes, resource allocation or research

\section{Raised a project grant}

24. Contributed to reputation-building of workplace

25. Participated in national and international collaboration

26. Participated in building a successful partnership (added)

Achievements which can be attributed to the leadership of the graduate, e.g. individual or organisational awards (deleted)

*Bold type indicates that the variable was changed after feedback from experts and discussion by the research group 
In relation to the impact variables in the workplace, 19 of the 26 variables had a median of 4 , and seven had a median of 5 (Tables 1 and 3). Seven of the impact variables in society had a median of 4, and three had a median of 5 (Tables 1 and 4).

As regards to cross-country variability for the competencies, alumni from one school rated two competencies at 3, alumni from two different schools scored five out of 23 work impact variables at 3, while alumni from other schools scored a median of 3 for zero, one or three variables. With regard to the impact variables in society, alumni from two different schools scored two and three different impact variables at 3.

General qualitative feedback suggested that the impact variables were dependent on the actual job or workplace of an MPH graduate, as well as the expectation of a student at the start of a program, which concurred with the feedback from the experts. Qualitative feedback suggested that wording could be more specific in 12 of the 23 competencies, 11 of the 26 impact variables on work and five of the 10 impact variables on society. For example, of the fourth competency, 'Commissions research', two alumni (A15 male, A20 male) commented: 'Consider adding application of ethical principles'. For the second impact variable on society: 'Contributed to changed guidelines, regulations, ordinances beyond the workplace', alumni commented: 'It's hard because of the old thought about what public health is, but we're pushing for the change' (A23, Female) and [it is] 'not easy to demonstrate' (A27, Female) (See Additional file 3) .

Table 4: Results of validation of impact variables on society

\begin{tabular}{|c|c|c|}
\hline Impact variables on society (as sent to alumni) & $\begin{array}{l}\text { Experts } \\
\text { Median }\end{array}$ & $\begin{array}{l}\text { Alumni } \\
\text { Median }\end{array}$ \\
\hline 1. Contributed to changes in policy or strategy in general & 4 & 5 \\
\hline 2. Contributed to changed guidelines, regulations, ordinances beyond the workplace & 4 & 4 \\
\hline $\begin{array}{l}\text { 3. Contributed to influencing communities, organisations, health sector and other } \\
\text { sectors than health }\end{array}$ & 4 & 4 \\
\hline 4. Contributed to equity/pro-poor orientation towards health access at all levels & 4 & 4 \\
\hline $\begin{array}{l}\text { 5. Contributed to changes in resource allocation for interventions, and research, orien- } \\
\text { tated towards equity and addressing the determinants of health }\end{array}$ & 4 & 4 \\
\hline 6. Contributed to equitable access to quality services & 4 & 4,5 \\
\hline $\begin{array}{l}\text { 7. Contributed to improved Public Health in specific areas related to work context, e.g. } \\
\text { improved utilization of services }\end{array}$ & 4 & 4 \\
\hline 8. Contributed to increased resource mobilization for Public Health & 4 & 4 \\
\hline 9. Contributed to increased resource mobilization for disadvantaged groups & 4 & 4 \\
\hline $\begin{array}{l}\text { 10. Influenced better understanding of Public Health measures amongst general popu- } \\
\text { lation (added) }\end{array}$ & 0 & 5 \\
\hline
\end{tabular}

*Bold type indicates that the variable was changed after feedback from experts and discussion by the research group 


\section{Discussion}

A set of competencies and impact variables of $\mathrm{MPH}$ programmes were formulated and validated with public health experts and alumni of the programmes. This is the first time, to our knowledge, that public health competencies have been validated for MPH programmes located in or intended for LMICs, across continents. It was also the first time that impact variables of MPH programmes have been formulated and validated. Although there were some variations across countries, the results show an overall consensus of the 23 public health competencies, 26 impact variables on the workplace and 10 impact variables on society.

The process of competency development has differed across the globe: in the USA as well as in the UK, a large number of experts were involved $(8,13)$, but in both cases, the process was criticized for being too strongly directed by the higher ranks (12). Another approach was taken by ASPHER in the European region, which involved local employer and workforce representatives (12). Other recent studies reviewing public health competency formulation surveyed only specific stakeholders such as employers (29), experts (20), academic practitioners and employers, but not alumni $(18,19)$. Higher numbers of people than were used in this study were sometimes included in the panel $(18,30)$, however, the response rate and the level of consensus was lower. None of the initiatives reviewed in the literature developed impact variables.

Public health is in different stages of development in the different countries. However, in spite of this and other contextual diversity factors, the validation process yielded high consensus. It is possible, however, that if experts and alumni had been asked to prioritize or weight the competencies and impact variables, differences would have become more pronounced (30).

The nature of the Delphi method is qualitative in design and does not seek statistical representativeness in the number of experts invited, but rather attempts to achieve maximum variation of the characteristics of the experts, based on purposeful selection (21). Future work could engage a larger number of experts or ensure a wider variety of experts.

In this validation process, the 'public health science skills' as well as the 'context sensitive competencies' received the highest ratings from both experts and alumni: clearly the addition of the 'context sensitive competencies' was deemed important in the context of LMICs. Further high scoring competencies were 'planning and management', 'communication' as well as 'leadership' and 'systems thinking' competencies. Slightly lower ratings were assigned to 'policy development' and 'community and intersectoral competencies'. Though still highly rated, the 'policy development competencies' and 'community competencies' might be less valued because of assumptions regarding the working level and roles played by MPH alumni.

The highest scoring impact variables on the workplace amongst experts and alumni were: 'Created evidence for decision making', 'Developed a study or research proposal', 
'Reported and made recommendations on populations health status or needs', as well as the variable 'Implemented performance improvement strategies in response to monitoring and evaluation findings'. Interestingly the variable, 'Contributed to addressing determinants of health' was scored higher by alumni than experts, possibly reflecting the alumni' current experience in the field as well as recent public health developments emphasising the determinants. As for impact variables in society, there was not much difference between the rating of experts and alumni, except for the first indicator: 'Contributes to changes in policy or strategy in general': this was rated higher by the alumni. The highest rated competencies and variables were clearly strongly endorsed and indicated a high degree of consensus.

\section{Limitations}

Although the experts came from four different continents and six countries, there was a high degree of consensus regarding the rating of competencies, though this applied to a lesser extent to the impact variables. It is suggested that consensus might have been promoted by social desirability: although the experts were anonymous to one another, they were selected by MPH programme convenors who had developed the competencies and variables. Intra-rater variability, however, showed scores from 1-5. In addition, no prioritization of competencies was requested which might have elicited even greater social desirability bias. By using selection criteria for experts to ensure maximum variation, this bias was reduced.

The validation by alumni yielded similar results, with increased congruency, i.e. no impact variable with a median of 3 , and more with a median of 5 . For the graduate respondents, it is possible that social desirability may have influenced the results, as they were informed that the competencies and variables had already been reviewed by experts. However given the fact that there was less consensus regarding the impact variables and intra-rater variability was mostly between $2-5$, this was probably not the case. In retrospect, it might have been better to engage the alumni in the first rather than the second round, to avoid this possible risk of bias. The question is, however, whether that would have yielded different results, given the already high consensus in the first round. The fact that the alumni were only invited to participate in the second round created the opportunity to improve the competencies and impact variables before they received them. The selection of alumni may also have been biased, as this was undertaken by MPH programme convenors; this bias was minimized through the use of explicit selection criteria.

The validated impact variables yielded relatively high consensus although less than the competencies. Both the experts and alumni commented that contextual factors, such as the position of the graduate or the level at which the graduate was working, influenced whether these variables could be measured; this was raised as a greater concern for the impact variables on society. Some cross-country variability was identi- 
fied however, given the small number of experts and alumni per country and the fact that no specific school could be identified as differing markedly from others, and given the otherwise high consensus, these findings were thought not to be material to the study.

\section{Conclusion}

This study contributes to the debates and deliberations on appropriate selection of public health competencies in LMICs. The validation of the competencies and impact variables suggests that public health competencies in LMICs should differ from those in high income countries by placing emphasis on factors which impact on the health of their populations, such as examining the social determinants of health, focusing on context specificity and intersectoral competencies, with less emphasis on financial planning in management.

Inasmuch as this formulation and validation process of public health competencies is understood to be a first initiative and that impact variables for MPH alumni working in LMICs have not previously been developed or at least publicised, the study can be said to have provided a foundation for further refinement, and suggested surprising consensus across countries. Although the social, cultural and political situation and the state of public health development differs considerably between the countries where the six MPH programmes are situated, clear consensus emerged as to what the public health competencies and impact variables should entail.

These public health competencies and impact variables can, therefore, be used to design or evaluate MPH programmes and to assess the competencies of individuals engaged in formal programmes and continuous professional education.

\section{Additional files}

Additional file 1 Responses experts quantitative Additional file 2 Responses alumni quantitative Additional file 3 Responses alumni qualitative and summarized quantitative To be found at: http://www.biomedcentral.com/1471-2458/14/55 


\section{References}

1. Hongara C, McPake B: How to bridge the gap in human resources for health. Lancet 2004, 364:14511458.

2. World Health Organization: The World Health Report 2006: Working together for health. Geneva: WHO press, World Health Organisation; 2006.

3. Petrakova A, Sadana R: Problems and progress in public health education. Bulletin of the World Health Organization 2007, 85(12):963-965.

4. Sadana R, Petrakova A: Shaping public health education around the world to address health challenges in the coming decades. Bulletin of the World Health Organization 2007, 85(12):902.

5. Sadana R, Chowdhury AMR, Petrakova A: Strengthening public health education and training to improve global health. Bulletin of the World Health Organization 2007, 85:163.

6. Plugge E, Cole D: Oxford graduates' perceptions of a global health master's degree: a case study. Human Resources for Health 2011, 9(1):26.

7. Calhoun JG, Davidson PL, Sinioris ME, Vincent ET, Griffith JR: Toward an understanding of competency identification and assessment in health care management. Quality Management in Health Care, 2002, 11(1):14-38.

8. Calhoun J, Ramiah K, McGean Weist E, Shortell SM: Development of a Core Competency Model for the Master of Public Health Degree. American Journal of Public Health 2008, 98:1598-1607.

9. Frank JR, Mongroo R, Ahmad Y, Wang M, De Rossi S, Horsley T: Toward a definition of competencybased education in medicine: a systematic review of published definitions. Medical Teacher 2010, 32:631-637.

10. The Council on Linkages Between Academia and Public Health Practice: Core Competencies for Public Health Professionals Tier 1, Tier 2 and Tier 3 (adopted 3 May 2010) http://www.phf.org/resourcestools/Documents/Core_Competencies_for_Public_Health_Professionals_2010May.pdf.

11. Public health agency of Canada. Core competencies for public health in Canada Release 1.0; 2007. http://www.phac-aspc.gc.ca/php-psp/ccph-cesp/stmts-enon-eng.php.

12. Birt CA, Foldspang A: The Developing Role of Systems of Competences in Public Health Education and Practice. Public Health Reviews 2011, 33(1):134-147.

13. Wright J, Rao M, Walker K: The UK public health skills and career framework - could it help to make public health the business of every workforce? Public health 2008 122:541-544.

14. Genat B, Robinson P, Parker E: Foundation competencies for Master of Public Health graduates in Australia. Brisbane QUT Publications: Australian Network of Academic Public Health Institutions; 2009.

15. Public Health Foundation of India: Report of International Conference on New Directions for Public Health Education in Low and Middle Income Countries, Processes, Proceedings and Proposed Next Steps. Hyderabad, India, Public Health Foundation; 2008.

16. Magaña Valladares L: Essential Skills Regional Framework Public Health, Latin America, working paper. Cuernavaca: INSP/MEX Dr. Charles Godue, OPS/OMS; 2011.

17. Zwanikken PAC, Dieleman M, Samaranayake D, Akwataghibe N, Scherpbier A.: A systematic review of outcome and impact of Master's in health and health care. BMC Medical Education 2013, 13:18 doi:10.1186/1472-6920-13-18.

18. Retoo KN, Harrington JM, Macdonald EB: Required competencies of occupational physicians: a Delphi survey of UK customers. Occupational and Environmental Medicine 2005, 62:406-413.

19. Jonsdottir S, Hughes R, Thorsdottir I, Yngve A: Consensus on the competencies required for public health nutrition workforce development in Europe - the JobNut project. Public Health Nutrition 2011, 14:1439-1449.

20. Kennie-Kaulbach N, Farrell B, Ward N, Johnston S, Gubbels A, Eguale T, Dolovich L, Jorgenson D, Waite N, Winslade N: Pharmacist provision of primary health care: a modified Delphi validation of pharmacists' competencies BMC Family Practice 2012, 13:27.

21. Powell C: The Delphi technique: myths and realities. Journal of Advanced Nursing 2003, 41(4):376-82. 
22. Von der Gracht HA: Consensus measurement in Delphi studies Review and implications for future quality assurance. Technological Forecasting \& Social Change 2012, doi:10.1016/j.techfore.2012.04.013.

23. Argyrous G: Statistics for Research, 2nd ed. Sage Publications, London, 2005.

24. Borders S, Blakely C, Quiram B, McLeroy K: Considerations for increasing the competences and capacities of the public health workforce: assessing the training needs of public health workers in Texas. $\mathrm{Hu}$ man Resources for Health 2006, 4:18.

25. Van der Putten M, Vichit-Vadakan N, Chuchat A, Love EJ: Assessing required skill mastery in public health competencies in Thailand. Journal Education for Health 2006, 19(2):233-243.

26. Hagopian A, Spigner C, Gorstein JL, Mercer MA, Pfeiffer J, Frey S, Benjamin L, Gloyd S: Developing competencies for a graduate school curriculum in international health Public Health Reports 2008, 123(3):408-414.

27. Tuck R: An Introductory Guide to National Qualifications Frameworks: Conceptual and Practical Issues for Policy Makers. Geneva: ILO,2007.

28. Ten Cate O: Trust, competence, and the supervisor's role in postgraduate training British Medical Journal, 2006; 333(7571):748-751.

29. Biesma RG, Pavlova M, Vaatstra R, Van Merode GG, Czabanowska K, Smith T, Groot W: Generic versus specific competencies of entry-level public health graduates: employers perceptions in Poland, the UK, and the Netherlands. Advances in Health Sciences Education, 2008, 13:325-343.

30. Pfeiffer J, Beschta J, Hohl S, Wasserheit J: Competency-based curricula to transform global health: redesign with the end in mind. Academic Medicine 2013, 88 0-0 doi: 10.1097/ACM.0b013e318276bdf4. 


\section{CHAPTER 6}

\section{Outcome and impact of MPH programs across six countries: education for change}

\section{Published as:}

Zwanikken PA, Huong NT, Ying XA, Alexander L, Magaña-Valladares L, Wadidi MS, Gonzalez-Robledo MC, Qian X, Linh NN, Tahir H, Leppink J, Scherpbier A: Outcome and impact of Master of Public Health programs across six countries: education for change. Human Resources for Health, 2014, 12:40,DOI: 10.1186/1478-4491-12-40 


\section{Abstract}

Introduction: The human resources for health crisis has highlighted the need for high-level public health education to add specific capacities to the workforce. Recently, it was questioned whether Master of Public Health (MPH) training prepared graduates with competencies relevant to low- and middle-income countries (LMIC). This study aims to examine the influence of the MPH programs geared towards LMIC offered in Vietnam, China, South Africa, Mexico, Sudan and the Netherlands on graduates' careers, application of acquired competencies, graduates' performance at the workplace and their professional contribution to society.

Methods: A self-administered questionnaire was sent to graduates from $6 \mathrm{MPH}$ programs asking about competencies, outcome and impact variables. Frequency distributions of the answers were calculated, and a bivariate analysis and logistic regression of certain variables was performed.

Results: The response rate was $37.5 \%$. Graduates reported change in leadership (69\%), in technical position (69\%), acquiring new responsibilities (80\%) and increased remuneration (63\%); they asserted that MPH programs contributed significantly to this. Graduates' attribution of their application of 7 key competencies 'substantially to the MPH program' ranged from 33\% - 48\%. Of the 26 impact variables, graduates attributed the effect they had on their workplace substantially to the MPH program; the highest rated variable ranged from: $31 \%-73 \%$; the lowest rated variable ranged from: $9 \%-$ $43 \%$. Of the 10 impact variables on society, graduates attributed the effect they had on society substantially to the MPH program for the highest rated variable: $13 \%-71 \%$; for the lowest rated variable: $4 \%-42 \%$. Candidates' attribution of their application of acquired competencies as well as their impact at the workplace varied significantly according to institution of study and educational background.

Conclusion: From this study it can be concluded that these MPH programs contribute to improving graduates' careers and to building leadership in public health. The MPH programs contribute to graduates' application of competencies, such as public health analytical competencies as well as leadership, context specific and planning and management competencies. MPH programs contribute substantially towards impact variables on the workplace, such as development of research proposals and reporting on population health needs, and less substantial to their impact on society, such as contributing equitable access to quality services. Differences reported between MPH programs merit further study. The results can be used for curriculum reform. 


\section{Introduction}

The human resources for health crisis (i.e. the severe shortage of human resources in 57 low- and middle-income countries, LMIC), has highlighted the need for high-level public health education to add specific capacities to the workforce (1-5). However, questions have been posed whether Master of Public Health (MPH) training prepared graduates with competencies relevant for LMIC (6-8). These questions have also been raised in high-income countries (9-10) and were probably influenced by the general debate on the impact of higher education (11-15). In addition, WHO identified evaluation of the education of health professionals as a knowledge gap (16).

Measuring outcome and impact of educational programs is fraught with methodological difficulties $(14,15,17)$. Blömeke pointed to the dearth of literature measuring competencies of students and graduates in higher education, especially internationally comparable measurements (15). A systematic review of Master's in Health and Health Care programs showed that outcome was usually measured through alumni surveys. In these alumni surveys however, no questions whether graduates attributed their advancement in their career or their application of competencies to the Master's program were included. Other methods used, though less often, were focus group discussions, employer survey and semi- or unstructured interviews (18). Furthermore, although alumni were sometimes asked what they accomplished in their work, these questions were open-ended and did not address outcome or impact indicators. Impact on the workplace was measured in four studies (19-22) and impact on society was only reported in two studies $(20,22)$. Impact was not measured in a systematic manner in any of these studies. Self-reported competency and academic outcome by students and graduates is a valid measure for higher education learning as shown by earlier studies (15, 23-27).

Outcome in this study is defined as the application of competencies and as the effects on career, such as increase in leadership, new responsibilities, change in position and increase in remuneration. Impact in this study is defined as impact on the workplace, e.g. "developed a study or a research proposal" and impact on sector or society e.g. "contributed to equitable access to quality services". Competencies for the Master of Public Health and impact variables on work and society were jointly constructed and validated prior to the study. The designed competencies were based on the competencies and learning objectives of the six participating institutions offering MPH programs and the set of competencies of the Council on Linkages Between Academia and Public Health Practice as a reference. The competencies and impact variables were validated with experts in the field and alumni in the 6 different countries (28).

The aim of this study was to analyse the influence of the MPH programs on graduates' careers and their leadership, on application of competencies acquired in the MPH program as well as on impact at the workplace and on their contribution to society. 


\section{Methods}

This is a cross-sectional study of graduates from six MPH programs: Hanoi School of Public Health, Vietnam (HSPH), School of Public Health Fudan University, China (SPHFU), School of Public Health University of Western Cape, South Africa (SPHUWC), National Institute of Public Health Mexico, Mexico (INSP), University of Medical Sciences and Technology, Sudan (UMST) and the Royal Tropical Institute, Netherlands (KIT). All offer MPH programs geared towards LMIC.

HSPH and KIT offer fulltime programs, SPHFU offers a part-time program and since 2010 a fulltime program. At SPHUWC, INSP and UMST students can follow the programs full- and part-time.

An anonymous self-administered questionnaire was designed, based on the analytical framework of the systematic review by Zwanikken and a previous questionnaire $(18,29)$. As attribution was rarely addressed in articles reviewed (18), specific questions were asked regarding the graduates' attribution of competencies and impact variables to the MPH program. The range of ratings was kept small to avoid the recognized tendency for respondents to repeat a rating where the range is wider, see Appendix 1 (24, 26).

The questionnaire was pretested with graduates from different years in all countries and revised, based on comments received. In Vietnam, Mexico and China the questionnaire was translated into the national language and translated back to check for consistency of the translation. The questionnaire was administered by each institution through free online tools or through email, see table 1. Graduates were reminded two times by email, or by telephone. The questionnaire targeted graduates from the MPH programs of the six participating institutions from 2005-2010, in total 1187 graduates, to allow sufficient time for graduates to have applied their newly gained competencies. The questionnaire was online throughout November 2012 - February 2013.

Table 1: Approaching graduates and tools used

\begin{tabular}{lll}
\hline Institution & How graduates were approached & Tool for filling in questionnaire \\
\hline HSPH (Vietnam) & By email/reminder by telephone & Questionnaire send through email \\
SPHFU (China) & By telephone & www.sojump.com \\
SPHUWC (South Africa) & By email & www.surveymonkey.com \\
INSP (Mexico) & By email & Webserver of the institute \\
UMST(Sudan) & By email/ telephone & Questionnaire send through email or \\
& & hard copy \\
KIT (The Netherlands) & By email & www.surveymonkey.com \\
\hline
\end{tabular}

Prior to embarking on the study, the ethics committees of the six participating institutions, i.e. the University of Western Cape Senate Research and Ethics Committee, Hanoi School of Public Health Ethic Committee, Fudan University School of Public Health Insti- 
tutional Review Board, Sudan Medical and Scientific Research Institute Ethical Clearance Committee, National Institute of Public Health Mexico Ethic Committee, Royal Tropical Institute Research Ethics Committee, granted ethical approval for the study.

\section{Data analysis}

The answers from all institutions were analysed using Microsoft Excel 2013 and SPSS 21. Descriptive and bivariate analysis of specific variables was performed.

Logistic regression was performed to examine whether a medical doctor background (yes/no), additional degree (yes/no), institution, gender, time of graduation (2005-2007 or 2008-2010) and age (in years) can predict change in leadership level (yes/no), change in technical position (yes/no), change to position involving more responsibility (yes/no), increase in remuneration (yes/no) and/or a change to another employer (yes/no).

We performed analysis of variance (ANOVA) and analysis of covariance (ANCOVA) to examine which of the aforementioned predictor variables yield a significant contribution to the perceived extent to which MPH contributed to a change in leadership, in technical position, in employer and/ or increase in remuneration.

The questionnaire included a component on the extent to which MPH contributed to application of acquired competencies (Cronbach's $\alpha=0.957)$, to graduates' performance at the work place (Cronbach's $\alpha=0.954$ ), and to their contribution to society (Cronbach's $\alpha=0.940$ ). For each of these three components, exploratory factor analysis using generalized least squares estimation was performed to compute factor scores following the Anderson-Rubin method (Field, 2013). These standardized factor scores, having a mean of zero and standard deviation of approximately one, were used as response variables in ANOVA and ANCOVA to examine which of the aforementioned predictor variables yield a significant contribution to a higher extent of application of acquired competencies, better performance of graduates at the workplace, and an increased impact on society. For all ANOVAs and ANCOVAs, Eta-squared $\left(\eta^{2}\right)$ was used as measure of effect size. Values of .01 indicate small effects, values of .06 indicate medium size effects, and values of .14 are indicative of large effects (30).

While Anderson-Rubin factor scores are generally somewhat more precise than simple sum or average scores, a drawback of these factor scores is that one cannot use them to study to which the MPH program contributed more - application of competencies or workplace performance or impact on society - because the mean of the aforementioned factor scores is zero. Therefore, for the latter, a proportion (i.e. a value somewhere between 0 and 1) was calculated for each of these three components; we divided the number of 'substantial attribution' responses by the number of items in the component. We then performed between-subjects-by-within-subjects ANOVA, treating the three components as within-subjects factor and treating institution as betweensubjects factor. 


\section{Results}

\section{Response rate and demographics of respondents}

The overall response rate was 37.5\%. In Vietnam there was the highest response rate, in Mexico and China the lowest, but overall the response rate between the institutions did not differ much, see table 2 .

Table 2: Response rate and demographics of respondents

\begin{tabular}{|c|c|c|c|c|c|c|}
\hline & Number & \% Response rate & $\%$ Female & $\%$ Male & $\begin{array}{l}\text { Median year } \\
\text { born } \\
\text { of respondents }\end{array}$ & $\begin{array}{l}\text { \% Medica } \\
\text { Doctor }\end{array}$ \\
\hline HSPH (Vietnam) & 153 & 52 & 57 & 43 & 1971 & 64 \\
\hline KIT (The Netherlands) & 86 & 39 & 43 & 57 & 1972 & 47 \\
\hline INSP (Mexico) & 61 & 26 & 71 & 29 & 1972 & 56 \\
\hline SPHFU (China) & 60 & 26 & 43 & 57 & 1975 & 22 \\
\hline SPHUWC (South Africa) & 50 & 39 & 54 & 46 & 1967 & 22 \\
\hline UMST (Sudan) & 35 & 41 & 48 & 52 & 1976 & 54 \\
\hline Total/ Average & 445 & 37.5 & 51 & 49 & 1972 & 49 \\
\hline
\end{tabular}

Of the respondents, $50.8 \%$ are female, the median year of birth was 1973 , ranging from 1955-1997. Respondents had professional educational backgrounds in medicine (48.5\%), Bachelor of Public Health (9.9\%), nursing (7.4\%), dentistry (6.3\%), social science $(3.8 \%)$, nursing/midwifery $(2.3 \%)$, pharmacy $(2 \%)$, BSc or BA $(5.4 \%)$ or other (14.3\%). Most respondents (69\%) studied fullime. All graduates from HSPH, Vietnam and KIT studied fulltime; all alumni from SPHFU, China studied part-time. Graduates had an average work experience of 9.2 years (median 8 years) prior to the MPH, ranging from 0-30 years of work experience.

\section{Career and leadership}

The effect on career and leadership were measured by changes in: level of employment, leadership, technical position, responsibilities, remuneration and graduates' attribution to the MPH.

Level of employment before MPH and currently

Almost $50 \%$ of the alumni indicated that they worked in a clinic (18.9\%) or at district $(13.9 \%)$ or state health public health service (14.1\%) prior to the MPH. After graduation more than $50 \%$ of the graduates shifted towards: working for the national Ministry of Health $(12.7 \%)$, international non-governmental organizations $(9.9 \%)$, a research institute $(7 \%)$ or other $(26 \%)$ (see figure 1$)$. 


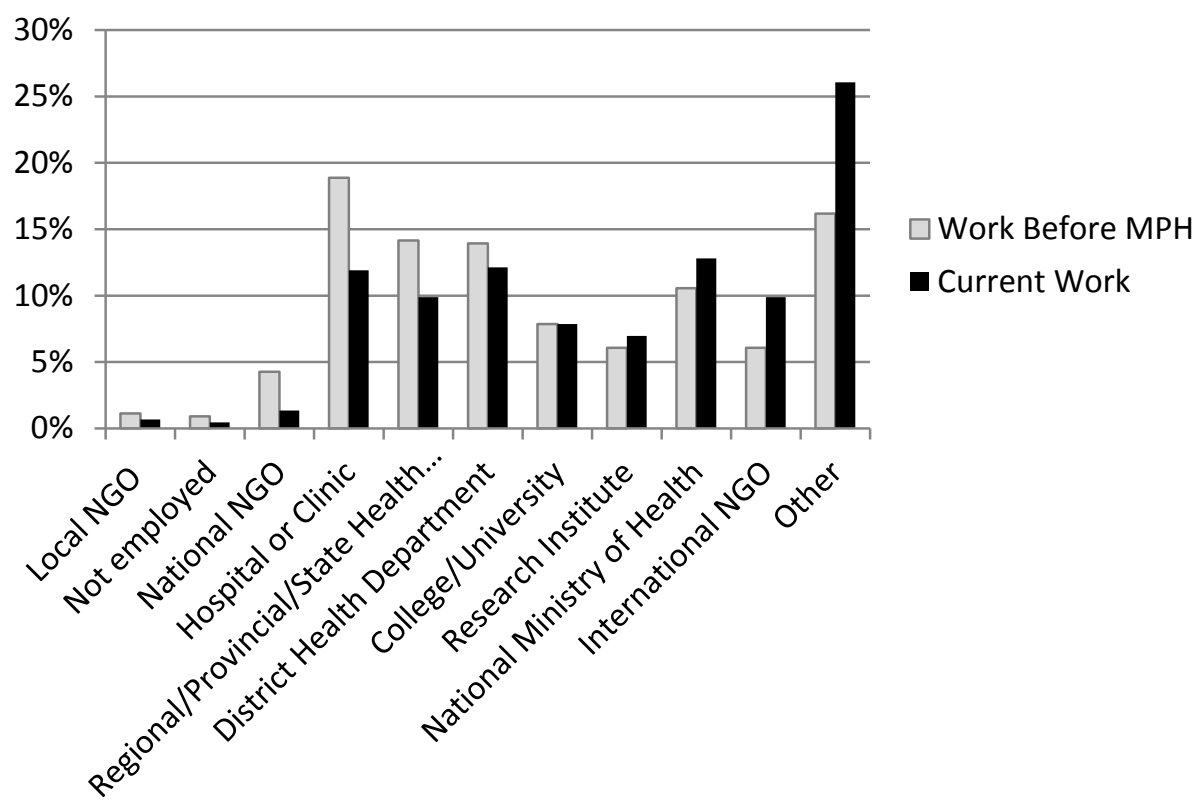

Figure 1: Level of employment of graduates before MPH and currently ( $N=445)$

Only $5 \%$ (24) of the graduates reported working currently outside their home country; this included 2 graduates who originated from a high income country. Fifteen of the graduates working outside their home country, worked within the region (i.e. Africa), while 7 of them went to work in a high income country. No graduates from the schools of China and Vietnam worked outside their country, and only 2 from Mexico did so.

Changes in leadership, technical position, responsibilities and remuneration

Graduates reported a change in leadership in the management system after the MPH (mean: 69\%, ranges see figure 2), a change in technical position or area of focus (mean: $69 \%$; range: $57 \%$ - $85 \%$ ), acquisition of new responsibilities (mean: $80 \%$; range: $53 \%$ $100 \%$ ). More than half of the graduates (mean: 63\%; range: $53 \%-81 \%$ ) reported an increase in remuneration, while $32.7 \%$ remaining the same. 


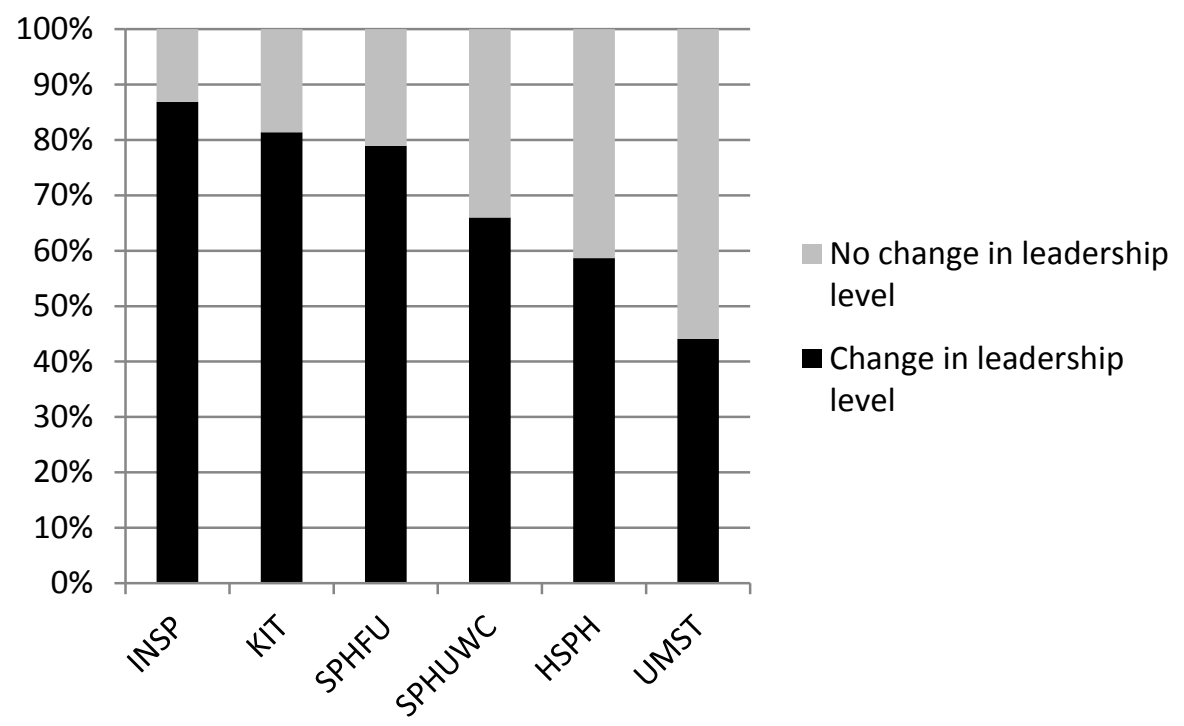

Figure 2: Reported change in leadership level by graduates, $\%$ per school, $N=419^{*}$.

*Missing: 26

Graduates were asked to attribute the change in leadership, technical position, remuneration and change of employer to the MPH graduation on a scale of 1-5 (insignificant to very significant). According to graduates, the MPH program contributed substantially to a change in leadership: nearly $76 \%$ responded with significant or very significant; as not enough people reported no change in leadership, a correlation could not be computed. The MPH program also contributed to change in employer: about $65 \%$ responded with significant or very significant. Furthermore, the MPH program was reported to contribute to change in technical position $(\rho=.371, p<.001)$ and to increase in remuneration $(\rho=.430, p<.001)$.

Further training after the $\mathrm{MPH}$

More than half of the graduates (57\%) reported to have completed certified workrelated training of 2 weeks or more, with a range from 1 to more than 10 courses. About a third (34\%) took a further degree or diploma, other than short training courses, after the MPH. Graduates reported to have taken a PhD (9\%), diploma (9\%), another Master degree (7\%), a postgraduate diploma (1\%) or other (10\%). Graduates were eager to pursue further studies: $74 \%$ planned another degree. 


\section{The extent to which the MPH program enabled the graduate to apply specific public health competencies in their work}

Seven core competencies were subdivided into detailed competencies. Graduates were asked to grade attribution to the MPH program per detailed competency (23 in total), scaled as follows: they did not use it/ it was not part of their work; the MPH program did not enable the graduate, the MPH program enabled the graduate a little to apply or enabled the graduate substantially to apply this competency in their work. Graduates stated that the MPH program enabled them substantially to apply the following core competencies: public health science skills including analytical assessment competencies (48\%), leadership and systems thinking competencies (44\%), context sensitive competencies (43\%) and planning and management competencies (42\%). About a third of the graduates stated that the MPH program enabled them substantially to apply the three following core competencies: communication competencies $(37 \%)$, community and inter-sectoral competencies (36\%) and policy development competencies (33\%). Strikingly within all competencies, there were graduates that did not use the competency or it was not part of their work, with a range from 9-19\%, of which the highest was the policy development competency (19\%), see table 3.

Table 3: Enablement of application of specific public health competencies attributed to the MPH program as reported by graduates $(n=420)^{*}$

\begin{tabular}{lcccc}
\hline $\begin{array}{l}\text { Public health competencies/ At- } \\
\text { tribution to MPH program* }\end{array}$ & $\begin{array}{c}\text { MPH enabled me } \\
\text { substantially to apply }\end{array}$ & $\begin{array}{c}\text { MPH enabled me a } \\
\text { little to apply }\end{array}$ & $\begin{array}{c}\text { Not due } \\
\text { to MPH }\end{array}$ & $\begin{array}{c}\text { Not used/ not } \\
\text { part of my work }\end{array}$ \\
\hline $\begin{array}{l}\text { Public Health science skills includ- } \\
\text { ing analytical assessment compe- } \\
\text { tencies }\end{array}$ & $48 \%$ & $34 \%$ & $9 \%$ & $9 \%$ \\
$\begin{array}{l}\text { Leadership and systems thinking } \\
\text { competencies }\end{array}$ & $44 \%$ & $36 \%$ & $10 \%$ & $11 \%$ \\
$\begin{array}{l}\text { Context sensitive } \\
\text { competencies }\end{array}$ & $43 \%$ & $33 \%$ & $12 \%$ & $12 \%$ \\
$\begin{array}{l}\text { Planning and management compe- } \\
\text { tencies }\end{array}$ & $42 \%$ & $33 \%$ & $9 \%$ & $15 \%$ \\
$\begin{array}{l}\text { Communication competencies } \\
\text { Community and inter-sectoral }\end{array}$ & $37 \%$ & $39 \%$ & $13 \%$ & $11 \%$ \\
$\begin{array}{l}\text { competencies } \\
\text { Policy development competencies }\end{array}$ & $36 \%$ & $34 \%$ & $16 \%$ & $15 \%$ \\
\hline
\end{tabular}

*Missing: 25

\section{The extent to which the MPH program enabled the graduate to impact on the workplace}

Graduates were asked to attribute their impact on the workplace to the MPH program as follows: they did not use it/ it was not part of their work; the MPH program did not 
enable the graduate; the MPH program enabled the graduate a little; or enabled the graduate substantially to impact on workplace. Graduates stating that the MPH program enabled them substantially to impact on their workplace ranged from $60 \%$ to $20 \%$ for the 26 variables. The three highest scored variables were: Developed a study or a research proposal (mean 60\%; range: 73\% - 32\%), Reported and made recommendations on population health status or needs (mean 43\%; range: $61 \%-31 \%$ ) and Made presentations at conferences (mean 41\%; range: 68\% - 21\%). The three lowest scored variables were: Published or posted in popular (including electronic) media (mean: 23\%), Contributed to change in policy at one level higher than work institution (mean: $22 \%$ ), Contributed to writing a published chapter of a book (mean: $20 \%$ ), see appendix 2.

\section{The extent to which the MPH program enabled the graduate to impact on society}

Graduates were asked to grade whether the MPH program enabled them to impact on society as follows: they did not use it/it was not part of their work; the MPH program did not enable the graduate; the MPH program enabled the graduate a little to impact; or enabled the graduate substantially to impact on society. Graduates stated that the MPH program enabled them substantially to impact on society with a range from $39 \%$ $17 \%$ for the 10 variables. The three highest scored variables were: Influenced better understanding of public health measures amongst general population (mean: 39\%; range: $71 \%$ - $13 \%$ ), Contributed to equitable access to quality services (mean $32 \%$ : range: $60 \%-12 \%$ ) and Contributed to increased resource mobilization for disadvantaged groups (mean: 31\%). The three lowest scored variables were Contributed to changes in policy or strategy in general (mean: 25\%), Contributed to equity/pro-poor orientation towards health access at all levels (mean: 25\%) and Contributed to changed guidelines, regulations, ordinances beyond the workplace (mean: 17\%), see appendix 3 .

\section{Changes in position, competencies, and impact variables by predictor variable}

Graduates with a medical doctor background or other additional degree appear to be more likely to change leadership after graduation $(p<0.001)$. Candidates graduating from HSPH, SPHUWC or UMST appear to be less likely to change leadership than graduates from other institutes, see appendix 4, table 6. Graduates with an additional degree appear to be somewhat more likely to change technical position. Graduates from HSPH, SPHFU or UMST appear to be less likely to change technical position than graduates from other institutes, see appendix 4 table 7. Graduates with an additional degree appear to be more likely to switch to a position involving more responsibility and graduates from INSP and KIT appear to be more likely to switch to a position involving more responsibility than graduates from other institutes see appendix 4, table 8 . 
Not unexpectedly, respondents who graduated fairly recently are less likely to have had an increase in remuneration; on average, they have been on the job market for less time than candidates who graduated before 2008. Men appear to be more likely to have an increase in remuneration than women $(p=0.005)$, and graduates from HSPH, SPHFU or UMST appear to be somewhat less likely to have an increase in remuneration, see appendix 4, table 9.

Recent graduates appear to be less likely to have switched employer than respondents who graduated before 2008. Furthermore, graduates from HPSH and SPHFU appear to be somewhat less likely to switch to another employer than graduates from other institutes, see appendix 4, table 10.

Institutional differences were found with regard to MPH contribution to change in leadership, $F(5,303)=16.217, p<.001, \eta^{2}=.211$, change in technical position, $F(5,303)$ $=19.762, p<.001, \eta^{2}=.237$, increase in remuneration, $F(5,303)=15.822, p<.001, \eta^{2}=$ .196 , and a change in employer, $F(5,303)=9.983, p<.001, \eta^{2}=.182$. With regard to contribution to change in leadership and contribution to change in technical position, graduates from KIT, INSP and SPHUWC gave significantly higher responses than did graduates from HSPH, SPHFU and UMST. With regard to MPH contributing to change in remuneration, graduates from KIT and SPHUWC gave significantly higher responses than did graduates from the other four institutions. Finally, with regard to attribution to change in employer, graduates from KIT, SPHUWC and UMST gave higher responses than respondents from HSPH, SPHFU and INSP. No other statistically significant predictor variables were found.

Institution also contributed significantly to differences between candidates in reported application of acquired competencies, $F(5,397)=13.178, p<.001, \eta^{2}=.166$, with graduates from KIT, INSP and SPHUWC responding significantly higher than graduates from HSPH, SPHFU and UMST. Besides, graduates with a medical doctor background responded significantly higher than graduates without such a background, $F(1$, 397 ) $=8.931, p=.003, \eta^{2}=.022$. The same group of institutions (KIT, INSP and SPHUWC $), F(5,376)=14.286, p<.001, \eta^{2}=.160$, and medical doctor background, $F(1$, $376)=10.278, p=.001, \eta^{2}=.027$, significantly contributed to differences in performance at the workplace, with graduates from SPHUWC, INSP and KIT giving significantly higher ratings than graduates from HSPH, SPHFU and UMST.

Institution where graduates studied also explained part of] the differences between candidates in increased impact on society, $F(5,403)=11.435, p<.001, \eta^{2}=.124$, with graduates from KIT and SPHUWC responding somewhat higher than graduates from other institutions. Furthermore, graduates with an additional degree rated impact higher than graduates without an additional degree, $F(1,403)=4.681, p=.031, \eta^{2}=$ .011.

Finally, split-plot ANOVA suggests that, for all institutions together, the MPH program contributed slightly more to application of competencies to graduates' performance at the workplace than to their contribution to society, $F(1,373)=13.863, p<$ 
$.001, \eta^{2}=.036$. However, significant differences between institutions were found with regard to this trend, $F(5,373)=6.288, p<.001, \eta^{2}=.078$. A closer look within institutions reveals that this trend is statistically significant in $\operatorname{HSPH}, F(1,108)=31.738, p<$ $.001, \eta^{2}=.227$, SPHFU, $F(1,59)=4.230, p=.044, \eta^{2}=.067$ and INSP, $F(1,60)=18.465, p$ $<.001, \eta^{2}=.235$, but not in SPHUWC or UMST. Finally, in KIT the trend appears to be reversed in that the difference is not statistically significant, $F(1,72)=3.561, p=.063$, $\eta^{2}=.047$.

\section{Discussion}

Our study across six MPH programs is the first study that asked graduates for attribution to the MPH program with regard to competencies and impact variables. Our study reports on one of the highest numbers of graduates of Masters in health and health care $(n=445)$; the highest was 478 ; response rates reported were similar (18).

The study shows that after graduation, graduates worked less in clinics and district health departments and moved to international NGOs and research institutes. The change of work of graduates is similar to that reported by others $(19,29,31)$. Possibly, the high number of changes to "other" workplaces indicates a move to centers of disease control, which was not differentiated in the questionnaire.

In contrast to the reported brain drain of higher educated health professionals (32, $33,34)$, only $5 \%$ of the graduates left their home country and of these, $7 / 24$ left to work in a high income country; the other 17/24 left their country to work in their region of origin. Only 5 respondents, who had substantial experience in LMIC, came from high income countries.

Though traditionally medical doctors enrolled for an $\mathrm{MPH}$, a wide range of different educational backgrounds are represented such as a Bachelor of Public Health, nursing, dentistry and social sciences (35).

As for career and leadership, a large proportion of graduates changed their leadership position, technical position, acquired new responsibilities and increased their remuneration and attributed these changes to the MPH program. In other studies change in leadership, technical position or new responsibilities have been reported, however in those studies it was not clear whether these changes occurred due to gaining seniority or other factors $(19,21,29,34,36-41)$. Richardson in 2008 was the only one who asked about satisfaction with professional skills and professional status and the contribution of the program, in this case occupational therapy, to that satisfaction (20). A higher salary was also reported by Bradley (2000), Gill (2005), Ruth (2006), Drennan (2008) $(39,41-43)$ but attribution was unclear.

An additional degree as well as graduation from specific institutions positively influenced change in leadership, technical position and more responsibility; a medical degree positively influenced change in leadership. As for the institutions, having gradu- 
ated from INSP, SPHUWC or KIT seemed to be more beneficial to someone's career in terms of change in leadership, technical position and remuneration. Having graduated from INSP or KIT positively influenced being assigned more responsibility. As the contexts, countries and programs are so different, it is difficult to surmise what might be the reason for the differences between the graduates of these institutions. In other studies, i.e. in the USA, gender influenced increase in remuneration; this was the case in our study as well (42).

A high proportion, about a third, undertook further studies other than short courses. A high proportion had completed their PhD (9\%), this might result from the time lapse between graduation and the study; others indicated that they were in the process of studying towards a $\operatorname{PhD}(20,34,41,44)$. Other studies reported also graduates undertaking further studies $(20,21,37,41,42)$.

In relation to the application of competencies, almost half of the graduates stated that the MPH program contributed substantially to the application of public health competencies, though with large variations between institutions. Specifically public health analytical competencies as well as leadership, context sensitive and planning and management competencies were mentioned. Other studies reported enhanced job skills and performance (45), a range of public health skills or international health competencies $(29,46)$. A number of studies reported specific skills such as management $(36,37)$. A number of studies reported generic competencies such as critical reflection and critical thinking, which this study did not explore $(21,47-53)$. Policy development competencies were the least mentioned, which may arise from, for example, the place of work, the degree of emphasis by specific MPH programs or the different processes of policy making.

As regards impact on the workplace, graduates attributed the enablement by the MPH program to impact on the workplace between $60 \%-20 \%$ for specific impact variables, with a large difference between institutions. Importantly graduates attributed, for example, Enablement in writing a research proposal and Reporting/ making recommendations on population health status, as this is what would be expected from a public health professional $(54,55)$. The diverse range of areas of work (management, research, policy, teaching) might contribute to the fact that graduates reported in a range of between $38 \%$ - $14 \%$ that each of the competencies was not used/ or not part of their work $(56,57)$. The highest reported variable not used or not part of their work was Contributed to writing a published chapter of a book, which in hindsight might have been too high an expectation. Other studies seldom asked for impact on the workplace, or asked it only qualitatively, while only 2 studies reported quantitatively and/or attribution $(20,22)$.

Concerning impact on society, graduates reported that the MPH program enabled them substantially to impact on society with variables rated from $39 \%$ to $17 \%$ for the 10 defined variables, with large ranges between institutions. Influencing better understanding of public health and Contributing equitable access to quality services are both 
important achievements in public health. Only 2 studies reported impact on society (20, 22 ) and this study was the first which looked at defined impact. Though impact on society through higher educated professionals is very difficult to measure, because of many influencing factors before, during and after the MPH program, the results give a good indication on what impact the graduates felt they did contribute.

\section{Limitations}

Self-reporting measures are easy to administer simultaneously at different locations, they are relatively easy to subject to quantitative analysis, they are inexpensive and are less time demanding than testing and assessment $(24,26)$. However, self-reported measures might be prone to biases such as an overly positive (i.e. loyalty of graduates to their MPH program) or exaggerated modesty, vagueness and ambiguities of questions and a tendency to give consistent evaluations across a set of specific items (24, 26). In this study the underlying factors for change in leadership and new responsibilities were not studied. It might be that those people who have potential become a leaders/managers have chosen MPH as a relevant training program to prepare for a potential higher position. On the other hand, people trained as MPH may show to hold competencies that are necessary for a leadership position, or are supposed to have those competencies because of the degree, so they tend to be promoted. Next to selfreporting as such, the use of different 'yardsticks' across programs and countries (anchoring), culture or different programs having a different emphasis might result in bias $(15,25,58)$. However the competencies and impact variables had been validated across countries before the study (28). In order to reduce the risk of poor anchoring as well as tendency to avoid extreme responses, the scales were kept as small as possible.

Using an online survey tool may have had some influence on completeness. Graduates may have left particular questions unanswered because of loss of connectivity with the institution or the online tool before or during the completion of the survey. Though the relatively low response rate influences the results of the study, as those who answered may have been more positive, the response rate of this study did not differ much from the response rate of other alumni surveys (28). Efforts were exerted to find as many graduates as possible and to encourage them to fill in the survey.

The questionnaire could have been constructed differently by mixing items to reduce the halo error, however that could have negatively impacted on the userfriendliness of the questionnaire. In order to increase validity, the questionnaire was pretested with graduates from all MPH programs and adjusted. The fact that the MPH program contributed less to the impact factors on society than the impact factors on the workplace can be seen as a measure of predictive validity as one would expect that graduates have less influence on society than on their workplace. Other methods, as mentioned before such as semi-or unstructured interviews could also have been used. This study is part of a larger research project, in which next to the alumni survey, per 
school 10 graduates, their peers and their supervisors were interviewed. These results are being analysed.

\section{Conclusion}

This is the first transnational study on outcome and impact of MPH programs and the first transnational study on Master's in health and health care. From this study it can be concluded that according to graduates, the MPH programs contribute to improvements in graduates' careers and to leadership building in public health. The MPH programs contributed substantially to the application of public health analytical competencies as well as leadership, context specific and planning and management competencies. Graduates reported substantial contribution by the MPH program on impact variables on the workplace such as: development of a research proposal and reporting on population health needs. The contribution to impact variables on society, such as "Contributing to equitable access to quality services", was less. The differences between the MPH programs from different countries warrant further study in order to find explanations. It is argued that this study makes some progress in problematizing and measuring impact of MPH programs for the first time. It is also concluded that the follow up of graduates as done in this study is an efficient and practical way to reach a large number of respondents across countries and could be readily replicated. The results of the indepth study will still follow. Further strategies to enhance understanding of impact might be focus group discussions with graduates, though more costly and logistically difficult, or an employer survey. Finally, the findings could, and will be in the cases of the participating institutions, used to steer curriculum reform and innovation. For example "policy development competencies" were assessed as lowly attributed to the MPH program, so curricula could include knowledge and skills building around analysing, evaluating and developing policy options for public health programs. 


\section{Appendix 1}

\section{ICHD/ Masters in Public Health Alumni Survey}

\section{December 2012}

\section{Dear graduate,}

Thank you very much for your consent to participate in this study of the application of Public Health competencies, as well as the possible outcome and impact of the Masters of Public Health program. The higher education institutions that run these programs are located across a range of countries and include: Fudan School of Public Health, Shanghai, China, Prof Qian Xu; Hanoi School of Public Health, Vietnam, Prof Nguyen Thi Huong, vice-dean National Institute of Public Health, Mexico, Dr Laura Magana Academic dean; University of the Western Cape, South Africa, Ms Lucy Alexander, Senior Academic Coordinator; Sudan through the Ministry of Health, Dr Nazar El Faki, Director Policy and Planning for Human resources for Health and the Royal Tropical Institute, Amsterdam, the Netherlands, Dr Prisca Zwanikken, Area Leader Education.

You will be asked questions about your work situation, the competencies that you applied, the changes that you possibly made in your workplace and the facilitating and hindering factors influencing this. The survey will take you approximately 25 minutes to fill in.

We will update you on the results of the survey through email.

Once again: thank you very much!

On behalf of the Research Team,

Rinia Sahebdin alumni officer

\begin{tabular}{|c|c|c|}
\hline Number & Question & Answer \\
\hline 0. & $\begin{array}{l}\text { I confirm that I understood the consent form and } \\
\text { agree to participate in this survey. }\end{array}$ & $\begin{array}{l}\square \text { Yes } \\
\square \text { No (please don't proceed with the ques- } \\
\text { tions until you can state yes) }\end{array}$ \\
\hline \multicolumn{3}{|c|}{ 1. DEMOGRAPHIC INFORMATION } \\
\hline 1.1 & Sex & $\begin{array}{l}\square \text { Female } \\
\square \text { Male }\end{array}$ \\
\hline 1.2 & In which year were you born? & $\ldots$ \\
\hline 1.3 & Country of origin & 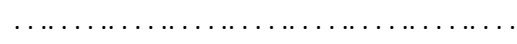 \\
\hline 1.4 & Country where you currently work & 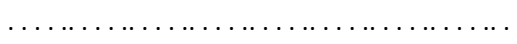 \\
\hline 1.5 & $\begin{array}{l}\text { What was your professional education, before you } \\
\text { started the MPH program? } \\
\text { (Please select one option which is most appropriate } \\
\text { to you) }\end{array}$ & $\begin{array}{l}\square \text { Medical Doctor } \\
\square \text { Nurse/Midwife } \\
\square \text { Nurse } \\
\square \text { Pharmacist } \\
\square \text { Social Scientist } \\
\square \text { Dentist } \\
\square \text { Bachelor of Public Health }\end{array}$ \\
\hline
\end{tabular}




\begin{tabular}{|c|c|c|}
\hline & & $\square$ Other (please specify):.. . . . . . . . ... \\
\hline 1.6 & $\begin{array}{l}\text { Did you study full time or part-time in the MPH } \\
\text { program? }\end{array}$ & $\begin{array}{l}\square \text { Full time } \\
\square \text { Part-time }\end{array}$ \\
\hline 1.7 & In which year did you start your MPH? & \\
\hline 1.8 & In which year did you complete your MPH? & $\ldots \ldots \ldots \ldots$ \\
\hline 1.9 & $\begin{array}{l}\text { Number of years of work experience between your } \\
\text { first degree and the start of your MPH program }\end{array}$ & $\ldots \ldots \ldots \ldots \ldots$ Years \\
\hline 1.10 & $\begin{array}{l}\text { What best describes your last place of employment } \\
\text { BEFORE starting the MPH course? }\end{array}$ & $\begin{array}{l}\square \text { National Ministry of Health } \\
\square \text { Regional/Provincial Health Department } \\
\square \text { District Health Department } \\
\square \text { Hospital or Clinic } \\
\square \text { College/University } \\
\square \text { Research Institute } \\
\square \text { International NGO } \\
\square \text { National NGO } \\
\square \text { Local NGO } \\
\square \text { Not employed } \\
\square \text { Other (please specify)............... }\end{array}$ \\
\hline 1.11 & $\begin{array}{l}\text { What best describes your main areas of work BEFORE } \\
\text { starting the MPH. } \\
\text { (Please select a maximum of } 3 \text { options which are } \\
\text { most appropriate to you) }\end{array}$ & $\begin{array}{l}\square \text { Clinical care/service } \\
\square \text { Disease prevention or control } \\
\square \text { Rehabilitation } \\
\square \text { Health promotion (including health educa- } \\
\text { tion, communication, social marketing, etc) } \\
\square \text { Teaching/training } \\
\square \text { Research } \\
\square \text { Information management } \\
\square \text { Public Health management } \\
\square \text { Program/project management } \\
\square \text { Public communication and involvement } \\
\text { with stakeholders } \\
\square \text { Policy process involvement } \\
\square \text { Other (please specify):............... }\end{array}$ \\
\hline \multicolumn{3}{|c|}{ 2. CURRENT EMPLOYMENT } \\
\hline 2.1 & $\begin{array}{l}\text { Number of years of public health related work expe- } \\
\text { rience since your MPH graduation }\end{array}$ & $\ldots \ldots \ldots$ years \\
\hline 2.2 & $\begin{array}{l}\text { After graduating from the MPH, did you change your } \\
\text { leadership level in the management system? }\end{array}$ & $\begin{array}{l}\square \text { No } \rightarrow \text { Please go to Question } 2.4 \\
\square \text { Yes } \rightarrow \text { Please go to Question } 2.3\end{array}$ \\
\hline \multirow[t]{2}{*}{2.3} & \multicolumn{2}{|c|}{$\begin{array}{l}\text { Please rate the contribution of the MPH graduation to your change of leadership level: } \\
\text { (Please select ONE number that most applies to your case) }\end{array}$} \\
\hline & Insignificant Little Significance Moderate Significa & Very significant \\
\hline 2.4 & $\begin{array}{l}\text { After graduating from the MPH, did you change your } \\
\text { technical position or area of focus (Your function but } \\
\text { at the same level)? }\end{array}$ & $\begin{array}{l}\square \text { Yes } \rightarrow \text { Please go to Question } 2.5 \\
\square \text { No } \rightarrow \text { Please go to Question } 2.6\end{array}$ \\
\hline 2.5 & \multicolumn{2}{|c|}{$\begin{array}{l}\text { Please rate the contribution of the MPH graduation to your change in technical position or area of } \\
\text { focus. }\end{array}$} \\
\hline
\end{tabular}




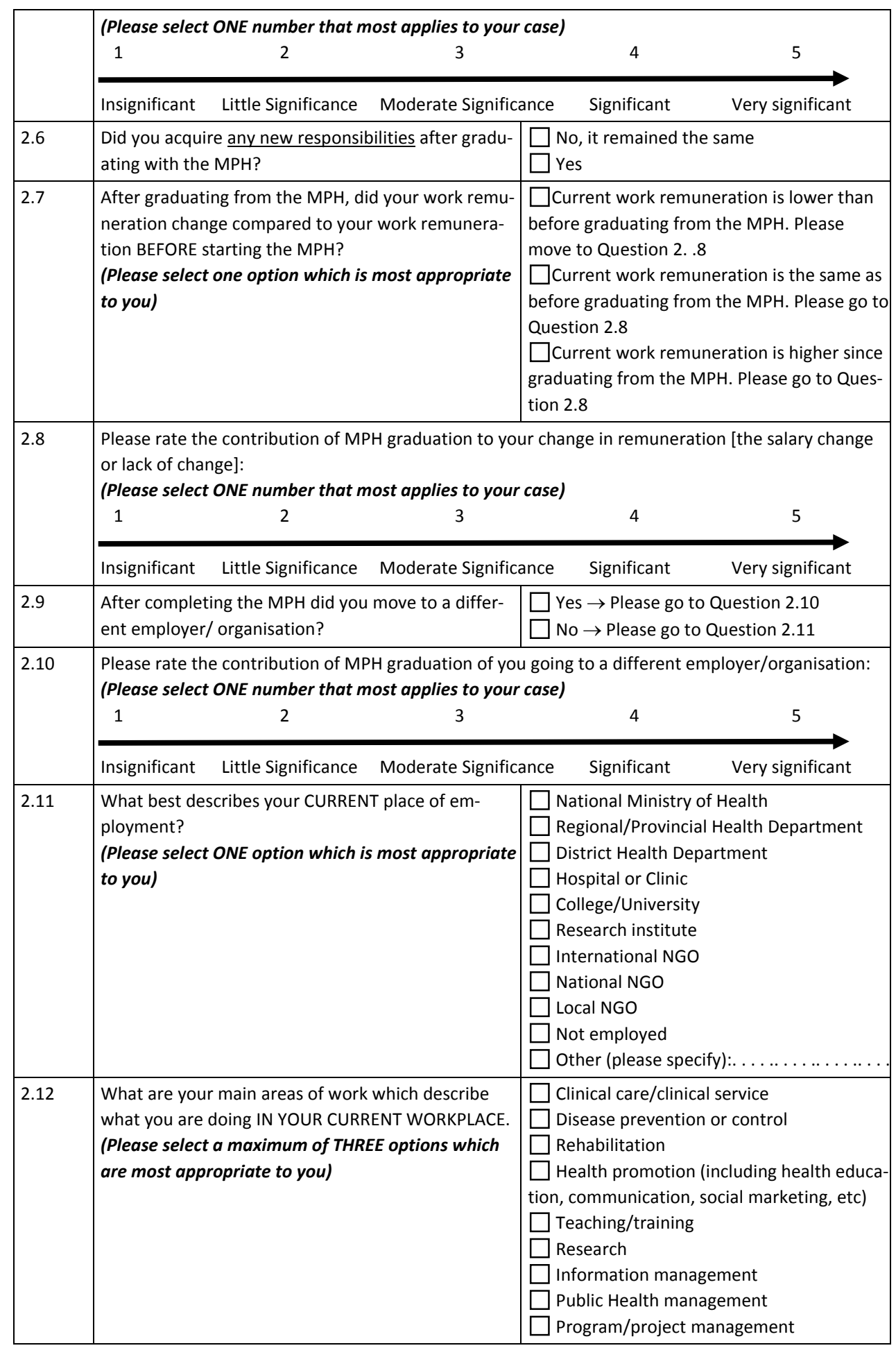




\begin{tabular}{|c|c|c|}
\hline & & $\begin{array}{l}\square \text { Public communication and involvement } \\
\text { with stakeholders } \\
\square \text { Policy process involvement } \\
\square \text { Other (please specify):. . . . . . . . . . }\end{array}$ \\
\hline \multicolumn{3}{|c|}{ 3. WORK-RELATED TRAINING } \\
\hline 3.1 & $\begin{array}{l}\text { Since graduating from the MPH, have you completed } \\
\text { any additional certificated work-related training for } \\
\text { TWO weeks or longer? }\end{array}$ & $\begin{array}{l}\square \text { No } \\
\square \text { Yes. Please specify the number of training } \\
\text { courses attended } \ldots \ldots \ldots \ldots \ldots \ldots \ldots \ldots \ldots\end{array}$ \\
\hline 3.2 & $\begin{array}{l}\text { Have you embarked on any further degree or diplo- } \\
\text { ma studies (qualifications other than short training } \\
\text { courses)? }\end{array}$ & $\begin{array}{l}\square \text { No } \rightarrow \text { Please go to Question } 3.4 \\
\square \text { Yes } \rightarrow \text { Please go to Question } 3.3\end{array}$ \\
\hline 3.3 & $\begin{array}{l}\text { Please mark as many degrees/diplomas as you have } \\
\text { been awarded after completing your } \mathrm{MPH}\end{array}$ & $\begin{array}{l}\square \text { Diploma } \\
\square \text { Postgraduate Diploma } \\
\square \text { Masters degree } \\
\square \text { PhD } \\
\square \text { Post doctorate award } \\
\square \text { Other (Please specify)... . .... }\end{array}$ \\
\hline 3.4 & $\begin{array}{l}\text { Do you plan to embark on any further studies for a } \\
\text { degree/diploma (qualifications other than short } \\
\text { training courses)? }\end{array}$ & $\begin{array}{l}\square \text { No } \\
\square \text { Yes }\end{array}$ \\
\hline
\end{tabular}




\section{Please rate to what extent the MPH program enabled you to apply specific public health competencies in your work?}

\section{TABLE A: KEY COMPETENCIES ANTICIPATED IN A MPH GRADUATE}

\begin{tabular}{|c|c|c|}
\hline $\begin{array}{l}\text { CATEGORY OF COM- } \\
\text { PETENCY }\end{array}$ & DETAILED COMPETENCIES & $\begin{array}{l}\text { Please select ONE number for } \\
\text { each sub-question that most } \\
\text { applies to your case. } \\
\text { The MPH degree has enabled } \\
\text { me to apply this competency: } \\
\text { 1. No- I don't use it/ It is not part } \\
\text { of my work } \\
\text { 2. Not due to the MPH } \\
\text { 3. MPH enabled me a little to } \\
\text { apply this competency } \\
\text { 4. MPH enabled me substantial- } \\
\text { ly to apply this competency }\end{array}$ \\
\hline \multirow[t]{4}{*}{$\begin{array}{l}\text { 1. Public Health sci- } \\
\text { ence skills including } \\
\text { analytical assessment } \\
\text { competencies }\end{array}$} & $\begin{array}{l}\text { 1. Applies the basic Public Health sciences (including } \\
\text { but not limited to biostatistics, epidemiology, envi- } \\
\text { ronmental health services, health services admin- } \\
\text { istration and social and behavioral health sciences) } \\
\text { to Public Health policies and programs }\end{array}$ & 1234 \\
\hline & $\begin{array}{l}\text { 2. Appraises scope, function and role of Public } \\
\text { Health in relation to local context, health system } \\
\text { and other social sectors }\end{array}$ & 1234 \\
\hline & $\begin{array}{l}\text { 3. Assesses population health status and identifies } \\
\text { population health problems, risk factors, related } \\
\text { Social Determinants, and determines needs }\end{array}$ & 1234 \\
\hline & $\begin{array}{l}\text { 4. Commissions and critically interprets research } \\
\text { findings and/or develops protocol and collects, } \\
\text { analyses and synthesizes reliable and valid data } \\
\text { using qualitative and quantitative methods }\end{array}$ & 1234 \\
\hline \multirow[t]{4}{*}{$\begin{array}{l}\text { 2.Policy process } \\
\text { competencies }\end{array}$} & $\begin{array}{l}\text { 5. Analyzes and evaluates policy options and deter- } \\
\text { mines feasibility for Public Health policies/ programs } \\
\text { in diverse community contexts, using appraisal of } \\
\text { evidence }\end{array}$ & 1234 \\
\hline & $\begin{array}{l}\text { 6. Participates in developing context sensitive } \\
\text { policies and strategic plans and translates them into } \\
\text { action }\end{array}$ & 1234 \\
\hline & $\begin{array}{l}\text { 7. Understands and contributes to developing and } \\
\text { using mechanisms to monitor and evaluate Public } \\
\text { Health policies and regulations }\end{array}$ & 1234 \\
\hline & $\begin{array}{l}\text { 8. Contributes to advocacy of new and existing } \\
\text { health policies to the public health and other sec- } \\
\text { tors }\end{array}$ & 1234 \\
\hline $\begin{array}{l}\text { 3. Communication } \\
\text { competencies }\end{array}$ & $\begin{array}{l}\text { 9. Communicates concisely in writing and orally, in } \\
\text { person and through electronic means with linguistic } \\
\text { and cultural proficiency and appropriateness }\end{array}$ & 1234 \\
\hline
\end{tabular}




\begin{tabular}{|c|c|c|}
\hline & $\begin{array}{l}\text { 10. Facilitates and integrates input to Public Health } \\
\text { policy and programs from a wide range of individual } \\
\text { and organizational stakeholders }\end{array}$ & 1234 \\
\hline & $\begin{array}{l}\text { 11. Uses a variety of culturally appropriate ap- } \\
\text { proaches to disseminate Public Health information } \\
\text { with consideration to ethical and confidential issues }\end{array}$ & 1234 \\
\hline \multirow[t]{2}{*}{$\begin{array}{l}\text { 4. Context sensitive } \\
\text { Competencies }\end{array}$} & $\begin{array}{l}\text { 12. Analyzes the role of gender, cultural, social, } \\
\text { economic, political and behavioral factors in the } \\
\text { accessibility, availability, acceptability and delivery } \\
\text { of Public Health services and programs }\end{array}$ & 1234 \\
\hline & $\begin{array}{l}\text { 13. Incorporates a Social Determinants of Health } \\
\text { approach to Public Health needs }\end{array}$ & 1234 \\
\hline \multirow[t]{3}{*}{$\begin{array}{l}\text { 5.Community and } \\
\text { inter-sectoral compe- } \\
\text { tencies }\end{array}$} & $\begin{array}{l}\text { 14. Assesses and engages community actors and } \\
\text { communities and their linkages and relationships } \\
\text { that affect health in diverse social and cultural } \\
\text { situations }\end{array}$ & 1234 \\
\hline & $\begin{array}{l}\text { 15. Collaborates in community-based participatory } \\
\text { efforts }\end{array}$ & 1234 \\
\hline & $\begin{array}{l}\text { 16. Develops and maintains partnerships with key } \\
\text { stakeholders, including from different sectors }\end{array}$ & 1234 \\
\hline \multirow[t]{3}{*}{$\begin{array}{l}\text { 6. Planning and man- } \\
\text { agement competen- } \\
\text { cies }\end{array}$} & $\begin{array}{l}\text { 17. Uses evidence and good practice to address } \\
\text { Public Health policy, planning and management } \\
\text { issues }\end{array}$ & 1234 \\
\hline & $\begin{array}{l}\text { 18. Plans, implements, monitors and evaluates } \\
\text { Public Health interventions, programs, resources, } \\
\text { services including input, process, outcome and } \\
\text { impact }\end{array}$ & 1234 \\
\hline & $\begin{array}{l}\text { 19. Prepares and contributes to manage and evalu- } \\
\text { ate Public Health information systems, human, } \\
\text { financial and logistic resources }\end{array}$ & 1234 \\
\hline \multirow[t]{4}{*}{$\begin{array}{l}\text { 7. Leadership and } \\
\text { systems thinking } \\
\text { competencies }\end{array}$} & $\begin{array}{l}\text { 20. Demonstrates leadership as a manager and in } \\
\text { team efforts, and is able to lead in Public Health } \\
\text { emergencies }\end{array}$ & 1234 \\
\hline & $\begin{array}{l}\text { 21. Demonstrates professional judgment and ethical } \\
\text { standards in data handling and addressing Public } \\
\text { Health issues and diverse opinions }\end{array}$ & 1234 \\
\hline & $\begin{array}{l}\text { 22. Leads with applying the understanding of the } \\
\text { interconnectedness and dynamic interactions of the } \\
\text { Public Health system }\end{array}$ & 1234 \\
\hline & $\begin{array}{l}\text { 23. Continues life-long learning and professional } \\
\text { development, and stimulates team to do so }\end{array}$ & 1234 \\
\hline
\end{tabular}




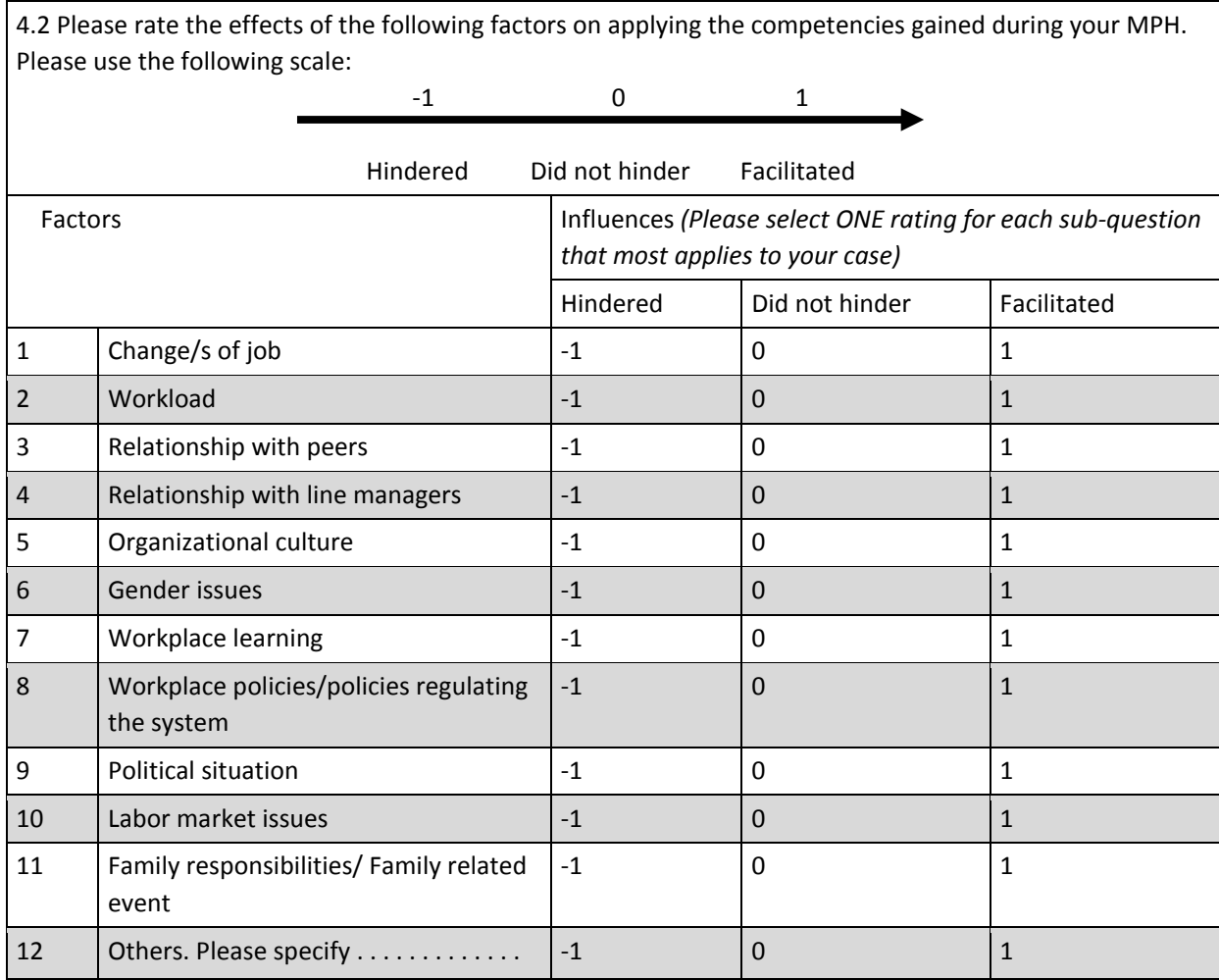

\section{Please rate to what extent the MPH program enabled you to impact on your work-} place?

Please note that, depending on your work or the context of your work or workplace, it is possible that not all variables apply to you.

\begin{tabular}{|l|l|}
\hline TABLE B: ANTICIPATED IMPACT VARIABLES AT THE WORKPLACE & $\begin{array}{l}\text { Please rate for each sub-question to } \\
\text { what extent the MPH program } \\
\text { enabled you to impact on your } \\
\text { workplace } \\
\text { 1. Not applicable to me/ my work- } \\
\text { place } \\
\text { 2. My impact is not attributable to } \\
\text { the MPH. } \\
\text { 3. The MPH enabled me a little to } \\
\text { impact on my workplace. } \\
4 . \text { The MPH enabled me substantially } \\
\text { to impact on my workplace }\end{array}$ \\
\hline 1. Created evidence (primary or secondary) for decision-making & 1234 \\
\hline 2. Developed a study or a research proposal & 1234 \\
\hline $\begin{array}{l}\text { 3. Reported and made recommendations on population health status } \\
\text { or needs }\end{array}$ & 1234 \\
\hline
\end{tabular}




\begin{tabular}{|c|c|}
\hline 4. Contributed to change in policy at workplace where needed & 1234 \\
\hline $\begin{array}{l}\text { 5. Contributed to change in policy at one level higher than work institu- } \\
\text { tion }\end{array}$ & 1234 \\
\hline $\begin{array}{l}\text { 6. Participated and influenced working committees for program design } \\
\text { or policy formulation at provincial, national or international level }\end{array}$ & 1234 \\
\hline 7. Published or posted in popular (including electronic) media & 1234 \\
\hline 8. Made presentations at conferences & 1234 \\
\hline 9. Published in peer reviewed publications & 1234 \\
\hline 10. Contributed to writing a published chapter of a book & 1234 \\
\hline $\begin{array}{l}\text { 11. Tutored or taught Public Health professionals, trainees or students } \\
\text { in the community }\end{array}$ & 1234 \\
\hline $\begin{array}{l}\text { 12. Developed, reviewed or commissioned educational or Health Pro- } \\
\text { motion media and materials }\end{array}$ & 1234 \\
\hline $\begin{array}{l}\text { 13. Planned or implemented community health education courses and } \\
\text { workshops }\end{array}$ & 1234 \\
\hline $\begin{array}{l}\text { 14. Intervened or worked with a Social Determinants of Health Frame- } \\
\text { work in a way that promotes equity and/or is pro-poor }\end{array}$ & 1234 \\
\hline $\begin{array}{l}\text { 15. Collaborated/networked/developed partnerships successfully with } \\
\text { other departments than health }\end{array}$ & 1234 \\
\hline $\begin{array}{l}\text { 16. Initiated, sustained and evaluated projects with community partici- } \\
\text { pation }\end{array}$ & 1234 \\
\hline $\begin{array}{l}\text { 17. Planned and implemented Public Health interventions, programs or } \\
\text { policies based on consultation with stakeholders and using evidence } \\
\text { and best practice }\end{array}$ & 1234 \\
\hline $\begin{array}{l}\text { 18. Implemented performance improvement strategies in response to } \\
\text { monitoring and evaluation findings }\end{array}$ & 1234 \\
\hline 19. Contributed to improvements in human resource management & 1234 \\
\hline 20. Contributed to improving regular working procedures & 1234 \\
\hline $\begin{array}{l}\text { 21. Instrumental in initiating a change within the workplace, or at some } \\
\text { level beyond }\end{array}$ & 1234 \\
\hline $\begin{array}{l}\text { 22. Contributed to addressing the determinants of health e.g. through } \\
\text { planning processes, resource allocation or research }\end{array}$ & 1234 \\
\hline 23. Raised a project grant & 1234 \\
\hline 24. Contributed to reputation-building of workplace & 1234 \\
\hline 25. Participated in national and international collaboration & 1234 \\
\hline 26. Participated in building a successful partnership & 1234 \\
\hline
\end{tabular}




\section{Please rate to what extend the MPH program enabled you to impact on society.}

Please note that, depending on your work or the context of your work, workplace or society, it is possible that not all variables apply to you.

\begin{tabular}{|c|c|}
\hline TABLE C: IMPACT VARIABLES ON SOCIETY & $\begin{array}{l}\text { Please rate for each sub-question to } \\
\text { what extend the MPH degree has } \\
\text { enabled you to impact on society } \\
\text { 1. Not applicable to me } \\
\text { 2. My impact is not attributable to } \\
\text { the MPH } \\
\text { 3. The MPH enabled me a little to } \\
\text { impact on society } \\
\text { 4. The MPH enabled me substantial- } \\
\text { ly to impact on society }\end{array}$ \\
\hline 1. Contributed to changes in policy or strategy in general & 1234 \\
\hline $\begin{array}{l}\text { 2. Contributed to changed guidelines, regulations, ordinances beyond } \\
\text { the workplace }\end{array}$ & 1234 \\
\hline $\begin{array}{l}\text { 3. Contributed to influencing communities, organisations, health sector } \\
\text { and other sectors than health }\end{array}$ & 1234 \\
\hline $\begin{array}{l}\text { 4. Contributed to equity/pro-poor orientation towards health access at } \\
\text { all levels }\end{array}$ & 1234 \\
\hline $\begin{array}{l}\text { 5. Contributed to changes in resource allocation for interventions, and } \\
\text { research, orientated towards equity and addressing the determinants } \\
\text { of health }\end{array}$ & 1234 \\
\hline 6. Contributed to equitable access to quality services & 1234 \\
\hline $\begin{array}{l}\text { 7. Contributed to improved Public Health in specific areas related to } \\
\text { work context, e.g. improved utilization of services }\end{array}$ & 1234 \\
\hline 8. Contributed to increased resource mobilization for Public Health & 1234 \\
\hline $\begin{array}{l}\text { 9. Contributed to increased resource mobilization for disadvantaged } \\
\text { groups }\end{array}$ & 1234 \\
\hline $\begin{array}{l}\text { 10. Influenced better understanding of Public Health measures } \\
\text { amongst general population }\end{array}$ & 1234 \\
\hline
\end{tabular}

Once again: thank you very much for your time! 


\section{Appendix 2}

Table 4: The extent to which the MPH program enabled the graduate to impact on the workplace $(N=418)^{*}$

\section{Impact variables at workplace / attribution to MPH program}

MPH enabled me MPH enabled me Not due Not use/ substantially to a little to impact to MPH not part of impact on my on my workplace (\%) my work workplace

(\%)

(\%)

1. Created evidence (primary or secondary) for

(\%)

decision-making.

2. Developed a study or a research proposal.

37.5

60.4

27.7

4.3

7.6

3. Reported and made recommendations on popu-

43.3

35.7

6.2 lation health status or needs.

4. Contributed to change in policy at workplace

39.0

11.3 where needed.

5. Contributed to change in policy at one level

15.7 28.5 higher than work institution.

6. Participated and influenced working committees for program design or policy formulation at provincial, national or international level.

7. Published or posted in popular (including electronic) media.

8. Made presentations at conferences.

41.0

31.0

14.6

9. Published in peer reviewed publications.

26.5

10. Contributed to writing a published chapter of a

19.8

26.5

15.7 book.

11. Tutored or taught public health professionals, trainees or students in the community.

12. Developed, reviewed or commissioned educational or Health Promotion media and materials.

13. Planned or implemented community health education courses and workshops.

14. Intervened or worked with a Social Determinants of Health Framework in a way that promotes equity and/or is pro-poor.

15. Collaborated/networked/developed partnerships successfully with other departments than health.

16. Initiated, sustained and evaluated projects with community participation.

17. Planned and implemented Public Health interventions, programs or policies based on consultation with stakeholders and using evidence and best practice.

18. Implemented performance improvement strat- 
egies in response to monitoring and evaluation findings.

19. Contributed to improvements in human re-

13.1

source management.

20. Contributed to improving regular working procedures. workplace, or at some level beyond.

22. Contributed to addressing the determinants of health e.g. through planning processes, resource allocation or research.

23. Raised a project grant.

24. Contributed to reputation-building of workplace.

25. Participated in national and international collaboration.

26. Participated in building a successful partnership (added)

*Missing: 27 


\section{Appendix 3}

Table 5:The extent to which the MPH program enabled the graduate to impact on society $(N=418)^{*}$

\begin{tabular}{|c|c|c|c|c|}
\hline $\begin{array}{l}\text { Impact variables on society/ attribution } \\
\text { to } \mathrm{MPH} \text { program }\end{array}$ & $\begin{array}{l}\text { MPH enabled me } \\
\text { substantially to } \\
\text { impact on society } \\
\text { (\%) }\end{array}$ & $\begin{array}{l}\text { MPH enabled me } \\
\text { a little to impact } \\
\text { on society } \\
(\%)\end{array}$ & $\begin{array}{l}\text { e Not due } \\
\text { to MPH } \\
\text { (\%) }\end{array}$ & $\begin{array}{l}\text { Not use/ } \\
\text { not part of } \\
\text { my work } \\
\text { (\%) }\end{array}$ \\
\hline $\begin{array}{l}\text { 1. Contributed to changes in policy or strategy in } \\
\text { general }\end{array}$ & 24.9 & 30.2 & 15.6 & 29.3 \\
\hline $\begin{array}{l}\text { 2. Contributed to changed guidelines, regulations, } \\
\text { ordinances beyond the workplace. }\end{array}$ & 17 & 38.8 & 14.5 & 29.7 \\
\hline $\begin{array}{l}\text { 3. Contributed to influencing communities, organi- } \\
\text { sations, health sector and other sectors than health. }\end{array}$ & 25.2 & 36.9 & 14.9 & 23 \\
\hline $\begin{array}{l}\text { 4. Contributed to equity/pro-poor orientation } \\
\text { towards health access at all levels. }\end{array}$ & 24.6 & 35.7 & 12.4 & 27.3 \\
\hline $\begin{array}{l}\text { 5. Contributed to changes in resource allocation for } \\
\text { interventions, and research, orientated towards } \\
\text { equity and addressing the determinants of health. }\end{array}$ & 25.7 & 31.8 & 14.4 & 28.1 \\
\hline $\begin{array}{l}\text { 6. Contributed to equitable access to quality ser- } \\
\text { vices. }\end{array}$ & 31.7 & 34.6 & 11 & 22.7 \\
\hline $\begin{array}{l}\text { 7. Contributed to improved Public Health in specific } \\
\text { areas related to work context, e.g. improved utiliza- } \\
\text { tion of services. }\end{array}$ & 30.2 & 36.7 & 12.7 & 20.4 \\
\hline $\begin{array}{l}\text { 8. Contributed to increased resource mobilization } \\
\text { for Public Health. }\end{array}$ & 27.2 & 29.1 & 14.3 & 29.4 \\
\hline $\begin{array}{l}\text { 9. Contributed to increased resource mobilization } \\
\text { for disadvantaged groups. }\end{array}$ & 31.1 & 30.4 & 13.9 & 24.7 \\
\hline $\begin{array}{l}\text { 10. Influenced better understanding of Public } \\
\text { Health measures amongst general population. }\end{array}$ & 39.3 & 36.5 & 7.1 & 17.1 \\
\hline
\end{tabular}

*Missing: 27 


\section{Appendix 4}

Tables 6-10: Changes in position by predictor variables, logistic regression

Tables 6-10 present the outcomes of logistic regression for change in leadership position (yes/no), switch in technical position (yes/no), switch to position involving more responsibility (yes/no), increase in remuneration (yes/no), change in employer (yes/no).

Table 6: Logistic regression for switch to leadership position ( $0=$ no, $1=y e s)$ : regression coefficients $(B)$ along with standard errors (SE), $p$-values, Odds Ratios $(O R)$ and confidence intervals $(\mathrm{Cl})$.

\begin{tabular}{llllll}
\hline Term & $B(S E)$ & $p$-value & $O R$ & \multicolumn{2}{l}{$95 \% \mathrm{Cl}$ for $O R$} \\
\cline { 5 - 6 } & & & & Lower & Upper \\
\hline Intercept & $1.076(0.216)$ & $<0.001$ & & \\
Medical doctor $^{1}$ & $0.801(0.247)$ & 0.001 & 2.229 & 1.373 & 3.617 \\
Additional degree $^{1}$ & $0.711(0.253)$ & 0.005 & 2.035 & 1.239 & 3.342 \\
HSPH $^{2}$ & $-1.455(0.273)$ & $<0.001$ & 0.233 & 0.137 & 0.399 \\
SPHUWC $^{2}$ & $-0.894(0.372)$ & 0.016 & 0.409 & 0.197 & 0.848 \\
UMST $^{2}$ & $-2.049(0.419)$ & $<0.001$ & 0.129 & 0.057 & 0.293 \\
\hline
\end{tabular}

${ }^{1}$ no $=0$, yes $=1 ;{ }^{2}$ compared to SPHFU, INSP and KIT which did not differ significantly from each other

Table 7: Logistic regression for switch to technical position ( $0=$ no, $1=y e s)$ : regression coefficients $(B)$ along with standard errors (SE), $p$-values, Odds Ratios $(O R)$ and confidence intervals $(\mathrm{CI})$.

\begin{tabular}{llllll}
\hline Term & $B(S E)$ & $p$-value & $O R$ & \multicolumn{2}{l}{$95 \% \mathrm{Cl}$ for OR } \\
\cline { 5 - 6 } & & & & Lower & Upper \\
\hline Intercept & $1.391(0.208)$ & $<0.001$ & & \\
Additional degree $^{1}$ & $0.575(0.248)$ & 0.021 & 1.776 & 1.092 & 2.889 \\
HSPH $^{2}$ & $-1.311(0.255)$ & $<0.001$ & 0.270 & 0.164 & 0.444 \\
SPHFU $^{2}$ & $-1.028(0.339)$ & 0.002 & 0.358 & 0.184 & 0.695 \\
UMST $^{2}$ & $-1.263(0.401)$ & 0.002 & 0.283 & 0.129 & 0.621 \\
\hline
\end{tabular}

${ }^{1}$ no $=0$, yes $=1 ;{ }^{2}$ compared to SPHUWC, INSP and KIT which did not differ significantly from each other 
Table 8: Logistic regression for switch to position involving more responsibility ( $0=$ no, $1=y e s)$ : regression coefficients $(B)$ along with standard errors $(S E), p$-values, Odds Ratios $(O R)$ and confidence intervals $(C I)$.

\begin{tabular}{llllll}
\hline Term & $B(S E)$ & $p$-value & $O R$ & \multicolumn{2}{l}{$95 \% \mathrm{Cl}$ for $O R$} \\
\cline { 5 - 6 } & & & & Lower & Upper \\
\hline Intercept & $3.033(0.461)$ & $<0.001$ & & \\
Additional degree $^{1}$ & $1.141(0.343)$ & 0.001 & 3.131 & 1.597 & 6.136 \\
HSPH $^{2}$ & $-1.971(0.502)$ & $<0.001$ & 0.139 & 0.052 & 0.372 \\
SPHFU $^{2}$ & $-2.967(0.528)$ & $<0.001$ & 0.051 & 0.018 & 0.145 \\
SPHUWC $^{2}$ & $-2.366(0.573)$ & $<0.001$ & 0.094 & 0.031 & 0.288 \\
UMST $^{2}$ & $-2.706(0.594)$ & $<0.001$ & 0.067 & 0.021 & 0.214 \\
\hline
\end{tabular}

${ }^{1}$ no $=0$, yes $=1 ;{ }^{2}$ compared to INSP and KIT which did not differ significantly from each other

Table 9: Logistic regression for increase in remuneration ( $0=$ no, $1=y e s)$ : regression coefficients $(B)$ along with standard errors $(S E), p$-values, Odds Ratios $(O R)$ and confidence intervals $(\mathrm{CI})$.

\begin{tabular}{llllll}
\hline Term & B $(S E)$ & $p$-value & $O R$ & \multicolumn{2}{l}{$95 \% \mathrm{Cl}$ for OR } \\
\cline { 5 - 6 } & & & Lower & Upper \\
\hline Intercept & $1.276(0.243)$ & $<0.001$ & & \\
Time of graduation $^{1}$ & $-0.636(0.226)$ & 0.005 & 0.529 & 0.340 & 0.825 \\
HSPH $^{2}$ & $-0.954(0.252)$ & $<0.001$ & 0.385 & 0.235 & 0.631 \\
SPHFU $^{2}$ & $-0.700(0.335)$ & 0.037 & 0.496 & 0.257 & 0.958 \\
UMST $^{2}$ & $-1.123(0.392)$ & 0.004 & 0.325 & 0.151 & 0.702 \\
Gender $^{3}$ & $0.608(0.217)$ & 0.005 & 1.836 & 1.199 & 2.811 \\
\hline
\end{tabular}

${ }^{1}$ 2005-2007=0, 2008-2010 $=1 ;{ }^{2}$ compared to SPHUWC, INSP and KIT which did not differ significantly from each other; ${ }^{3}$ woman $=0, \operatorname{man}=1$

Table 10: Logistic regression for switch to another employer $(0=$ no, $1=y e s)$ : regression coefficients $(B)$ along with standard errors (SE), $p$-values, Odds Ratios $(O R)$ and confidence intervals $(\mathrm{Cl})$.

\begin{tabular}{llllll}
\hline Term & $B(S E)$ & $p$-value & $O R$ & \multicolumn{2}{l}{$95 \% \mathrm{Cl}$ for OR } \\
\cline { 5 - 6 } & & & & Lower & Upper \\
\hline Intercept & $0.468(0.181)$ & 0.010 & & \\
Time of graduation $^{1}$ & $-0.722(0.202)$ & $<0.001$ & 0.486 & 0.327 & 0.722 \\
HSPH $^{2}$ & $-0.465(0.217)$ & 0.032 & 0.628 & 0.411 & 0.961 \\
SPHFU $^{2}$ & $-1.042(0.331)$ & 0.002 & 0.353 & 0.327 & 0.722 \\
\hline
\end{tabular}

${ }^{1}$ 2005-2007=0, 2008-2010 $=1 ;{ }^{2}$ compared to SPHUWC, INSP, UMST and KIT which did not differ significantly from each other 


\section{References}

1. World Health Organization: The World Health Report 2006: Working together for health Geneva: WHO press, World Health Organisation; 2006.

2. Sanders D, Guwatudde D, Alexander L: Accessible public health education: A potential growth area? Bull World Health Organ 2008; 86:577-656

3. Global Health Workforce Alliance Human resources for health: critical for effective universal health coverage. $\quad$ http://www.who.int/workforcealliance/knowledge/resources/hrhforuhcpost2015/en/index.html

4. UN General Assembly 2012. Resolution on Global Health and Foreign Policy. http://www.un.org/ga/search/view_doc.asp?symbol=A/67/L.36

5. Campbell J, Buchan J, Cometto G, David B, Dussault G, Fogsta H et al.: Human resources for health and universal health coverage: fostering equity and effective coverage. Bull World Health Organ 2013; 91: 853-863.

6. Sadana R, Petrakova A: Shaping public health education around the world to address health challenges in the coming decades. Bulletin of the World Health Organization 2007, 85(12):902.

7. Petrakova A, Sadana R: Problems and progress in public health education. Bulletin of the World Health Organization 2007, 85(12):963-965.

8. Plugge E, Cole D: Oxford graduates' perceptions of a global health master's degree: a case study. Human Resources for Health 2011, 9(1):26.

9. Davis MV, Dandoy S, Greaves W: Graduate programs: what is their contribution to the training of public health workforce? Am J Prev Med 2003, 24(4):361-6

10. Bennett CM, Lilley K, Yeatman H, Parker E, Geelhoed E, Hanne EG, Robinson P: Paving pathways: Shaping the public health workforce through tertiary education. Australia and New Zealand Health Policy 2010, $7: 2$

11. Nusche D: Assessment of learning outcomes in higher education: a comparative review of selected practices: OECD Education Working Paper No. 15D Nusche; 2008. http://econpapers.repec.org/paper/oeceduaab/15-en.htm.

12. Allen J, Van der Velden R: Competencies and labour market careers of higher education graduates. Maastricht: ROA, 2009.

13. Walker M, McLean M, Dison A, Vaughan R: Higher education and poverty reduction: the formation of public good professionals in universities. Nottingham: School of Education, University of Nottingham; 2010. http://www.dfid.gov.uk/r4d/PDF/Outputs/ESRC_DFID/60622_Case_Studies_Final.pdf

14. Rothem A, Zinovieff MA, Goubarev A: A framework for evaluating the impact of the United Nations fellowship programmes. Hum Resour Health 2010, 8:7.

15. Blömeke S: The challenges of measurement in higher education, IEA's Teacher Education and Development Study in Mathematics (TEDS-M). in Sigrid Blömeke, Olga Zlatkin-Troitschanskaia, Christiane Kuhn, Judith Feg Modeling and Measuring Competencies in Higher Education Tasks and Challenges. Page 2 Sense Publishers Rotterdam 2013, ISBN: 978-94-6091-867-4 (e-book)

16. WHO: Transforming and scaling up health professionals' education and training: WHO Education Guidelines 2013 http://www.who.int/hrh/resources/transf_scaling_hpet/en/

17. Kirkpatrick DL, Kirkpatrick JD: Evaluating Training Programs: The four levels. 3rd edition. San Francisco CA: Berrett-Koehler Publishers; 2006.

18. Zwanikken PAC, Dieleman M, Samaranayake D, Akwataghibe N, Scherpbier A: A systematic review of outcome and impact of Master's in health and health care. BMC Medical Education 2013, 13:18, doi:10.1186/1472-6920-13-18

19. Schattner P, Klein B, Piterman L, Sturmberg J, McCall L: Impact of master of family medicine degree by distance learning on general practitioners' career options. Med Teach 2007, 29(4):e85-e92

20. Richardson PK, MacRae A, Schwartz K, Bankston L, Kosten C: Student outcomes in a postprofessional online master's-degree program. Am J Occup Ther 2008, 62(5):600-610. 
21. Tsimtsiou $Z$, Sidhu $K$, Jones $R$ : The benefits and costs of a master's programme in primary health care: a cross-sectional postal survey. Br J Gen Pract 2010, 60(580):e434.

22. Gijbels $\mathrm{H}, \mathrm{O}^{\prime}$ Connell $\mathrm{R}$, Dalton-O'Connell $\mathrm{C}$, O’Donovan $\mathrm{M}$ : A systematic review evaluating the impact of post-registration nursing and midwifery education on practice. Nurse Educ Pract 2010, 10:64-69.

23. Anaya G: College impact on student learning: Comparing the use of self-reported gains, standardized test scores, and college grades. Research in higher education 1999, 40(5):499-526.

24. Gonyea R: Self-reported data in institutional research: review and recommendations. New Directions for Institutional Research 2005,127: 73-89.

25. Meng C: Discipline-Specific or Academic? Acquisition, role and value of higher education competencies 2005, Maastricht: Research Centre for Education and the Labour Market (ROA)

26. Allen J, van der Velden R: The Role of Self-Assessment in Measuring Skills, REFLEX Working paper 2, 2005a, Maastricht: ROA (http://arno.unimaas.nl/show.cgi?fid=17098)

27. Allen J, Ramaekers G, van der Velden R: Measuring Competencies of Higher Education Graduates, New Directions for Institutional Research 2005b, 126: 49-59.

28. Zwanikken PA, Alexander L, Huong NT, Qian X, Valladares LM, Mohamed NA, Ying XH, Gonzalez-Robledo MC, Linh LC, Abuzaid Wadidi MSE, Tahir H, Neupane S, Scherpbier A: Validation of public health competencies and impact variables for low-and middle-income countries. BMC public health 2014, 14(1), 55.

29. Gerstel L, Zwanikken PAC, Hoffman A, Diederichs C, Borchert M, Peterhans B: Fifteen years of the tropEd Masters in International Health programme: what has it delivered? Results of an alumni survey of masters students in international health. Tropical Medicine \& International Health 2013, 18(3), 377-384.

30. Field A: Discovering Statistics Using IBM SPSS 2013, 4th ed London: Sage

31. Green A, Perry J, Harrison K: The influence of a postgraduate clinical master's qualification in manual therapy on the careers of physiotherapists in the United Kingdom. Man Ther 2008, 13(2):139-147

32. Kuehn BM: Global shortage of health workers, brain drain stress developing countries. JAMA 2007, 298(16): 1853-1855

33. Kanchanachitra $C$, Lindelow $M$, Johnston $T$, Hanvoravongchai $P$, Lorenzo FM, Huong NL, Wilopo SA: Human resources for health in southeast Asia: shortages, distributional challenges, and international trade in health services. The Lancet, 2011, 377(9767), 769-781

34. Kellerman R, Klipstein-Grobusch K, Weiner R, Wayling S, Fonn S: Investing in African research training institutions creates sustainable capacity for Africa: the case of the University of the Witwatersrand School of Public Health masters programme in epidemiology and biostatistics. Health Res Policy Syst, 2012, 10(11).

35. Birt CA, Foldspang A: Public health capacity building-not only the property of the medical profession. The European Journal of Public Health, 2009, 19(3), 232-235

36. Wilson JP, Wen LK: Influence of a nontraditional master's degree on graduates' career paths. Am J Health Syst Pharm 2000, 57(23):2196-2201

37. Davis MV, Sollecito WA, Shay S, Williamson W: Examining the impact of a distance education MPH program: a one-year follow-up survey of graduates. J Public Health Manag Pract 2004, 10(6):556-563

38. Baron R, McKinlay D, Martin J, Ward B: Master's degree-accredited professional education and development courses for general practitioners in the North Western Deanery 1997-2002: Impact on effectiveness, retention and recruitment to additional roles. Educ Prim Care 2006, 17(2):147-154.

39. Gill KJ, Turjanick M, Bagherian P, Ali D: Evaluation of a Master's Degree Program in Psychiatric Rehabilitation. Am J Psychiat Rehab 2005, 8(2):165-174. Special issue: Psychiatric Rehabilitation Education and Credentials

40. Le LC, Bui $Q$, Nguyen HT, Rotem A: Alumni survey of masters of public health (MPH) training at the Hanoi School of Public Health. Hum Resour Health 2007, 5.

41. Drennan J: Professional and academic destination of masters in nursing graduates: a national survey. Nurse Educ Today 2008, 28:751-759

42. Bradley EH, White W, Anderson E, Mattocks K, Pistell A: The role of gender in MPH graduates' salaries. J Health Adm Educ 2000, 18(4):375-389 
43. Ruth BJ, Wyatt J, Chlasson E, Geron SM, Bachman S: Social work and public health: comparing graduates from a dual-degree program. J Soc Work Educ 2006, 42(2):429-439

44. Conneely AL: Study at Master's level: a qualitative study exploring the experience of students. $B r \mathrm{~J}$ Occup Ther 2005, 68(3):104-109.

45. Murray C: Evaluation of a post-professional master's program in allied health. J Allied Health 2001, 30(4):223-228

46. Petersen $D$, Hovington $M$, Pass $M$ : Assuring public health professionals are prepared for the future: the UAB Public Health Integrated Core Curriculum. Public Health Rep 2005, 20:496-503

47. Calvert G, Britten N: The United Medical and Dental School of Guy's and St Thomas's hospitals' MSc in general practice: graduates perspectives. Med Educ 1999, 33:130-135

48. Whyte DA, Lugton J, Fawcett TN: Fit for purpose: relevance of master's preparation for the professional practice of nursing. J Adv Nurs 2000, 31(5):1072-1080

49. Hardwick S, Jordan S: The impact of part-time post-registration degrees on practice. J Adv Nurs 2002, 38(5):524-535

50. LeCount J: Education, empowerment, and elderly adults - enhancing nursing expertise in the long-term care setting. J Gerontol Care 2004, 30(3):6-13.

51. Harris R, Kinsinger LS, Tolleson-Rinehart S, Viera AJ, Dent G: The MD-MPH program at the University of North Carolina at Chapel Hill. Acad Med 2008, 83(4):371-377

52. Cragg CE, Andrusyszyn M: Outcomes of Master's education in nursing. Int J Nurs Educ Scholarsh 2004, $1: 1$

53. Petty N, Scholes J, Ellis L: The impact of a musculoskeletal masters course: developing clinical expertise. Man Ther 2011, 16(6):590-595

54. IJsselmuiden C B, Nchinda TC, Duale S, Tumwesigye NM, \& Serwadda D. Mapping Africa's advanced public health education capacity: the AfriHealth project. Bulletin of the World Health Organization 2007, 85(12): 914-922

55. Frenk J, Chen L, Bhutta ZA, Cohen J, Crisp N, Evans T, Fineberg H, Garcia P, Ke Y, Kelley P, Kistnasamy B, Meleis A, Naylor D, Pablos-Mendez A, Reddy S, Scrimshaw S, Sepulveda J, Serwadda D, Zurayk H: Health professionals for a new century: transforming education to strengthen health systems in an interdependent world. Lancet 2010, 376: 1923-1958.

56. Ackerly DC, Parekh A, Stein D: Perspective: A Framework for Career Paths in Health Systems Improvement. Academic Medicine 2013, 88(1): 56-60.

57. Jeannot E, Stoll B, Chastonay P: Alumni Evaluation of a Community-Oriented Master of Public Health Program. Journal of community health 2013, 38(2): 357-359.

58. Blömeke S, Paine L: Getting the fish out of the water: Considering benefits and problems of doing research on teacher education at an international level. Teaching and Teacher Education 2008, 24(8):2027-2037. 
CHAPTER 7

Discussion 

This chapter will discuss the major findings of the study as well as the strengths and limitations of the research methods.

\section{Introduction}

The shortage of human resources for health in LMIC, specifically the shortage of public health professionals, has been highlighted in many publications (1-5). The identified crisis in human resources for health led to a call to increase the number of health workers, by increasing training, improving strategic planning, enhancing retention and managing attrition as well as increasing motivation and improving performance strategies $(3,6-8)$. It was noted that most schools of public health are situated in high-income countries and, therefore, the call to train public health professionals has led also to questions regarding the relevance of Master's in Health geared towards LMIC (9-12). Next to that a rapid expansion of Master's training in LMIC is occurring $(6,13)$. Not only in LMIC, also in high income countries questions are raised regarding the quality assurance, outcome and impact of master's programmes (14-17). This led to the overall question: are the MPH and the MIH relevant, and what is the influence of the MIH and $\mathrm{MPH}$ programmes on the graduates and their work? The sub-questions were answered per chapter.

\section{Research questions: discussions and conclusions}

The first research question was answered in chapter 2. When evaluating master's in health and health care, what are the outcome and impact looked at and how are these studied? In this thesis outcome is defined as application of competencies at the workplace as well as career advancement. Impact is defined as the effected changes at the workplace as well as in the sector or society. A systematic review found that from all the papers published on the outcome and impact of health-related master's programmes 1999-2011, only one of the 33 articles came from a low-income country. Eight papers studied Master's in Public Health. Outcome was defined in less than onethird of the articles, and impact was not defined. Graduates reported that they progressed in their career, and applied competencies gained such as research or management skills. Evidence of impact on the workplace was reported as organizational changes, changes in service delivery and publications. Only two articles reported impact on society: i.e. shorter hospital stays, launching community programmes and advocacy in state regulatory legislative issues (18-19). Except in one article the attribution of impact to the master's programme was not reported (19). Outcome and impact were studied through graduate surveys and/or qualitative methods, such as interviews and focus group discussions (20). Two more recent articles also studied the outcome and impact 
through graduate surveys (21-22). Graduates of a master's programme in epidemiology and biostatistics in South Africa reported new jobs, research output and training others as impact (21). Graduates from a community-oriented MPH programme reported that the programme helped them in their careers and had given them useful tools (22). Snoek (23) studied impact through transfer of leadership at the workplace and Van Houtte (24) studied outcome through services provided and turnover time of clients before and after a Master's programme in rehabilitation counselling. From the first study we concluded that outcome and impact were rarely defined before embarking on a study on outcome or impact of a Master's in Health or by the Master's in Health programme itself. We also concluded that the question of attribution was rarely asked, and that the study method most often used was a graduate survey. We can also conclude that the question of outcome and impact was rarely asked for Master's in Health in LMIC.

Chapter 3 considered the second research question, focusing on the output and outcome of the $\mathrm{MIH}$ : do graduates of the $\mathrm{MIH}$ programme find the programme appropriate, do they feel confident in applying their newly gained competencies and what kind of influence did the programme have in their career? This study revealed that graduates felt confident in all areas covered by the MIH. Graduates found most competencies essential or very relevant to their current work. Most graduates changed jobs after graduation and shifted towards work at national and international level. Although more graduates from Africa and Asia stayed in their countries than graduates from other continents, still a substantial proportion left their country, relative to comparable data from other studies $(21,25)$. This variety could be due to the focus of the master's, i.e. International Health. It could also be due to the fact that this master's degree attracts students whose primary aim is to work outside their country. Most respondents changed from curative to public health. Most graduates reported an increase in responsibilities, management, research and policymaking functions. Graduates also reported an increase in salary scale. In other studies new responsibilities have also been reported $(19,25-27)$. A change towards management has been reported by Wilson (2000), Hardwick (2002), Green (2008), and Drennan (2008) (27-30), while a move towards research is more rare $(21,27,31-32)$. An increase in salary was also reported by Bradley (2000), Gill (2005), Ruth (2006), and Drennan (2008) (30, 33-35). However, a change towards work in policymaking was not reported earlier.

According to the literature review, this is the first study to be carried out amongst graduates of a network master's in health. The findings reveal that most graduates changed position and reported an increase in responsibilities and for the first time also a shift towards policymaking involvement was reported. However, a substantial proportion of graduates left their home country.

Chapter 4 discusses the question: what are the key issues regarding quality assurance in a transnational network masters in health? Four key issues identified in the literature regarding quality assurance in transnational education were explored: true 
collaboration versus erosion of national education sovereignty, comparability of quality assurance frameworks, accreditation agencies and transparency. The quality assurance of the tropEd Network for Education in International Health is discussed in relation to these issues. The process of quality assurance was a participatory learning process for the involved institutions, sometimes working with resistance to change and institutional agendas. TropEd as a network developed its own quality assurance framework, refining it over the years. As there was no existing international accreditation agency at the time, tropEd functions as its own accreditation agency. The accreditation of core courses and advanced modules has been accepted by national and international agencies, implying that they find the quality assurance framework of tropEd acceptable. Transparency was enhanced through close involvement of students, from the earliest stages of the network. Quality assurance of transnational education has received more attention recently, driven by questions from receiving countries as well as sending countries, by the rapid increase of internationalization of higher education and by changes in modes of teaching $(15,36-41)$. According to some authors, quality assurance in transnational education has become more important due to the increasing regional economic competitiveness $(38,42)$, while others see the reasons in a shift in focus towards learning outcomes (37). Different types of transnational education activities exist: people mobility, either student mobility or academic/ trainer mobility; educational programmes, such as academic partnerships; and e-learning and institutions, such as universities, training centers and companies (43). For the type that includes student mobility, i.e. where students study part of their degree abroad in a flexible manner, not much literature exists regarding quality assurance (43-44). The description of the quality assurance of the tropEd network is to our knowledge the first description of a network master's degree, with countries from high-, middle- and low-income countries collaborating together in providing transnational higher education. The quality assurance in the network is based on discussions and agreements amongst institutions.

Chapter 5 answers the fourth research question: what are relevant public health competencies for LMIC, and what are relevant impact variables on the work and on society? A set of competencies and impact variables on work and on society were developed by the MPH programme conveners from 6 different MPH programmes for LMIC, located in China, Vietnam, South Africa, Sudan, Mexico and the Netherlands. These competencies and impact variables were validated in 2 Delphi rounds with public health experts and graduates working in the public health field. A high degree of consensus was found, indicating that these competencies and impact variables could be used for evaluation as well as programme development purposes. The validated impact variables can present a new way of reviewing fitness for purpose of educational programmes and can serve as a basis for improvements of the programmes. In a largescale, cross-country survey bachelor's degree graduates were asked questions on employability, but not on what they had achieved or were able to do with their newly gained competencies $(45,46)$. It was for the first time that competencies and impact 
variables for public health across LMIC were developed. These competencies and impact variables have a number of advantages: they allow cross-country comparison; they could be used for international standards for degree comparison; and they could be used for international human resource development and management purposes, such as recruitment and continuous education. These competencies and impact variables may not reflect the rich diversity amongst LMIC, and need to be adapted to local contexts.

Chapter 6 addresses the sub-questions: do the graduates of MPH programmes apply their newly gained competencies, do they attribute it to their MPH programme, what influence did the MPH programme have on their career, and do they attribute to the master's any influence on their work or society at large? A large proportion of graduates reported a change in their leadership position, technical position, acquiring new responsibilities and increased remuneration. They attributed these changes to the MPH programme. The MPH programme contributed substantially to the application of public health competencies according to almost half of the graduates, although it should be noted that there were substantial variations between institutions. The respondents mentioned in particular public health analytical competencies as well as leadership, context specific and planning and management competencies. Graduates attributed to the MPH programme the effect they had on their workplace from $20 \%$ $60 \%$ for the 26 impact variables, with a large difference between institutions. The MPH programme empowered graduates to deliver health impacts at the level of society at large, ranging from $17 \%$ to $39 \%$ for the 10 defined variables, again with large disparities between institutions. This is the first study on outcome and impact of MPH transnationally, and its results can be used to inform curriculum reform and innovation.

\section{Strengths and limitations}

The studies in this thesis all have their own strengths and limitations. The overall strengths and limitations are presented here.

\section{Strengths}

A key overall strength of the study is that very few studies have been performed transnationally on quality assurance, outcome and impact of master's degrees. Also few studies on outcome and impact of master's in health and health care have been published, especially regarding $\operatorname{LMIC}(13,17)$. Questions regarding the quality of higher education are very much alive, especially in the context of transnational education (15, 36). As stated by Evashwick (13), only a few studies in the public health educational literature examine what graduates are able to do after their graduation or the impact of the degree on their careers. This study has filled some of these gaps. 
The second strength of this study is that graduates of different programmes were surveyed. Other studies have surveyed either graduates of a single programme based in a $\operatorname{LMIC}(21,25)$ or graduates from high-income countries $(45,47)$.

The third strength of this study is that the competencies and impact variables developed for the graduate survey of the MPH have been validated in 6 different countries in a participatory approach.

\section{Limitations}

Even though the competencies of the MPH and impact variables were validated across 6 programmes, and $\mathrm{MIH}^{\prime}$ s standardized competencies for its network master's degree, the assessment regarding the competencies and impact variables were by provided only by the graduates themselves. Self-assessment has been acknowledged by a number of authors to be a valid and reliable instrument in assessing higher education competencies and outcomes, acknowledging possible biases such as over- or understating, culture, emphasis of differences between different programmes (17, 47-50). Others have been more critical, questioning the validity and reliability of self-assessment and have argued for more conceptual clarity and for more studies that validate and apply different tools (51-55). Peterson (2012) however identified that item averages of selfassessment ratings of competencies amongst preclinical medical students and their teaching staff correlated very strongly ( $r>0.85)$; students rating themselves statistically higher than staff. They concluded that aggregated self-assessment of students can be used to identify strengths and weaknesses in educational programme evaluation (56). An employer survey could also have been administered; however, the employer survey for the MIH yielded too few answers to support an adequate analysis and was therefore not used for the MPH programmes.

According to White (2010) an impact evaluation needs to be designed with a counterfactual sample, i.e. following a similar group of practitioners who did not study and graduate from a master's programme, which increases the likelihood of finding proof of impact (57). However, a counterfactual group is ethically difficult to defend in this case.

Given the transnational nature of the studies, context is very important. Interestingly the validation of the public health competencies and impact variables yielded high consensus across respondents, a finding that is echoed in other fields, such as the engineering and economics expert groups in the AHELO study taking place in OECD countries (46). However the educational, social, cultural and political context in which each of the master's programmes is placed does play a significant role in the student's learning, in application of competencies, in impact and in research on outcome and impact $(17,46,58)$. In the scope of the current studies it was not possible to elucidate this role, nor was it possible to deduce from the current studies what worked best in which context and why (59). 
The focus on career, competencies and observable variables meant that nonobservable affective elements i.e. accountability, humanism, altruism, tolerance, curiosity and innovation were not included (60-61). According to Cook (2010), focusing on outcomes has risks such as measuring the measurable but not for example deep understanding (60). We sought to engrain into the variables specific aspects such as: initiating change, equity/pro-poor orientation and resource mobilization for disadvantaged groups. 


\section{References}

1. Chen L, Evans T, Anand S, Boufford JI, Brown H, Chowdhury M, Cueto M, Dare L, Dussault G, Elzinga G, Fee E, Habte D, Hanvoravongchai P, Jacobs M, Kurowski C, Michael S, Pablos-Mendez A, Sewankambo N, Solimano G, Stilwell B, de Waal A, Wibulpolprasert S: Human Resources for Health: overcoming the crisis. Lancet 2004, 364:1984-1990

2. Hongara C, McPake B: 2004 How to bridge the gap in human resources for health. Lancet 2004, 364:1451-1458

3. World Health Organisation: The World Health Report 2006: Working together for health. Geneva: WHO press, World Health Organisation; 2006

4. Kanchanachitra $C$, Lindelow M, Johnston $T$, Hanvoravongchai $P$, Lorenzo FM, Huong NL, Wilopo SA: Human resources for health in southeast Asia: shortages, distributional challenges, and international trade in health services. Lancet 2011, 377(9767): 769-781.

5. Gulland A: Shortage of health workers is set to double, says WHO. BMJ: British Medical Journal 2013, 347

6. Frenk J, Chen L, Bhutta ZA, ., Cohen, J., Crisp, N., Evans, T., Fineberg, H., et al. Health professionals for a new century: transforming education to strengthen health systems in an interdependent world. Lancet 2010, 376: 1923-1958.

7. Global Health Workforce Alliance Human resources for health: critical for effective universal health coverage http://www.who.int/workforcealliance/knowledge/resources/hrhforuhcpost2015/en/index.html

8. UN General Assembly 2012. Resolution on Global Health and Foreign Policy. http://www.un.org/ga/search/view_doc.asp?symbol=A/67/L.36

9. Sadana R, Chowdhury AMR, Petrakova A. Strengthening public health education and training to improve global health. Bulletin of the World Health Organization 2007, 85:163.

10. Petrakova A, Sadana R: Problems and progress in public health education. Bulletin of the World Health Organization 2007, 85(12):963-965.

11. Plugge E, Cole D: Oxford graduates' perceptions of a global health master's degree: a case study. $\mathrm{Hu}$ man Resources for Health 2011, 9(1):26.

12. WHO: Transforming and scaling up health professionals' education and training: WHO Education Guidelines 2013 http://www.who.int/hrh/resources/transf_scaling_hpet/en/

13. Evashwick CJ: Educating the public health workforce. Frontiers in public health 2013, 1:1.

14. Nusche D: Assessment of learning outcomes in higher education: a comparative review of selected practices OECD Education Working Paper No. 15D Nusche; 2008. http://econpapers.repec.org/paper/oeceduaab/15-en.htm.

15. Kristensen B: Has external quality assurance actually improved quality in higher education over the course of 20 years of the 'quality revolution'? Quality in Higher Education 2010, 16(2):153-157

16. Jacobs GJ: Quality's Higher Education Dividends: Broadened Custodianship and Global Public Scholarship. Quality in Higher Education 2010, 16(2):163-167.

17. Blömeke S, Zlatkin-Troitschanskaia O, Kuhn C, Fege J: Modeling and Measuring Competencies in Higher Education: tasks and challenges. SensePublishers 2013 ISBN: 978-94-6091-867-4 (e-book)

18. Gijbels $\mathrm{H}, \mathrm{O}^{\prime}$ Connell $\mathrm{R}$, Dalton-O'Connell $\mathrm{C}$, O’Donovan $\mathrm{M}$ : A systematic review evaluating the impact of post-registration nursing and midwifery education on practice. Nurse Educ Pract 2010, 10:64-69.

19. Richardson PK, MacRae A, Schwartz K, Bankston L, Kosten C: Student outcomes in a postprofessional online master's-degree program. Am J Occup Ther 2008, 62(5):600-610.

20. Zwanikken PAC, Dieleman M, Samaranayake D, Akwataghibe N, Scherpbier A.: A systematic review of outcome and impact of Master's in health and health care. BMC Medical Education 2013, 13:18

21. Kellerman R, Klipstein-Grobusch K, Weiner R, Wayling S, Fonn S. Investing in African research training institutions creates sustainable capacity for Africa: the case of the University of the Witwatersrand School of Public Health masters programme in epidemiology and biostatistics. Health Res Policy Syst 2012, 10:11 
22. Jeannot E, Stoll B, Chastonay P: Alumni Evaluation of a Community-Oriented Master of Public Health Program. Journal of community health 2013, 38(2): 357-359

23. Snoek $M$, Volman $M$ : The impact of the organizational transfer climate on the use of teacher leadership competences developed in a post-initial Master's program. Teaching and Teacher Education 2014, 37: 91-100.

24. Van Houtte EM: The Effects of Level of Counselor Education on Client Outcomes in the Public Vocational Rehabilitation System of New Jersey. Rehabilitation Research, Policy, and Education 2013, 27(4):234245.

25. Le LC, Bui $Q$, Nguyen HT, Rotem A: Alumni survey of masters of public health (MPH) training at the Hanoi School of Public Health. Hum Resour Health 2007, 5

26. Baron R, McKinlay D, Martin J, Ward B: Master's degree-accredited professional education and development courses for general practitioners in the North Western Deanery 1997-2002: Impact on effectiveness, retention and recruitment to additional roles. Educ Prim Care 2006, 17(2):147-154.

27. Green A, Perry J, Harrison K: The influence of a postgraduate clinical master's qualification in manual therapy on the careers of physiotherapists in the United Kingdom. Man Ther 2008, 13(2):139-147.

28. Wilson JP, Wen LK: Influence of a nontraditional master's degree on graduates' career paths. Am J Health Syst Pharm 2000, 57(23):2196-2201.

29. Hardwick S, Jordan S: The impact of part-time post-registration degrees on practice. J Adv Nurs 2002, 38(5):524-535.

30. Drennan J: Professional and academic destination of masters in nursing graduates: a national survey. Nurse Educ Today 2008, 28:751-759.

31. Murray C: Evaluation of a post-professional master's program in allied health. J Allied Health 2001, 30(4):223-228.

32. Tsimtsiou Z, Sidhu K, Jones R: The benefits and costs of a master's programme in primary health care: a cross-sectional postal survey. Br J Gen Pract 2010, 60(580):e434

33. Bradley EH, White W, Anderson E, Mattocks K, Pistell A: The role of gender in MPH graduates' salaries. $J$ Health Adm Educ 2000, 18(4):375-389.

34. Gill KJ, Turjanick M, Bagherian P, Ali D: Evaluation of a Master's Degree Program in Psychiatric Rehabilitation. Am J Psychiat Rehab 2005, 8(2):165-174. Special issue: Psychiatric Rehabilitation Education and Credentials

35. Ruth BJ, Wyatt J, Chlasson E, Geron SM, Bachman S: Social work and public health: comparing graduates from a dual-degree program. J Soc Work Educ 2006, 42(2):429-439.

36. Harvey L, Williams J: Fifteen years of quality in higher education Quality in Higher Education 2010, 16(1): 3-36.

37. Ewell P: Twenty years of quality assurance in higher education: what's happened and what's different? Quality in Higher Education 2010, 16(2): 173-175.

38. Tham SY, Kam AJY: Internationalising higher education: Comparing the challenges of different higher education institutions in Malaysia. Asia Pacific Journal of Education 2008, 28(4):353-367.

39. Fang W: The Development of Transnational Higher Education in China A Comparative Study of Research Universities and Teaching Universities. Journal of Studies in International Education 2012, 16(1):5-23.

40. Hou AYC, Morse R, Chiang CL, Chen $\mathrm{HJ}$ : Challenges to quality of English medium instruction degree programs in Taiwanese universities and the role of local accreditors: a perspective of non-Englishspeaking Asian country. Asia Pacific Education Review 2013, 14(3):359-370.

41. Hou AYC: Quality in cross-border higher education and challenges for the internationalization of national quality assurance agencies in the Asia-Pacific region: the Taiwanese experience. Studies in Higher education 2014, 39(1):135-152

42. Singh $M$ : Quality assurance in higher education: which pasts to build on, what futures to contemplate? Quality in Higher Education 2010, 16(2): 189-194

43. OECD: Cross-border Tertiary Education, a way towards capacity development. 2007 OECD publications Paris ISBN 978-92-64-03363-4 
44. Cremonini, L, Epping E, Westerheijden DF, Vogelsang K: Impact of quality assurance on cross-border higher education. 2012 Center for Higher Education Policy Studies (CHEPS) Universiteit Twente http://doc.utwente.nl/84413/1/Cremonini12impact.pdf

45. Støren LA, Aamodt PO: The quality of higher education and employability of graduates. Quality in Higher Education 2010, 16(3):297-313

46. OECD: Assessment of higher education learning outcomes. Feasibility study report Vol. 2 Data analysis and national experiences 2013 http://www.oecd.org/edu/skills-beyond-school/AHELOFSReportVolume2.pdf

47. Meng C: Discipline-Specific or Academic? Acquisition, role and value of higher education competencies 2005, Maastricht: Research Centre for Education and the Labour Market (ROA)

48. Anaya G: College impact on student learning: Comparing the use of self-reported gains, standardized test scores, and college grades. Research in higher education 1999, 40(5):499-526.

49. Allen J, van der Velden R: The Role of Self-Assessment in Measuring Skills, REFLEX Working paper 2, 2005, Maastricht: ROA http://arno.unimaas.nl/show.cgi?fid=17098

50. Gonyea R: Self-reported data in institutional research: review and recommendations. New Directions for Institutional Research 2005, 127:73-89.

51. Ward M, Gruppen L, Regehr G: Measuring self-assessment: current state of the art. Advances in Health Sciences Education 2002, 7(1):63-80.

52. Eva KW, Regehr G: Self-assessment in the health professions: a reformulation and research agenda. Academic Medicine 2005, 80(10):S46-S54.

53. Davis DA, Mazmanian PE, Fordis M, Van Harrison R, Thorpe KE, Perrier L: Accuracy of physician selfassessment compared with observed measures of competence: a systematic review. Jama 2006, 296(9):1094-1102

54. Eva KW, Regehr G: Knowing when to look it up: A new conception of self-assessment ability. Academic Medicine 2007, 82(10): S81-S84.

55. Eva KW, Regehr G: Exploring the divergence between self-assessment and self-monitoring. Advances in health sciences education 2011, 16(3): 311-329.

56. Peterson LN, Eva KW, Rusticus SA, Lovato CY: The readiness for clerkship survey: can self-assessment data be used to evaluate program effectiveness? Academic Medicine 2012, 87(10):1355-1360.

57. White H: A contribution to current debates in impact evaluation. Evaluation 2010, 16(2):153-164.

58. Blömeke S, Paine L: Getting the fish out of the water: Considering benefits and problems of doing research on teacher education at an international level. Teaching and Teacher Education 2008, 24(8):2027-2037.

59. Wong G, Greenhalgh T, Westhorp G, Pawson R: Realist methods in medical education research: what are they and what can they contribute? Med Educ 2012, 46:89-96

60. Cook DA: Twelve tips for evaluating educational programs Medical Teacher 2010, 32: 296-301

61. Morcke AM, Dornan T, Eika B: Outcome (competency) based education: An exploration of its origins, theoretical basis, and empirical evidence. Advances in Health Sciences Education, 2013 18(4):851-863 

CHAPTER 8

\section{Valorization}



This chapter will provide recommendations for future research as well as practice.

\section{Future research}

The first suggestion comes from the first limitation that only self-assessment was used to measure outcome and impact of the MIH and MPH programmes. Several different methods can be used when assessing outcome and impact, for example, conducting indepth interviews with graduates as well as their peers and supervisors, in order to allow for triangulation.

The next suggestion arises from the limitation that the studies were unable to elucidate what works in which context and why in terms of public health education. Possibly a realist evaluation, with more emphasis on context and mechanisms will help to identify critical pathways necessary for $\mathrm{MIH}$ and $\mathrm{MPH}$ programmes to improve outcome and impact (1).

Another suggestion originates from the observation that very few evaluation studies are published in public health educational literature. Potential areas include identifying change in competencies through a retrospective post-test, as done by Drennan in the evaluation of master's in nursing (2), how to enhance learning through selfreflection in a multicultural environment, or how to enhance learning through peer feedback in a multicultural environment, as done by Kamp amongst graduate medical students in the Netherlands (3). Other areas are: involving other stakeholders in the evaluation, as performed by Hart at an English University (4), as well as studies on the perceptions and competencies of teachers, as done by Sutkin and Singh amongst medical clinical teachers $(5,6)$.

Another possibility for study would be to study interprofessional education within the $\mathrm{MIH}$ and $\mathrm{MPH}(7,8)$. Given the diverse background of the participants, the programmes are by virtue of their nature examples of interprofessional education. The suggestion would be to study whether and how this interprofessional education contributes to a better understanding of each other's role and improved team work in public or international health, as advocated by Frenk (2010) (7).

To study the actual need and planning, including projections for public health professionals in LMIC, is recommended, such as done in the US and suggested for Europe by Bjegovic $(9,10)$. For example in Switzerland a study on the public health workforce was recently conducted (11). The number of public health professionals educated by schools of public health have been documented (7). However in most LMIC, and a number of high income countries, studies on actual need, planning and implications for human resource and education policy such as production by schools of public health have not been conducted. Interestingly the 2012 WHO statistics lump environmental and public health professionals together, therefore it is difficult to relate the number of public health professionals to population or health status of a country (12). The two 
types of professionals should be recorded separately in order to allow for disaggregated analysis and planning.

Another suggestion is to compare the applied competencies and impact of the two different master's programmes, the Master of Public Health and the Master in International Health.

Other aspects to the competencies and/or impact variables could be added: such as networking, humanism, ethics, accountability, reflection (13) and to validate those.

A question that remains is whether the emphasis on quality assurance does improve learning and in the end outcome and impact. Harvey states in his journal review of 15 years of quality in higher education, that external quality reviews did little to encourage quality improvement, especially when those external reviews had a strong accountability focus $(14,15)$. According to Støren however, using "employability" as an indicator of quality in a comparative survey among graduates in 13 countries, the quality indicators of study programmes influence the graduates' job performance, but have little influence on their success rate in securing employment. Future research could focus on how to achieve a balance in quality assurance between accountability and improvement.

\section{Implications for practice}

As for the Master of Public Health, given the fact that some competencies scored overall higher and some scored lower and the differences between and in specific institutions, the results can be used for curriculum reform. All involved institutions have stated that they will use the overall results, as well as the respective specific results for their specific institution for curriculum review and reform (NT Huong, L. Magaña Valladares, Q. Xu, H. Tahi, L. Alexander, personal communication).

The number of public health schools has been rapidly increasing, placing quality assurance in focus $(7,16)$. The validated cross-country public health competencies and impact variables can be used by low- and middle-income countries as a framework for establishing international standards for education and accreditation of institutions. The public health competencies and impact variables can be used for role definition and delineation of the public health profession, for job descriptions and job function standardization. Subsequently the competencies and impact variables can be used for workplace assessment, continuous education and continuous professional development as well as in programme assessment and programme evaluation.

As public health is a relatively young discipline, in order to gain in importance and enhance the quality of practising public health professionals, certification and credentialing or licensing of public health professionals could be started using the competencies and impact variables as an international framework, such as is done in the USA and as suggested by ASPHER for Europe $(17,18)$. 
The public health competencies and impact variables could be used by those responsible for public health human resources, such as policymakers, trainers and human resource managers as a standard for adaptation to the local situation in each specific country.

The expected competencies together with the size estimation of the public health workforce can be used to evaluate how well the current or projected workforce will be able to address the public health needs of a country or region.

With regards to the $\mathrm{MIH}$, a number of action points that emerged from the alumni survey and the quality assurance review have already been implemented, such as an improved tropEd website with a search function, including key words for modules. Currently the future of tropEd is being discussed within the network, including such topics as the development of specific tracks within the MIH to tailor to the needs and expectations of students and offering the quality assurance of courses to institutions outside the network (19). When course coordinators advise students regarding the possibilities of the tropEd MIH programme, students are more clearly pointed to the strengths and weaknesses as identified in the study (L. Gerstel, personal communication).

As suggested by Evashwick and Koo, public health education needs to be established as a separate discipline. Within public health education a number of areas have not been studied, for example what works in terms of learning and teaching methodology, how to develop specific competencies, what is the use of new learning methods, such as e-learning and social media and the types of assessments that work well (16, 20-22). Even though there is some overlap between public health education and other educational disciplines (e.g. medical education) and fragmentation should be avoided, due to its inter- and transdisciplinary nature, public health education should be given specific attention. 


\section{References}

1. Wong G, Greenhalgh T, Westhorp G, Pawson R: Realist methods in medical education research: what are they and what can they contribute? Med Educ 2012, 46:89-96

2. Drennan J: Masters in nursing degrees: an evaluation of management and leadership outcomes using a retrospective pre-test design. Journal of Nursing Management 2012, 20:102-112

3, Kamp RJA: Peer feedback to enhance learning in problem-based tutorial groups 2013, Uitgevery BOXPress Maastricht, ISBN 978-90-8891-731-8

4. Hart D, Diercks-O'Brien G, Powell A: Exploring stakeholder engagement in impact evaluation planning in educational development work. Evaluation 2009, 15(3): 285-306.

5. Sutkin G, Wagner E, Harris I, Schiffer R: What makes a good clinical teacher in medicine? A review of the literature. Acad Med 2008, 83(5):452-466.

6. Singh S, Pai, DR, Sinha NK, Kaur A, Soe HH, Barua A: Qualities of an effective teacher: what do medical teachers think? BMC medical education 2013, 13(1):128.

7. Frenk J, Chen L, Bhutta ZA, Cohen J, Crisp N, Evans T, Fineberg H, et al: Health professionals for a new century: transforming education to strengthen health systems in an interdependent world. Lancet 2010, 376: 1923-1958.

8. WHO: Transforming and scaling up health professionals' education and training: WHO Education Guidelines 2013 http://www.who.int/hrh/resources/transf_scaling_hpet/en/

9. Gebbie KM, Turnock BJ: The public health workforce, 2006: new challenges. Health Affairs 2006, 25(4): 923-933.

10. Bjegovic-Mikanovic V, Vukovic D, Otok R, Czabanowska K, Laaser U: Education and training of public health professionals in the European Region: variation and convergence. International journal of public health 2013, 58(6):801-810.

11. Frank M, Weihofen A, Duetz Schmucki M, Nocera S, Paccaud F: Public Health Workforce in Switzerland: a National Census. Swiss School of Public Health Zurich Switzerland 2013, Federal Office of Public Health Bern, Switzerland.

12. WHO Global Health Workforce Statistics 2012 http://www.who.int/hrh/statistics/hwfstats/en/

13. Morcke AM, Dornan T, Eika B: Outcome (competency) based education: An exploration of its origins, theoretical basis, and empirical evidence. Advances in Health Sciences Education, 2013 18(4):851-863.

14. Harvey L, Williams J: Fifteen years of quality in higher education. Quality in Higher Education 2010, 16(1): 3-36.

15. Støren LA, Aamodt PO: The Quality of Higher Education and Employability of Graduates. Quality in Higher Education 2010, 16(3):297-313

16. Evashwick, CJ: Educating the public health workforce. Frontiers in public health 2013, 1:1.

17. Foldspang A, Otok R: ASPHER's position paper concerning: 'The new European policy for health Health 2020' and 'The European Action Plan for Strengthening Public Health Capacities and Services, 2012 ASPHER publications Brussels

18. Certified in Public Health. National Board of Public Health Examiners 2014: http://www.nbphe.org

19. tropEd 2014 Minutes General Assembly meeting Uppsala, January 2014.

20. Koo D, Miner K: Outcome-based workforce development and education in public health. Public Health 2010, 31(1):253.

21. Calhoun JG, Wrobel CA, Finnegan JR: Current State in US Public Health Competency-Based Graduate Education. Public Health Reviews 2011, 33(3): 2107-6952

22. Kind T, Patel PD, Lie D, Chretien KC: Twelve tips for using social media as a medical educator. Medical teacher 2014, 36:284-290 


\section{Summary}

Chapter 1 introduces the thesis and presents the problem of shortage of human resources for health in 57 low- and middle-income countries (LMIC), specifically the shortage of public health professionals, as highlighted in the literature. This shortage led to the question regarding the relevance of the Master of Public Health (MPH) and the Master in International Health (MIH) geared towards LMIC, and what the influence of the MIH and MPH programmes is on the graduates, their work and on society. The overall question was further specified in a number of sub-questions: when evaluating master's in health and health care: which outcome and impact are examined and how? Do the graduates of the MIH programme find the programme appropriate, do they feel confident in applying their newly gained competencies and what kind of influence did the programme have in their career? What are key issues regarding quality assurance in a transnational network master's in health? What are relevant public health competencies and what are relevant impact variables on the work and on society? Do the graduates of MPH programmes apply their newly gained competencies, do alumni attribute to the master's any influence on their work or society at large?

Chapter 2 answers the question: Which outcomes and impact are examined when evaluating Master's on health and health care and how? A systematic review found that from all the papers published on the outcome and impact of health-related master's programmes 1999-2011, only one of the 33 articles came from a low-income country. Eight papers studied Master's in Public Health. Outcome was defined in less than onethird of the articles, and impact was not defined. Graduates reported that they progressed in their career and applied the competencies gained, such as management and research skills but also generic competencies such as critical reflection and critical thinking. The evidence of the impact on the workplace was reported as organizational changes and changes in service delivery, publications and also self-reported retention. Only two articles reported broader societal impacts, i.e. shorter hospital stays, community health programmes being launched and advocacy in state regulatory legislative issues. In all but one article attribution for outcome or impact to the master's program was not reported. Outcome and impact were studied through alumni surveys and qualitative methods, such as interviews and focus group discussions. From the first study we concluded that outcome and impact were rarely defined before the study or the master's programmes as such, and that the study method most often used were alumni surveys.

Chapter 3 considers the second research question focusing on the output and outcome of the $\mathrm{MIH}$ : do graduates of the $\mathrm{MIH}$ programme find the programme appropri- 
ate; do they feel confident in applying their newly gained competencies; and what kind of influence did the programme have on their career? This study revealed that graduates felt confident in all areas covered by the MIH. Graduates found most competencies essential or very relevant to their current work. Most respondents (77\%) changed jobs after graduation and shifted towards work at national and international level. Almost half of the respondents (46\%) were working outside their country of origin, although graduates from Africa and Asia worked more in their country of origin (66\% and $63 \%$ respectively). Most graduates changed from curative to public health. Most graduates reported an increase in responsibilities, management, research and policymaking functions. Slightly more than half of the graduates (57\%) also reported an increase in their salary scale, while $9 \%$ reported a decrease. The results suggest that the competencies gained through the MIH programme are relevant for the graduates and helped advance their careers.

Chapter 4 addresses quality assurance in transnational higher education through the case study of tropEd, Network for Education in International Health. Four key issues identified in the literature regarding quality assurance in transnational higher education were explored: true collaboration versus erosion of national education sovereignty, comparability of quality assurance frameworks, accreditation agencies and transparency. It was found that tropEd used a participatory learning approach for all members, and individual members cited specific benefits, such as validation of their own institution's standards and procedures. Challenges mentioned were the frequency and timing of meetings. TropEd developed its own quality assurance framework, aided by the Bologna process, and is developing towards a global quality assurance model. As no accreditation agency for worldwide transnational higher education network exists, tropEd functions as its own accreditation agency. The accreditation of core courses and advanced modules has been accepted by national and international agencies, implying that they find the quality assurance framework of tropEd acceptable. Increasing transparency towards stakeholders is demanded in transnational education, and tropEd has worked hard to improve transparency towards potential students. Stakeholder engagement is still under development.

Chapter 5 explains the process and the results of the construction and validation of competencies as well as the impact variables on work and society of the MPH geared towards LMIC. The competencies were defined in an iterative process, using the competencies defined by the Council for Education of Public Health (CEPH) as a basis and adding, subtracting or changing competencies based on the learning objectives and/or competencies of six MPH programmes located in China, Vietnam, South Africa, Sudan, Mexico and the Netherlands. In the end, 23 competencies were identified in total, subdivided in seven categories. The impact variables, related to workplace (26) and society (10), were defined using the refined competencies. These variables were validated in two Delphi rounds. The first Delphi round included five experts from each of the six countries where the participating MPH programmes were located. After that the com- 
petencies and variables were revised and put forward in another Delphi round with five graduates from each programme, from varying years and gender. The Delphi rounds showed high consensus (from 4 to 5 on a $0-5$ Likert scale). The competencies differed from the CEPH competencies by focusing more on the social determinants of health, context specificity and inter-sectoral competencies, and less on financial planning in management. The high consensus means that the competencies and impact variables can be used to evaluate outcome and impact of MPH programs.

Chapter 6 investigates whether the graduates of MPH programs apply their newly gained competencies, whether they attribute these competencies to their MPH programme and whether they attribute the impact on their work and society to the master's. A survey was conducted amongst 445 graduates ( $35.7 \%$ response rate) from six MPH programmes geared towards LMIC from China, Vietnam, South Africa, Sudan, Mexico and the Netherlands. Graduates reported a change in leadership: $69 \%$, a change in technical position: $69 \%$, acquiring new responsibilities: $80 \%$, increase in remuneration: $63 \%$ and $45 \%$ moved to a different employer. Graduates asserted that the MPH programmes contributed significantly to these outcomes. Between a third and half of all surveyed graduates (33\%-48\%) attributed the enablement of the application of 7 key competencies substantially to the MPH program. Of the 26 impact variables on the workplace, graduates attributed the effect they had on their workplace substantially to the MPH program; for the highest rated variable: $31 \%-73 \%$; for the lowest rated variable: $9 \%-43 \%$. Of the 10 impact variables on society, graduates attributed the effect they had on society substantially to the MPH programme for the highest rated variable: $13 \%-71 \%$; for the lowest rated variable: $4 \%-42 \%$. Logistic regression showed that institution and educational background also contributed significantly to differences between candidates in attributed application of acquired competencies as well as impact at the workplace. The institution and the completion of an advanced degree significantly contributed to the attributed impact on society.

Chapter 7 discusses the research questions as a whole and the strengths and limitations of the study. MIH as well as MPH graduates reported a change in position, an increase in management and policymaking; MPH graduates attributed this to the program. A strength of the overall study is that very few studies have been performed transnationally on quality assurance, outcome and impact of master's in health. Another strength is that competencies and impact variables developed for the graduate survey of the MPH programme have been validated in 6 different countries in a participatory approach. A limitation of the overall study is that the outcome and impact was based on self-assessment by graduates, and that no triangulation with employers, peers or documentation was done. A further limitation is that the educational, social, cultural and political context in which each of the Master's programs is placed could not be elucidated.

The concluding chapter 8 elaborates on the implications for research and practice. Future research is suggested such as interviewing employers and peers of graduates for 
triangulation as well as using realist evaluation to identify critical pathways necessary for MIH and MPH programs to improve outcome and impact. Finally, chapter 8 presents implications for practice. The results can be used for curriculum innovation and reform. The validated public health competencies and impact variables can be used in LMIC as a framework for international standards of education and accreditation of institutions, for role definition of the public health profession, job descriptions, workplace assessment, continuous education and continuous professional development. It is argued that public health education as a discipline has been neglected and that by itself public health education warrants specific attention. 


\section{Samenvatting (Dutch summary)}

Hoofdstuk 1 is de introductie van het proefschrift. Hierin worden de in de literatuur omschreven problemen ten aanzien van het tekort aan menskracht in de gezondheidszorg in 57 lage en middeninkomenslanden (LMIL) beschreven, met nadruk op de tekorten aan volksgezondheidsprofessionals. Deze tekorten leiden tot de vraag naar de relevantie van de Master of Public Health (MPH) en Master in International Health (MIH) opleidingen, voor LMIL, en wat de invloed van de MPH en MIH op de afgestudeerden, hun werk en de samenleving is. De hoofdvraag is onderverdeeld in sub-vragen, die bij het evalueren van masters programma's in gezondheid en gezondheidszorg aan de orde komen: welke outcome en impact worden gemeten en op welke manier? Vinden de afgestudeerden van de $\mathrm{MIH}$ het programma relevant, hebben ze vertrouwen in het gebruiken/toepassen van hun nieuw verworven competenties en wat voor invloed had het programma op hun carrière? Wat zijn de kernpunten ten aanzien van kwaliteitszorg in een transnationaal masternetwerk in gezondheid? Wat zijn relevante volksgezondheid competenties en wat zijn relevante outcome en impact variabelen in het werk en de samenleving? Gebruiken de afgestudeerden van de MPH programma's hun nieuw verworven competenties, zien de afgestudeerden hun invloed op hun werk of samenleving als een effect van het masters programma?

Hoofdstuk 2 beantwoordt de vraag welke outcome en impact gemeten worden bij het evalueren van masters programma's in gezondheid en gezondheidszorg en op welke manier? Uit de systematic review blijkt dat van alle artikelen gepubliceerd over outcome en impact van masters programma's in gezondheid en gezondheidszorg slechts een van de 33 artikelen een laag-inkomensland betrof. Acht artikelen onderzochten specifiek Master's in Public Health. De outcome was in minder dan een derde van de 33 artikelen gedefinieerd en impact was niet gedefinieerd. Afgestudeerden meldden dat ze vooruitgang in hun carrière geboekt hadden en dat ze competenties toepasten zoals management- en onderzoekvaardigheden, maar ook algemene competenties zoals kritische reflectie en kritisch denken. Als bewijs van impact op de werkplek noemden ze: organisatorische veranderingen, veranderingen in dienstenaanbod, publicaties en behoud voor het beroep. Slechts twee artikelen meldden bredere maatschappelijke impact, bijvoorbeeld kortere duur van ziekenhuisopname, het starten van gezondheidsprogramma's in de gemeenschap en het lobbyen voor wet- en regelgeving op staatsniveau. Met uitzondering van een artikel, werd in geen van de andere artikelen vermeld of de outcome en impact aan het masters programma konden worden toegeschreven. Outcome en impact werden onderzocht door alumni te enquêteren (alumni survey) en kwalitatieve methodes, zoals interviews en focus groep discussies. Uit dit 
hoofdstuk blijkt dat outcome en impact slechts zelden voor de aanvang van de studie of in de masters programma's zelf waren gedefinieerd. Verder blijkt dat de meest gebruikte onderzoeksmethode een alumni survey was.

Hoofdstuk 3 gaat in op de tweede onderzoeksvraag, met de nadruk op het resultaat (output) en outcome van de $\mathrm{MIH}$ : vinden de afgestudeerden van het MIH het programma toepasselijk? Hebben ze vertrouwen in het toepassen van hun nieuw verworven competenties? Wat was de invloed van het programma op hun carrière? Dit hoofdstuk laat zien dat de afgestudeerden van mening zijn dat het MIH programma in alle onderwerpen voorziet. Afgestudeerden vonden de meeste competenties essentieel of erg relevant voor hun huidige werk. De meeste respondenten (77\%) veranderden na het afstuderen van baan en schoven van een lokaal of regionaal niveau door naar nationaal of internationaal niveau. Bijna de helft van de respondenten (46\%) werkten buiten hun eigen land, alhoewel de afgestudeerden die uit Afrika en Azië kwamen, meer in hun land of hun regio werkten (respectievelijk 66\% en 63\%). De meeste afgestudeerden veranderden van curatieve gezondheidszorg naar volksgezondheid. De meeste afgestudeerden rapporteerden een toename in verantwoordelijkheden, management, onderzoek- en beleidsfuncties. Een kleine meerderheid rapporteerde een verhoging in hun salarisschaal, terwijl $9 \%$ een vermindering meldde. De resultaten impliceren dat de competenties verworven door het $\mathrm{MIH}$ programma relevant zijn voor de afgestudeerden en het MIH programma hielp in het bevorderen van hun carrière.

Hoofdstuk 4 richt zich op kwaliteitszorg in een transnationaal hoger onderwijs netwerk aan de hand van de casus van tropEd, het Network for Education in International Health. Vier kernpunten over kwaliteitszorg in transnationaal hoger onderwijs zijn daarvoor onderzocht te weten: daadwerkelijke samenwerking versus uitholling van nationale onderwijssoevereiniteit; vergelijkbaarheid van kwaliteitszorgkaders; de accreditatie-agentschappen en de transparantie. De uitkomst is dat tropEd een participatieve leerbenadering gebruikt voor alle leden, en dat individuele leden specifieke voordelen benoemen, waaronder validatie van hun eigen institutionele standaarden en procedures. Als uitdagingen worden de frequentie en de timing van de vergaderingen genoemd. TropEd heeft zijn eigen kwaliteitszorgkader ontwikkeld, geholpen door het Bologna proces, en is zich aan het ontwikkelen tot een wereldwijd kwaliteitszorgkader model. Vanwege het feit dat er geen wereldwijd accreditatie-agentschap voor een hoger onderwijs netwerk bestaat, functioneert tropEd als zijn eigen accreditatieagentschap. De accreditatie van de kerncursus en de gevorderde modules is geaccepteerd door nationale en internationale agentschappen; dit betekent dat zij het kwaliteitszorgkader van tropEd accepteren. Van het transnationaal onderwijs wordt steeds meer transparantie naar belanghebbenden toe geëist. TropEd heeft in dit kader hard gewerkt om de transparantie naar potentiele studenten te verbeteren, maar het betrekken van andere belanghebbenden is nog in ontwikkeling.

In hoofdstuk 5 wordt het proces en de resultaten van de constructie en de validatie van de competenties uitgelegd. Het proces en resultaten van de constructie en validatie 
van de "impact variables" op werk en samenleving van de MPH voor LMIL worden ook beschreven. Bij het formuleren van de competenties is gebruik gemaakt van de competenties, zoals die gedefinieerd zijn door de Council for Education of Public Health (CEPH). Aan deze basiscompetenties zijn categorieën toegevoegd, verwijderd of veranderd, gebruik makend van de leerdoelen en/of de competenties van zes MPH programma's uit China, Vietnam, Zuid Afrika, Sudan, Mexico en Nederland. Uiteindelijk zijn in totaal 23 competenties geïdentificeerd, onderverdeeld in 7 categorieën. De impact variabelen, gerelateerd aan werk (26) en samenleving (10) zijn gedefinieerd aan de hand van de competenties. Deze competenties en variabelen zijn gevalideerd in twee Delphi rondes. De eerste Delphi ronde bestond uit vijf experts uit elk van de zes deelnemende landen. Daarna werden de competenties en variabelen verbeterd en opnieuw uitgestuurd in een Delphi ronde bestaande uit vijf afgestudeerden van elk programma, van verschillende afstudeerjaren en een mix van man en vrouw. De Delphi ronde liet een hoge mate van consensus zien (van 4 tot 5 op een 0-5 Likert schaal).

De geformuleerde competenties verschilden van de CEPH competenties. In de geformuleerde competenties ligt meer nadruk op de sociale determinanten van gezondheid, contextspecificiteit en intersectorale competenties en minder nadruk op financiële planning binnen management. De hoge mate van consensus betekent dat de competenties en impact variabelen gebruikt kunnen worden bij het evalueren van outcome en impact van MPH programma's.

Hoofdstuk 6 onderzoekt of afgestudeerden van MPH programma's hun nieuw verworven competenties gebruiken, of ze deze competenties toeschrijven aan het MPH programma en of ze de impact op hun werk en de samenleving toeschrijven aan de masters. Onder de 1187 afgestudeerden van wie 445 antwoordden (respons 35.7\%) van zes op LMIL gerichte MPH programma's in China, Vietnam, Zuid Afrika, Sudan, Mexico en Nederland werd een survey gedaan. Afgestudeerden rapporteerden een verandering in leiderschap: $69 \%$, een verandering in technische positie: $69 \%$, verkrijging van nieuwe verantwoordelijkheden: $80 \%$, verhoging van bezoldiging: $63 \%$ en $45 \%$ wisselde van werkgever. Afgestudeerden bevestigden dat de MPH programma's significant bijdroegen aan deze outcome. Tussen een derde en de helft van alle geenquêteerde afgestudeerden $(33 \%-48 \%)$ schreven de toepassing van de 7 kerncompetenties toe aan het $\mathrm{MPH}$ programma. De afgestudeerden schreven een substantieel deel van het effect van de impactvariabelen op de werkplek toe aan het MPH programma (voor de hoogst gescoorde variabele: $31 \%-73 \%$; voor de laagst gescoorde variabele: $9 \%-43 \%$ ). Van de impact variabelen op de samenleving, schreven de afgestudeerden het effect toe aan het MPH programma; voor de hoogst gescoorde variabele $(13 \%-71 \%$; voor de laagst gescoorde variabele: $4 \%-42 \%$ ). Logistische regressie toonde aan dat opleidingsinstituut en onderwijsachtergrond ook significant bijdroegen aan verschillen tussen de afgestudeerden in toegeschreven gebruik van verkregen competenties. Deze verschillen zijn ook aangetoond ten aanzien van de impact op de werkplek. Het opleidingsinstituut en 
het behalen van een andere graad na de MPH voegden significant toe aan de toegeschreven impact op de samenleving.

Hoofdstuk 7 is het validatie hoofdstuk. Het behandelt de onderzoeksvragen als geheel, de sterke en zwakke punten. Afgestudeerden van de MIH en MPH rapporteren een verandering in positie, in verbetering in management en beleid maken; afgestudeerden van de MPH schrijven dit toe aan het programma. Een sterk punt van de gehele studie is dat erg weinig transnationale studies zijn gedaan over kwaliteitszorg, outcome en impact van masters in gezondheid. Een volgende sterkte is dat competenties en impact variabelen zijn gevalideerd in een participatieve benadering voordat de survey werd uitgevoerd onder afgestudeerden van MPH programma's in zes verschillende landen. Een beperking van de gehele studie is dat de evaluatie van outcome in impact gebaseerd is op zelfevaluatie door de afgestudeerden en dat er geen triangulatie met werkgevers, collega's of documentatie is gedaan. Een verdere beperking is dat de onderwijskundige, sociale, culturele en politieke context waarin elk MPH programma zich bevindt, niet is bestudeerd.

Het concluderende hoofdstuk 8 gaat in op de aanbevelingen voor onderzoek en praktijk. Als toekomstig onderzoek wordt gesuggereerd om werkgevers en collega's te interviewen voor triangulatie doeleinden, en ook om "realist evaluation" te gebruiken om contextuele mechanismen te identificeren die noodzakelijk zijn voor MPH programma's om hun outcome en impact te vergroten. Tot slot presenteert hoofdstuk 8 aanbevelingen voor de praktijk. De resultaten kunnen worden gebruikt voor curriculum vernieuwing en -hervorming. De gevalideerde volksgezondheid competenties kunnen als een raamwerk dienen voor internationale standaarden voor onderwijs en accreditatie van onderwijsinstellingen, voor het definiëren van rollen van de volksgezondheid professionals, functieomschrijvingen, werkplek beoordelingen, permanente educatie en permanente professionele ontwikkeling. Beargumenteerd wordt dat onderwijs in volksgezondheid als discipline is verwaarloosd en dat volksgezondheidonderwijs specifieke aandacht behoeft. 


\section{Acknowledgments}

Without support no PhD, and that is also true for this PhD. Dear Albert, throughout this trajectory I felt your support, at crucial moments I could call you, there was no hesitation in your support, and otherwise there was always the email. Dear Huong, at a distance and still close, patient and thorough advise and always helping in our transnational research group.

A special thanks to all our alumni of our Master's, all over the world, you were the inspiration for me to take on this PhD.

To all my colleagues, at KIT Dev, later Health especially Marjolein who encouraged me to start with a PhD, Yme with his academic wisdom and relativism, Sumit and his critical look. Lisanne, as the author of one of the articles, while having a baby, I admired you! Fernando for the statistical support always with a smile. Rinia indispensable, never no to a question and long-time colleague for finding alumni and supporting the surveys. Ilse, thinking along in the literature review. Bart, Catherine and Serge for the unfailing support in the background. Ngozi first a student, now a colleague and Dulani, first near than far away but email made it close supporting in the systematic review.

In our tropEd network it was thanks to the enthusiasm of Bernadette and Lorraine that we finally wrote our article which was in the air for some time already. Together with the addition of Axel and Matthias, after thorough discussions during several tropEd meetings we could launch the alumni survey, with support of Ning, Amanguli and Camiele.

Our transnational consortium was and is special: all of you took on the challenge of the study, without any extra or additional financial support, the enthusiasm and the quest to find out what happened with our alumni bound us together across 4 continents. I want to thank especially Lucy Alexander in Capetown, Qian Xu and Xiao Hua Ying in Shanghai, Laura Magana Valladares and Maria Cecilia Gonzalez-Robledo in Guernavaca, Marwa SE Abuzaid Wadidi and Hanan Tahir in Khartoum, Nazar A Mohamed now in Qatar, Nguyen Thanh Huong, Le Cu Linh and Nguyen Nhat Linh in Hanoi and Sunisha Neupane in Canada. Infinite thanks to Jimmie Leppink for his support in understanding the higher mythic of statistics.

My appreciation goes to the Directorate-general for International Development Cooperation of the Netherlands Ministry of Foreign Affairs and the Royal Tropical Institute for supporting the studies and publications of this thesis. My appreciation as well to all the institutions who willingly participated in this study: School of Public Health, University of the Western Cape, South Africa, Hanoi School of Public Health, Vietnam, School 
of Public Health, Fudan University, China, National Institute of Public Health, Mexico, Ministry of Health, Sudan, University of Medical Sciences and Technology, Sudan.

To my friends who were kind enough to hear no when there was another deadline for an article, but then fortunately didn't let me go: Caro, Karin, Roelien, Pauline, Eric and Catherine, leke and Frank, Netty, Antje, Pia, Wies, Ineke and my friends from Wallabi.

To my sister Hanka, my brothers Bob and Tim and their families who enjoyed my stories from abroad, but who were also able to make the necessarily relativizing comments.

A special thanks to my mother, who at her advanced age, though missing my Dad dearly, learned to navigate the web, sent me emails from her Ipad, read all my articles, was able to question me about those articles, and who was always supportive, also financially. Ma: I learned from you that one never stops learning even at 82 years!

And the last but not the least: Ton, my partner, I don't know how I can thank you for all your support, dedication and love. 


\section{Curriculum vitae}

\section{Curriculum Vitae}

Prisca Zwanikken was born on 31 October 1958 in Heerlen, the Netherlands. She spent her youth in Heerlen, where she completed her secondary education at the Coriovallum College. In 1985 she obtained her medical practitioner degree at the State University Leiden. After graduation she proceeded with the tropical doctor training and finished her National Course on Tropical Medicine and Hygiene at KIT, Amsterdam in 1987.

She worked for 5 years in a Community Based Health Program in the Philippines for SNV. She continued her education and gained her Masters of Science in Community Health Degree in Heidelberg in 1993. She worked in Vietnam, for the Quang Tri Holland Development and Friendship programme.

When she came back to the Netherlands, she started to work at the Royal Tropical Institute (KIT) as a course coordinator and public health advisor. From 1999 she worked for 3 years at the Netherlands School of Public Health as the Program Director for the National and International MPH program. She re-joined KIT in 2002, as area leader education and program director of the International Course on Health Development (ICHD)/ MPH and from 2005 onwards the Master in International Health. At KIT she is responsible for the 2 Master's programmes, including the different tracks, short health courses as well as capacity building programs of health educational institutions in Low and Middle Income countries. She conducts advisory work, training and research on curriculum development, capacity building and human resources for health in a number of countries in Africa, Asia and Latin America.

She has conducted research in public health education and human resources for health. She is particularly interested in postgraduate educational research. She is a reviewer for international peer reviewed journals.

\section{Publications}

Zwanikken PA, Huong NT, Ying XA, Alexander L, Magaña-Valladares L, Wadidi MS, Gonzalez-Robledo MC, Qian X, Linh NN, Tahir H, Leppink J, Scherpbier A: Outcome and impact of Master of Public Health programs across six countries: education for change. Human Resources for Health, 2014, 12:40 doi: 10.1186/1478-4491-12-40

Zwanikken PA, Alexander L, Huong NT, Qian X, Valladares LM, Mohamed NA, Ying XH, Gonzalez-Robledo MC, Linh le C, Wadidi MS, Tahir H, Neupane S, Scherpbier A: Valida- 
tion of Public Health Competencies and Impact Variables for Low- and Middle-Income Countries. BMC Public Health, 2014;14:55 doi: 10.1186/1471-2458-14-55

Dieleman M, Zwanikken P: “Looking at human resources for health through a governance lens" in: Going for governance: lessons learned from advisory interventions by the Royal Tropical Institute. KIT Publishers ISBN 978-94 60221897

Zwanikken P, Peterhans B, Dardis L, Scherpbier A: Quality assurance in transnational higher education: a case study of the tropEd network; BMC Medical Education 2013, 13:43 doi: 10.1186/1472-6920-13-43

Zwanikken PAC, Dieleman M, Samaranayake D, Akwataghibe N, Scherpbier A: A systematic review of outcome and impact of Master's in health and health care BMC Medical Education 2013, 13:18 doi:10.1186/1472-6920-13-18

Gerstel L, Zwanikken PAC, Hoffman A, Diederichs C, Borchert M and Peterhans P: Fifteen years of the tropEd Masters in International Health programme: what has it delivered? Results of an alumni survey of masters students in international health. Tropical Medicine and International Health 2013 doi:10.1111/tmi.12050

Zwanikken PAC and Oosterhoff P (2011) Why a research ethics committee for social science? Reflections on three years of experience at the Royal Tropical Institute, Amsterdam, Medische Anthropologie, 23 (1) 2011, 165-181

Dieleman M, Shaw DMP and Zwanikken PAC (2011) Improving the implementation of health workforce policies through governance: a review of case studies Human Resources for Health 2011, 9:10 doi:10.1186/1478-4491-9-10

Dieleman MA, Kane S, Zwanikken P and Gerretsen B(2011). Realist review and synthesis of retention studies for health workers in rural and remote areas. WHO, Geneva ISBN 9789241501262

Shaw D, Zwanikken P, Dieleman M (2010) Human Resources for Health and governance in lower and middle-income countries: a literature review, for WHO and DGIS.

Dieleman MA, Kane S, Zwanikken P, Gerretsen B (2009) "Identifying patterns in retention intervention studies: revisiting the evidence from a realist perspective", paper for WHO, DGIS.

Pauline Oosterhoff, Prisca Zwanikken, and Evert Ketting (2006), in book: gendered bodies: feminist perspectives, Chapter 8 "Sexual Torture of Men". 
Ghambarian MA, Feenstra TL, Zwanikken P and Kalinina AM (2004) 'COPD: can prevention be improved? Proposal for an integrated intervention strategy', Preventive Medicine 2004, Vol 39/2 pp 337-343.

Oosterhoff P, Zwanikken P, Ketting E (2004) 'Sexual Torture of Men in Croatia and Other Conflict Situations: An Open Secret' Reproductive Health Matters 2004;12(23):68-77 Zwanikken PA (2002) 'Service role of schools of public health: in between research and education?’ Public Health Rev. 2002;30(1-4):133-41.

Cornel MC, Zwanikken PAC (2002). 'GGD en Genetica: een introductie in community genetics, (Municipal health services and genetics: an introduction to genetics)' $G G D$ nieuws, 2002; 7:17-21

Cornel MC, Zwanikken PAC (2002) 'Aandacht voor "Public Health Genetics", (Attention for genetics)' Tijdschrift voor gezondheidswetenschappen, 2002; 5: 339-340.

Klazinga N, Zwanikken PAC (2000) 'Meesterstukken over public health ("Masterpieces about public health")' Tijdschrift voor gezondheidswetenschappen, 2000; 6: 331-332

Lever P, Bijlmakers L, Zwanikken P, Sanderson P (1998) 'Health Systems Research in Leprosy Control - What contributions can it make?’ Leprosy Review 1998;69, 122-127.

Pace NL, Stanley TH, Andriano KP, Wilbrink J, Zwanikken P (1985) 'Transcutaneous po2 poorly estimates arterial po2 in adults during anesthesia' International Journal of Clinical Monitoring and Computing, 1985; 1: 227-232.

Bailey PL, Wilbrink J, Zwanikken P, Pace NL, Stanley TH (1985) 'Aesthetic induction with fentanyl' Anesthesia and Analgesia, 1985; 64: 48-53.

\section{Abstracts}

Andriano KP, Pace NL, Wilbrink J, Zwanikken P, Stanley TH (1984) 'Intraoperative transcutaneous po2 (Tcpo2) monitoring quantitates Pao2. Fact or fiction?' Anesthesia and Analgesia, 63: 178,

Clark N, Liu WS, Meuleman T, Zwanikken P, Pace NL, Stanley TH (1984) 'Sufentanil versus fentanyl as a supplement to N2O during anesthesia'. Anesthesia and Analgesia, 63: 198, 1984.

Gosling BM, Zwanikken PAC, Hermans JH (1982) 'Differentiated Thyroid Carcinoma: Follow-up data on 115 cases'. Endocrinology Suppl. 94: 12p, 1982. 



\section{SHE dissertation series}

The SHE Dissertation Series publishes dissertations of PhD candidates from the School of Health Professions Education (SHE) who defended their PhD theses at Maastricht University. The most recent ones are listed below. For more information go to: www.maastrichtuniversity.nl/she.

Hill, E. (11-12-2014) A cutting culture: gender and identification in the figured world of surgery

Diemers, A. (03-10-2014) Learning from pre-clinical patient contacts

Tjiam, I. (17-09.2014) Learning in Urology. Designing simulator based skills Training \& Assessment

Berkenbosch, L. (30-06-2014) Management and leadership education for medical residents

Bergman, E.M. (30-06-2014) Dissecting anatomy education in the medical curriculum

Dijkstra, J. (25-06-2014) Guidelines for designing programmes of assessment

Van Loon, M.H. (08-05-2014) Fostering monitoring and regulation of learning

Frambach, J.M. (26-03-2014) The cultural complexity of problem-based learning across the world

Hommes, J.E. (26-02-2014) How relations, time \& size matter in medical education

Van der Zwet, J. (30-01-2014) Identity, Interaction and Power. Explaining the affordances of doctor-student interaction during clerkships

Watling, C.J. (22-01-2014) Cognition, Culture, and Credibility. Deconstructing Feedback in Medical Education 
Winston, K. (12-12-2013) Remediation Theory and Practice: Transforming AtRisk Medical Students

Kamp, R.J.A. (28-11-2013) Peer Feedback to Enhance Learning in ProblemBased Tutorial Groups

Junod Perron, N. (24-10-2013) Towards a learner-centered approach to postgraduate communications skills teaching

Pratidina Susilo, A. (24-10-2013) Learning to be the Patient Advocate

The Development of a Communication Skills Course to Enhance Nurses' Contribution to the Informed Consent Process

Alves de Lima, A. (23-10-2013) Assessment of clinical competence: Reliability, Validity, Feasibility and Educational Impact of the mini-CEX

Sibbald, M. (09-10-2013) Is that your final answer? How doctors should check decisions

Ladhani, Z. (05-07-2013) Competency based education and professional competencies: a study of institutional structures, perspectives and practices in Pakistan

Jippes, M. (01-02-2013) Culture matters in medical schools: How values shape a successful curriculum change

Duvivier, R. J. (12-12-2012) Teaching and Learning Clinical Skills. Mastering the Art of Medicine

De Feijter, J.M. (09-11-2012) Learning from error to improve patient safety

Prescott, L. (09-11-2012) Ensuring the Competence of Dental Practitioners through the Development of a Workplace-Based System of Assessment

Cilliers, F.J. (05-09-2012) The Pre-assessment Learning Effects of Consequential Assessment: Modelling how the Examination Game is Played 
Spanjers, I. A.E. (05-07-2012) Segmentation of Animations: Explaining the Effects on the Learning Process and Learning Outcomes

Al-Kadri, H.M.F. (28-06-2012) Does Assessment Drive Students' Learning?

Leppink, J. (20-06-2012) Propositional manipulation for conceptual understanding of statistics

Van Zundert, M.J. (04-05-2012) Conditions of Peer Assessment for Complex Learning

Claramita, M. (30-03-2012) Doctor-patient communication in a culturally hierarchical context of Southeast Asia: A partnership approach

Kleijnen, J.C.B.M. (21-03-2012) Internal quality management and organizational values in higher education

Persoon, M.C. (19-01-2012) Learning in Urology; The influence of simulators and human factors

Pawlikowska, T.R.B. (21-12-2011) Patient Enablement; A Living Dialogue

Sok Ying Liaw, (14-12-2011) Rescuing A Patient In Deteriorating Situations (RAPIDS): A programmatic approach in developing and evaluating a simulationbased educational program

Singaram, V.S. (7-12-2011) Exploring the Impact of Diversity Factors on Problem-Based Collaborative Learning

Balslev, T. (24-11-2011) Learning to diagnose using patient video cases in paediatrics: Perceptive and cognitive processes

Widyandana, D. (19-10-2011) Integrating Pre-clinical skills training in skills laboratory and primary health care centers to prepare medical students for their clerkships 
Durning, S.J. (09-09-2011) Exploring the Influence of Contextual Factors of the Clinical Encounter on Clinical Reasoning Success (Unraveling context specificity)

Govaerts, M.J.B. (08-09-2011) Climbing the Pyramid;Towards Understanding Performance Assessment

Stalmeijer, R. E. (07-07-2011) Evaluating Clinical Teaching through Cognitive Apprenticeship

Malling, B.V.G. (01-07-2011) Managing word-based postgraduate medical education in clinical departments

Veldhuijzen, J.W. (17-06-2011) Challenging the patient-centred paradigm: designing feasible guidelines for doctor patient communication

Van Blankenstein, F. (18-05-2011) Elaboration during problem-based, small group discussion: A new approach to study collaborative learning

Van Mook, W. (13-05-2011) Teaching and assessment of professional behavior: Rhetoric and reality

De Leng, B. (8-12-2009). Wired for learning. How computers can support interaction in small group learning in higher education

Maiorova, T. (29-05-2009). The role of gender in medical specialty choice and general practice preferences

Bokken, L. (04-03-2009). Innovative use of simulated patients for educational purposes

Wagenaar, A. (18-09-2008). Learning in internships. What and how students learn from experience

Driessen, E. (25-06-2008). Educating the self-critical doctor. Using portfolio to stimulate and assess medical students' reflection 
Derkx, H. (18-06-2008). For your ears only. Quality of telephone triage at outof-hours centres in the Netherlands

Niessen, Th. (30-11-2007). Emerging epistemologies: making sense of teaching practice

Budé, L. (05-10-2007). On the improvement of students' conceptual understanding in statistics education

Niemantsverdriet, S. (26-07-2007). Learning from international internships: A reconstruction in the medical domain

Marambe, K. (20-06-2007). Patterns of student learning in medical education A Sri Lankan study in traditional curriculum

Pleijers, A. (19-01-2007). Tutorial group discussion in problem-based learning

Sargeant, J. (21-09-2006). Multi-source feedback for physician learning and change

Dornan, T. (12-06-2006). Experience-based learning

Wass, V. (12-05-2006). The assessment of clinical competence in high stakes examinations

Prince, K. (21-04-2006). Problem-based learning as a preparation for professional practice 